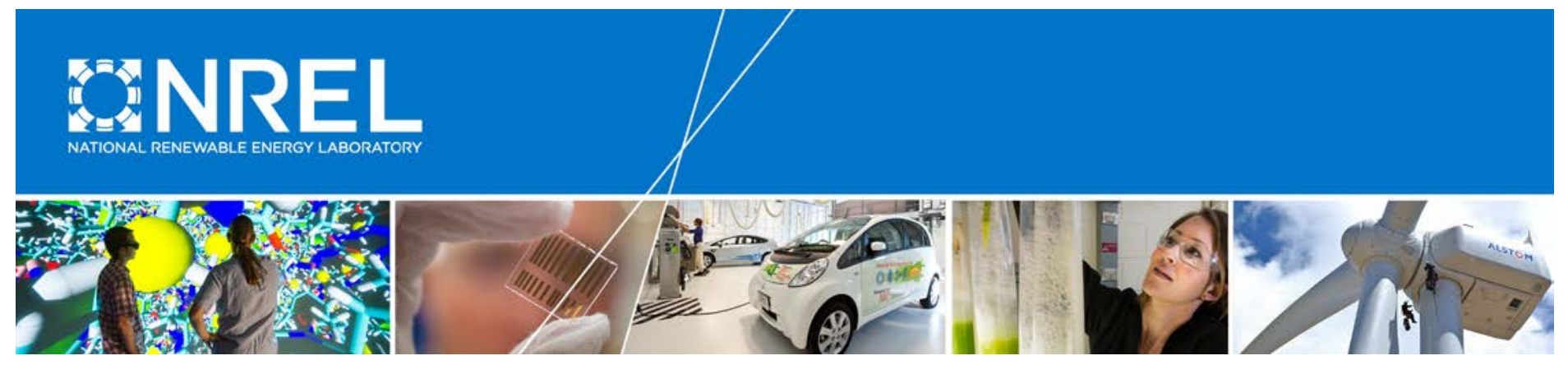

\title{
Case Study Analysis of U.S. Policy Solutions to Enable China New Energy Cities
}

J. Simon, T. Tian, C. Liu, and M. Miller National Renewable Energy Laboratory

NREL is a national laboratory of the U.S. Department of Energy Office of Energy Efficiency \& Renewable Energy Operated by the Alliance for Sustainable Energy, LLC

This report is available at no cost from the National Renewable Energy Laboratory (NREL) at www.nrel.gov/publications.

Technical Report

NREL/TP-7A40-63529

May 2015

Contract No. DE-AC36-08GO28308 


\section{Case Study Analysis of U.S. Policy Solutions to Enable China New Energy Cities}

J. Simon, T. Tian, C. Liu, and M. Miller National Renewable Energy Laboratory

Prepared under Task No. IGIN.1830

NREL is a national laboratory of the U.S. Department of Energy Office of Energy Efficiency \& Renewable Energy Operated by the Alliance for Sustainable Energy, LLC

This report is available at no cost from the National Renewable Energy Laboratory (NREL) at www.nrel.gov/publications.

National Renewable Energy Laboratory 15013 Denver West Parkway Golden, CO 80401 303-275-3000 • www.nrel.gov

\section{Technical Report}

NREL/TP-7A40-63529

May 2015

Contract No. DE-AC36-08GO28308 


\title{
NOTICE
}

This report was prepared as an account of work sponsored by an agency of the United States government. Neither the United States government nor any agency thereof, nor any of their employees, makes any warranty, express or implied, or assumes any legal liability or responsibility for the accuracy, completeness, or usefulness of any information, apparatus, product, or process disclosed, or represents that its use would not infringe privately owned rights. Reference herein to any specific commercial product, process, or service by trade name, trademark, manufacturer, or otherwise does not necessarily constitute or imply its endorsement, recommendation, or favoring by the United States government or any agency thereof. The views and opinions of authors expressed herein do not necessarily state or reflect those of the United States government or any agency thereof.

This report is available at no cost from the National Renewable Energy Laboratory (NREL) at www.nrel.gov/publications.

Available electronically at SciTech Connect http:/www.osti.gov/scitech

Available for a processing fee to U.S. Department of Energy and its contractors, in paper, from:

\author{
U.S. Department of Energy \\ Office of Scientific and Technical Information \\ P.O. Box 62 \\ Oak Ridge, TN 37831-0062 \\ OSTI http://www.osti.gov \\ Phone: 865.576.8401 \\ Fax: 865.576.5728 \\ Email: reports@osti.gov
}

Available for sale to the public, in paper, from:

\author{
U.S. Department of Commerce \\ National Technical Information Service \\ 5301 Shawnee Road \\ Alexandra, VA 22312 \\ NTIS http://www.ntis.gov \\ Phone: 800.553 .6847 or 703.605 .6000 \\ Fax: 703.605.6900 \\ Email: orders@ntis.gov
}




\section{Acknowledgments}

This report was funded under the U.S. China Renewable Energy Partnership through the U.S. Department of Energy Office of Energy Efficiency and Renewable Energy's International Team. The authors would like to thank the U.S. China Renewable Energy Partnership team for the opportunity to collaborate on the scoping and development of this case study. The analysis considers the policy approach and impact on the deployment and investment of renewable energy technologies for several different cities and regions. The authors thank Renqing Hu from the Energy Research Institute of the National Development and Reform Commission for her review, suggestions, and input. In addition, the authors would like to thank Ben Foster and Tyler Espinoza from Optony Inc. and Bo Bi and Peipei Zhang from Peking University for their thoughtful and dedicated coordination, guidance, input, and support of this report to help ensure that the information and analysis presented are relevant and accurate. In addition, the authors would like to thank Marguerite Kelly and Elizabeth Doris of the National Renewable Energy Laboratory (NREL) for their careful review and recommendations, as well as Linh Truong and Alexis Powers from NREL for editorial support. Any conclusions drawn or errors made remain the responsibility of the authors. 


\section{Acronyms}

ACP

$\mathrm{AE}$

BPU

CCA

CORE

CPUC

CSP

DBEDT

DG

DML

DOE

DSIRE

EDECA

EEPS

EIA

EIS

EPA

FIT

GATS

GDP

GEMS

GHG

GWh

HCEI

HECO

HELCO

HOST

IOU

IRS

ITC

JCP\&L

KIUC

$\mathrm{kW}$

$\mathrm{kWh}$

LBNL

LEED

LNG

MDT

MECO

MOU

MW

MWh

NEA

NEC

NELH

NREL

O\&R

PACE alternative compliance payments

Atlantic City Electric

Board of Public Utilities

community choice aggregation

customer on-site renewable energy

California Public Utility Commission

concentrating solar power

Department of Business, Economic Development and

Tourism

distributed generation

daytime minimum load

U.S. Department of Energy

Database of State Incentives for Renewable Energy

Electric Discount and Energy Competition Act

Energy Efficiency Portfolio Standard

Energy Information Administration

Environmental Information Services

Environmental Protection Agency

feed-in tariff

generation attribute tracking system

gross domestic product

Green Energy Market Securitization Program

greenhouse gas

gigawatt hour

Hawaii Clean Energy Initiative

Hawaiian Electric Company

Hawaii Electric Light Company

Hawaii Ocean Science \& Technology

investor-owned utility

Interconnection Requirement Study

investment tax credit

Jersey Central Power \& Light

Kauai Island Utility Cooperative

kilowatt

kilowatt-hour

Lawrence Berkeley National Laboratory

Leadership in Energy and Environmental Design

liquefied natural gas

million dry tons

Maui Electric Company

memorandum of understanding

megawatt

megawatt-hour

National Energy Administration

New Energy City

Natural Energy Laboratory of Hawaii

National Renewable Energy Laboratory

Orange \& Rockland Electric

property-assessed clean energy 
PCPI

PG\&E

PPA

PSE\&G

PTC

PUC

PV

R\&D

REC

RGGI

RPS

SACP

SAM

SFPUC

SGIP

SREC

TOU

USCREP

VOST

WREGIS per capita personal income

Pacific Gas \& Electric

power purchase agreement

Public Service Electric \& Gas

production tax credit

public utility commission

photovoltaic

research and development

renewable energy credit

Regional Greenhouse Gas Initiative

renewable portfolio standard

solar alternative compliance payment

System Advisor Model

San Francisco Public Utility Commission

Self-Generation Incentive Program

solar renewable energy credit

time-of-use

U.S.-China Renewable Energy Partnership

value of solar tariff

Western Renewable Energy Generation Information

System 


\section{Executive Summary}

The United States has extensive experience in developing and deploying renewable energy technologies across the country, spanning various climates and institutional environments, and in both urban and rural areas.

Some of the lessons learned from these examples may be useful to China, which is currently seeking to support the successful development of more than a hundred New Energy Cities across the country. A New Energy City (NEC) is a city that is currently experiencing rapid development, but where pollution is impacting the development patterns of the new city. By committing to using new renewable energy, the city can grow sustainably. Each city will focus on technologies such as solar photovoltaic (PV), solar thermal, biomass, or wind power. To encourage investment, it is critical to understand various policy options and their potential impacts on investment.

This report summarizes various policies for encouraging investment and installation of renewable energy across the country. In particular, we attempt to explain the benefits of, and considerations behind, each policy type and provide examples of implementation across the United States While recognized as important, this report does not address policies or examples of successful energy efficiency or alternative-fuel vehicle strategies. In addition, we summarize the renewable energy policy strategies undertaken by three areas of the United States: New Jersey, Hawaii, and San Francisco.

Policies can range from tax credits to payments based on production or installed capacity. However, at their core, each policy seeks to increase the financial returns for investors who choose to install renewable energy capacity. The overall impact of policies and incentives implemented by the government on the renewable and new-energy market will depend on the total number and type of policies implemented. Through case studies, we demonstrate that it is important for cities to first prepare the market for success, then support the early adopters, and finally, lead market expansion through financial benefit.

Some of the most successful areas in deploying distributed renewable energy in the United States have first established "market preparation" policies, then accomplished "market creation" tasks, and are now pursuing numerous "market expansion" topics (see table below).

When considering policies appropriate for a NEC, it is important to understand: 1) policy interactions, in other words how one policy may impact another and 2) policy efficacy, in other words whether or not a particular policy incentivizes the type of application desired. As discussed above, some policies are effective at promoting distributed generation on rooftops, whereas others encourage utility-scale investments in renewable energy. Similarly, some policies focus more on initial deployment and system size, whereas others focus on longer-term energy production. Depending on their design, these policies can either complement each other or compete with each other. Accounting for efficacy and interactions between policies is important, as is consideration of the current market, need for subsidies, and appropriate size of each incentive. Together, these considerations will help ensure that government investment to support NECs - and renewable energy technologies broadly - is used as effectively as possible. 


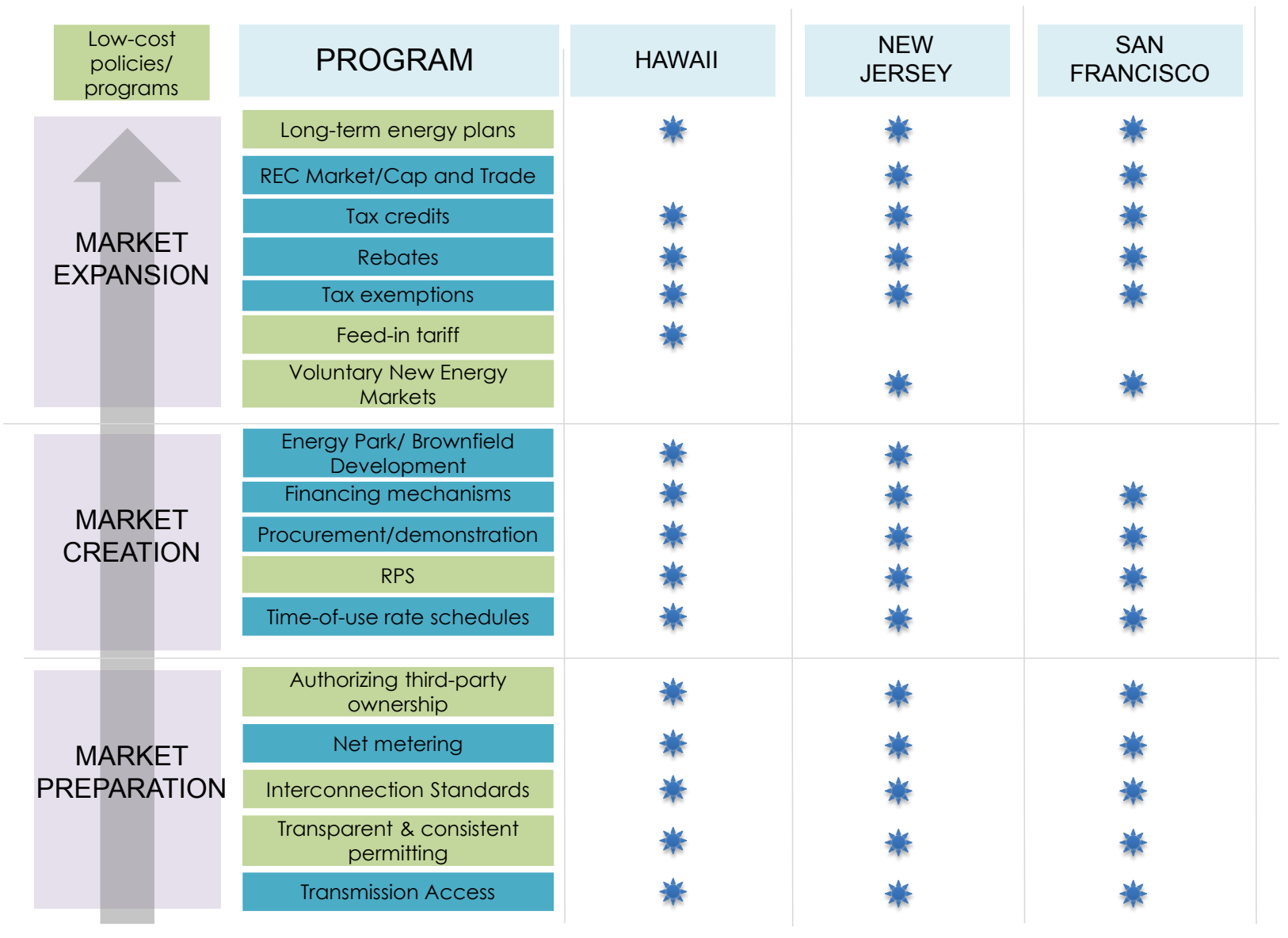

Figure 1. Renewable energy policies adopted by key markets in the United States 


\section{Table of Contents}

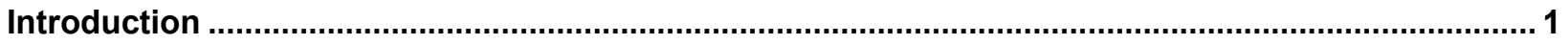

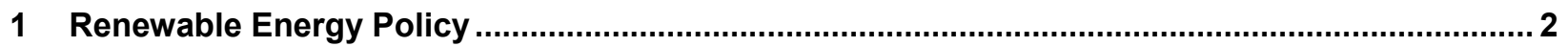

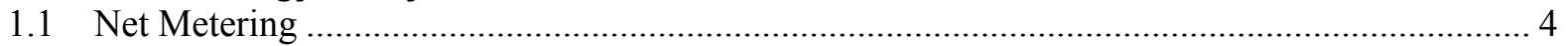

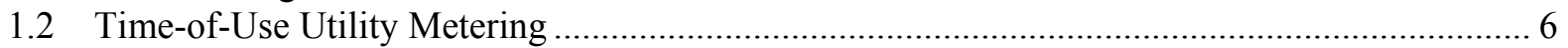

1.3 Interconnection Policies ...................................................................................... 6

1.4 Complementary Policy Areas that Impact Renewable Energy ............................................ 8

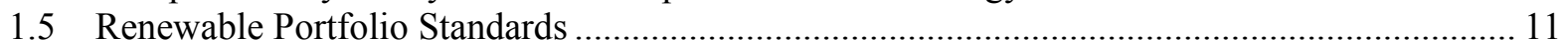

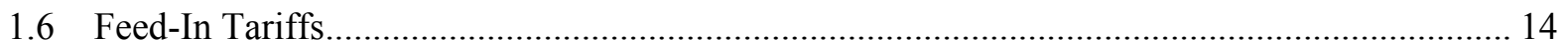

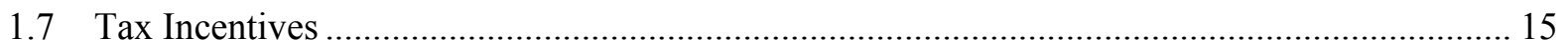

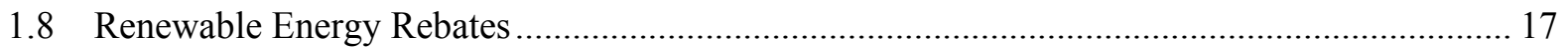

1.9 Cap-and-Trade Systems .................................................................................. 19

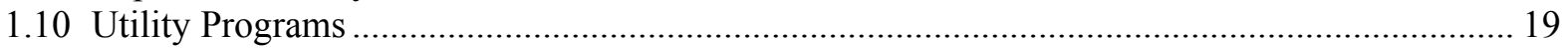

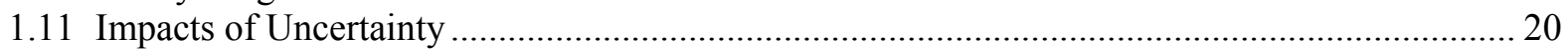

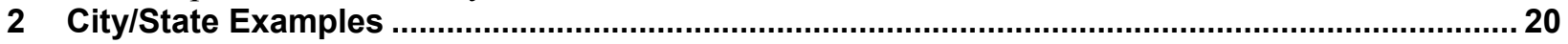

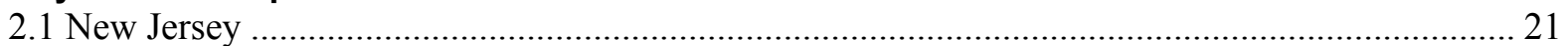

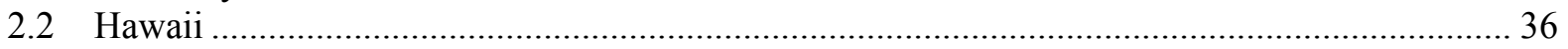

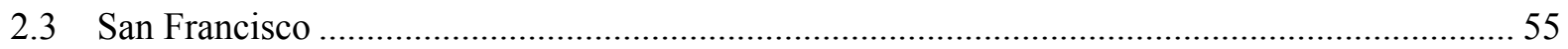

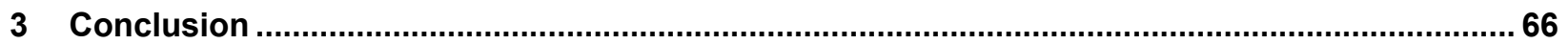

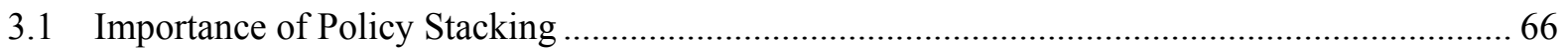

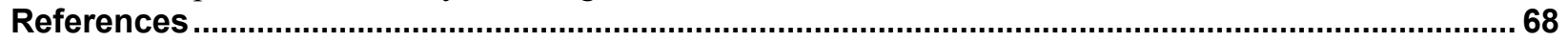




\section{List of Figures}

Figure 1. Renewable energy policies adopted by key markets in the United States........................ vii

Figure 2. Policy stacking approach for U.S. renewable energy policy............................................ 4

Figure 3. State net metering program cap policies .................................................................... 5

Figure 4. State interconnection policies in the United States (as of February 2013)......................... 7

Figure 5. Total PV system price, by sector and system size (first half of 2012)............................. 9

Figure 6. Summary of RPS policies (as of January 2015) ................................................................12

Figure 7. Estimated incremental RPS costs compared to recent and future RPS targets ................13

Figure 8. Areas with feed-in tariffs in the United States .................................................................. 14

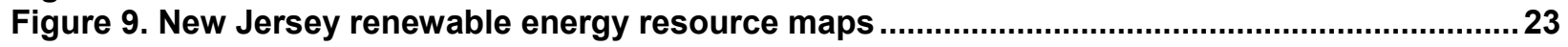

Figure 10. Electricity generation in New Jersey ......................................................................24

Figure 11. New Jersey renewable electricity generation by source 2001-2013 (GWh) ..................26

Figure 12. Summary of policies under the stacking framework for New Jersey..............................27

Figure 13. New Jersey's solar installations and rebates 2001-2014 ............................................. 30

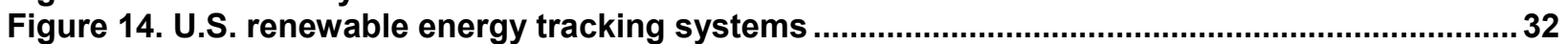

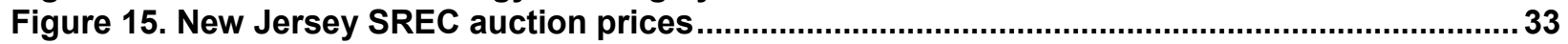

Figure 16. New Jersey solar requirements under Solar Act of 2012 vs. previous legislation ........... 33

Figure 17. Transactions in the bond-PPA hybrid model on government property ...........................34

Figure 18. Hawaii annual solar radiation at latitude tilt $\left(\mathrm{kWh} / \mathrm{m}^{2} /\right.$ day $)$............................................. 38

Figure 19. Hawaii onshore wind resource map at $80 \mathrm{~m}$ (annual average wind speed $\mathrm{m} / \mathrm{s}$ ) .............. 39

Figure 20. Hawaii offshore wind resource map at $90 \mathrm{~m}$ (annual average wind speed $\mathrm{m} / \mathrm{s}$ ) .............. 39

Figure 21. Geothermal resource areas in Hawaii....................................................................... 40

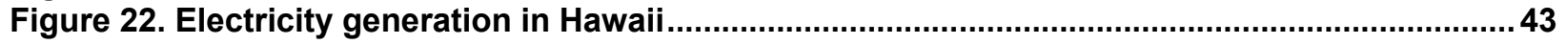

Figure 23. Summary of load generation profile in Hawaii................................................................ 43

Figure 24. Hawaii utility territory summary ....................................................................................45

Figure 25. Summary of policies under the stacking framework for Hawaii ......................................47

Figure 26. DG interconnection locational value maps for Oahu $(2 / 13 / 2015)$. .................................... 49

Figure 27. Renewable Watch (04/07/2015) .......................................................................... 49

Figure 28. San Francisco electricity deliveries by supplier...........................................................5 57

Figure 29. Summary of policies under the stacking framework for San Francisco, CA .................59

Figure 30. Overview of interconnection screening process used in select states in the United

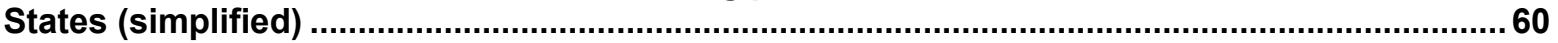

Figure 31. Step-level changes under the California Solar Initiative General Market Program .........63

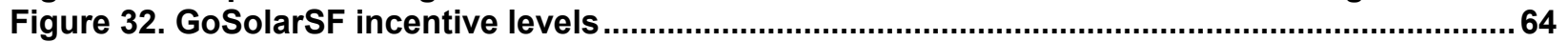

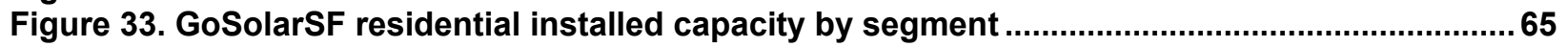

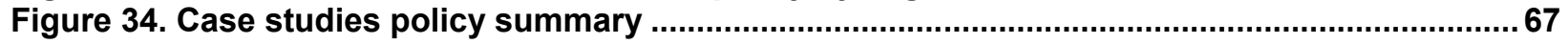

\section{List of Tables}

Table 1. New Jersey Demographic and Economic Indicators ........................................................22

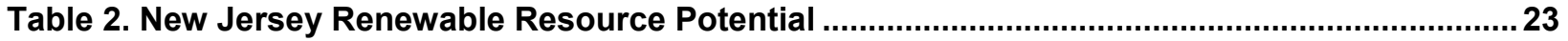

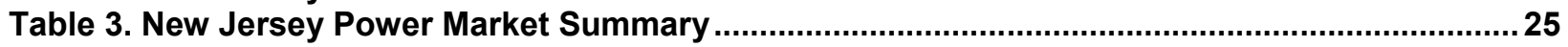

Table 4. Potential MW Contribution from Utility Solar Programs ........................................................... 31

Table 5. Hawaii Demographic and Economic Indicators ............................................................... 37

Table 6. Hawaii Renewable Energy Resource Summary ........................................................... 41

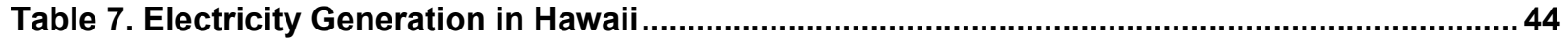

Table 8. Interconnection Policy for HECO (as of February 2014) ......................................................48

Table 9. San Francisco Demographic and Economic Indicators ....................................................56 


\section{Introduction}

This report summarizes U.S. federal, state, and local policies and programs that seek to incentivize renewable energy development. The report supports the U.S. China Renewable Energy Partnership (USCREP) project to promote the growth of New Energy Cities in China.

A New Energy City (NEC) is a city that is currently experiencing rapid development, but where pollution is impacting the development patterns of the new city. By committing to using renewable energy, the city can grow sustainably. Each city will focus on technologies such as solar photovoltaic (PV), solar thermal, geothermal, biomass, or wind power.

The benefits of renewable energy development in cities extend beyond emissions reduction and pollution control. Renewable growth in cities can result in economic stimulation, job creation, enhanced security of energy supply, promotion of technological development and innovation, and increased exports.

Recognizing these benefits, the National Energy Administration (NEA) has made NECs a priority policy in the $12^{\text {th }}$ Five-Year Plan for Energy Development. One hundred NECs and one thousand New Energy Districts are planned with the objective of promoting new energy technologies investment to achieve sustainable development.

In 2014, NEA released the first list of 81 cities and 8 industrial parks as the first New Energy Cities and Parks for wide deployment of renewables. In submitting their planning documents to the NEA, the cities needed to demonstrate a minimum of $6 \%$ of primary energy consumption coming from renewable sources as well as targets for more ambitious growth.

To encourage and enable successful NECs, the government plays a crucial role in implementing effective policies that will encourage private investment in local renewable generation across China. China has experienced tremendous success in rapid deployment of renewable energy in the past decade, reaching $28 \mathrm{GW}$ of solar PV and $96 \mathrm{GW}$ of wind installation capacity by the end of $2014^{1}$. These achievements were made possible under the central government's top-down policy support. However, in pursuing a bottoms-up approach of building renewable energy capacity within local entities, the government faces a new set of challenges. Low awareness of renewable energy, low availability of financial and human resources, and a lack of established practical tools for performance monitoring challenge the success of NECs.

In contrast to the policy drivers in China, long-term renewable energy demand in the United States have historically been generated at the state level and supported by national subsidies. The U.S. market has also experienced significant growth in distributed generation, particularly solar. An estimated $8.5 \mathrm{GW}$ of the cumulative $18.4 \mathrm{GW}$ of total solar PV capacity by year-end 2014 have come from the non-utility segments. ${ }^{2}$ This is crucial for localizing generation to meet load demand and decreasing the burden on transmission infrastructure. Therefore, a study of U.S. state and local policies for renewable energy could inform various policy approaches in China's NECs. Understanding of the extensive policy experience in the United States can be strengthened

\footnotetext{
${ }^{1}$ National Energy Administration

${ }^{2}$ Bloomberg New Energy Finance
} 
through example case studies that represent a variety of economic conditions, political environments, renewable energy resources, and demographics.

To support this effort, three case studies have been identified: New Jersey, Hawaii, and San Francisco. New Jersey is an area with a strong and growing economy dependent on energy imports. Hawaii has abundant renewable sources of energy and is heavily dependent on energy imports. San Francisco represents an extremely strong economy that is currently undergoing energy-source transformation as the city seeks to purchase $100 \%$ renewable energy in the near future. Together, the case studies contained within this report are intended to represent potential opportunities for cities throughout China.

Two parallel studies complement this report: 1) a case study of five Chinese New Energy Cities and 2) comparative analysis of U.S. and Chinese local renewable energy development based on the findings of the U.S. and Chinese case studies.

\section{Renewable Energy Policy}

According to the U.S. Energy Information Administration (EIA), 40\% of carbon dioxide emissions in the United States come from fossil fuel combustion in the electricity sector. The federal governement, as well as state and local governements, have implemented a wide range of policies to support efforts to reduce climate change and encourage renewable energy growth. Together, these policies have helped to substantially increase the investment in renewable energies across the United States in measurable and impactful ways.

Building successful NECs depends on limiting electricity consumption requirements as well as using renewable sources to produce the electricity required. The bulk of this report will investigate solutions that encourage increased renewable energy production; however, limiting energy consumption is equally important. NECs are focused on ensuring that at least $6 \%$ of all production comes from renewable sources. Therefore, it is important to understand that reducing consumption also reduces the amount of renewable energy capacity that needs to be built and installed. As such, although this report focuses on policies to encourage investment and deployment of renewable energy technologies, the case studies also illustrate that energy efficiency measures and strategies work in tandem with a cleaner generation fleet.

Consideration of a suite of policies that can be implemented across an entire city can maximize renewable growth and emissions reduction goals. However, although some policies work well together, others work against one another or have unintended consequences that reduce overall effectiveness. Thus, when considering various policies, it is important to understand whether or not they are synergistic. Throughout the United States, many distinct and overlapping policies exist such that it is impossible to meaningfully assess the impact due to a particular policy on renewable energy investment or deployment. To understand the role that a particular policy has in a state's overall renewable energy goals or supplemental impacts, one would need to conduct research that isolates the effects of one policy from those of other concurrent policies also intended to stimulate investment and renewable energy growth. This type of study does not exist, so most examples here are anecdotal rather than analytical. 
A recent National Renewable Energy Laboratory (NREL) study examined whether low-cost market-opening policies can be effective in incentivizing distributed PV growth. The authors concluded that even non-subsidizing projects could have a statistically significant impact on industry growth:

A cross-section econometric analysis that takes into account the quality of interconnection standards, net metering standards, Renewable Portfolio Standards (RPS), RPS set-asides, and a non-policy determinant (population) explains about $70 \%$ of the variation in newly installed PV capacity across states and indicates that all of the selected policies are significant. Nonparametric statistical tests confirm the regression results (Krasko and Doris 2013).

Consequently, it is important to understand that one must consider non-subsidizing policies before considering whether to adopt policies such as tax credits or rebates.

Several specific policy types are analyzed and discussed to provide a framework for developing an overall approach to successfully encourage NECs investment. A combination of different policies will encourage individuals, businesses, and government entities to invest in renewable energy in the future.

Policies developed should be built on a logical order of policies, potentially in categories that include market preparation, market creation, and market expansion. This framework for policy stacking is described below. "Market preparation policies focus initially on removing institutional barriers to prepare the market for solar PV; such policies "ensure that market players can, technically and legally, use the technology to its fullest extent" (Krasko and Doris 2013).

As such, the policies described here are ordered from those that relate to market preparation to those associated with market creation and finally to those associated with market expansion. Even if a NEC already has some technology deployed, it is important to review the existing policies and ensure that the market is properly prepared to enable cost-effective investment, deployment, and expansion. 


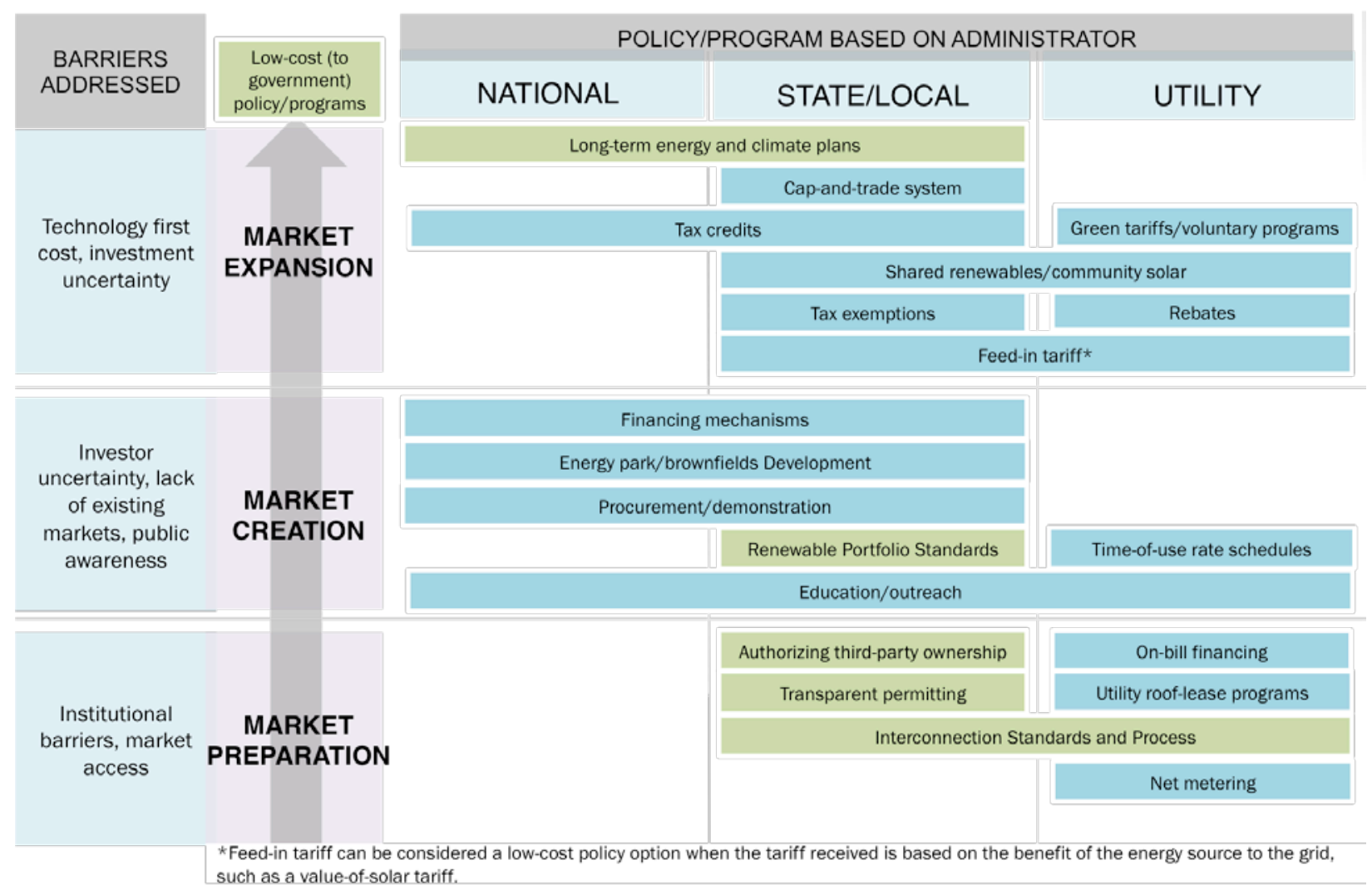

Based on framework from Krasko and Doris 2013

Figure 2. Policy stacking approach for U.S. renewable energy policy

\subsection{Net Metering}

Net metering is defined under the Public Utility Regulatory Policies Act as "service to an electric consumer under which electric energy generated by that electric consumer from an eligible onsite generating facility and delivered to the local distribution facilities may be used to offset electric energy provided by the electric utility to the electric consumer during the applicable billing period."

Net metering is considered a market preparation policy because it focuses on standardizing market access to distributed generation across multiple areas and jurisdictions. Although net metering alone is not likely an attractive enough incentive to encourage investment in renewable energy (Forsyth, Pedden and Gagliano 2002), it can help to encourage private investment in distributed generation when used in combination with other policies.

In general, net metering policies allow commercial and residential electricity customers to receive utility bill credits for renewable energy generated on site in excess of their instantaneous demand and to credit that excess generation toward future energy requirements. Typically, credits are equivalent to the total energy rate paid - the rate that includes generation costs but also includes transmission and distribution costs. In the United States, the typical form of net metering described above is currently under scrutiny following arguments that requiring net metering at the retail electricity rate constitutes a subsidy because the generators of renewable 
energy are not paying the appropriate cost for transmission, distribution, and other system-wide utility costs beyond the actual cost of generation.

As of August 2012, some 44 states have adopted a net metering program. However, these programs vary greatly from one another and may have different impacts on encouraging the adoption of renewable energy.

Most states that have adopted a net metering program have also adopted a cap on unit system size under which a utility is required to provide net metering to customers. These limits are typically implemented with limits ranging from an installed nameplate capacity of $25 \mathrm{~kW}$ to 2 MW. A number of states and utilities have also instituted a variety of restrictions on the total amount of distributed energy allowed within the net metering program. Some have placed a program cap based on a percentage of the utility or state's peak demand, capacity, or load. Others have a fixed number of megawatts as the threshold (e.g., Maryland, New Hampshire). Three states have placed a "trigger" policy, which notifies the utility or state to examine and possibly modify net metering (Heeter, Gelman and Bird 2014).

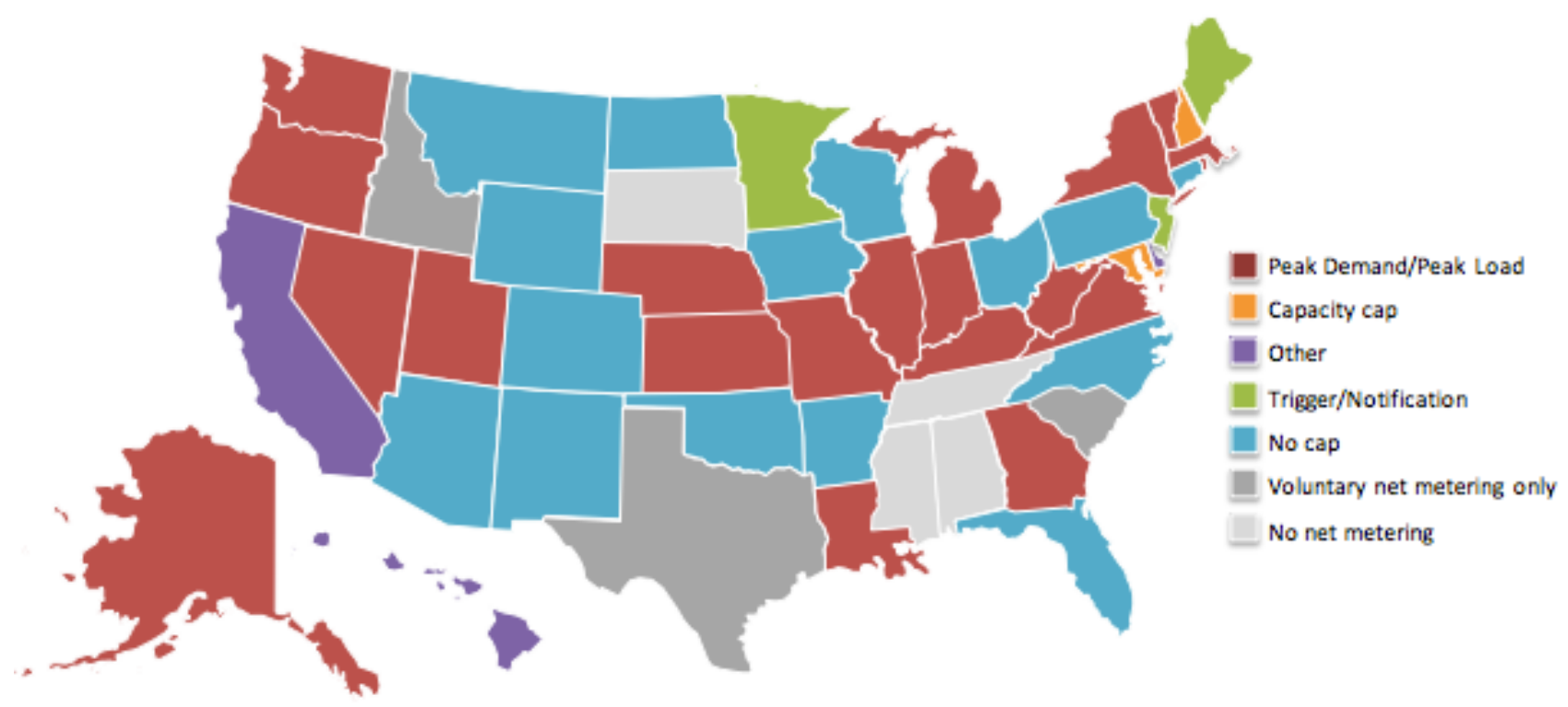

Source: Heeter, Gelman and Bird 2014

Figure 3. State net metering program cap policies 
Net metering can be understood as a policy that benefits property owners who choose to install distributed generation. But when considering net metering from the utility's perspective, it can be understood that utilities are required to pay the net-metered customer for electricity produced at the full retail rate even if the utility would otherwise, at that particular moment in time, choose to buy power elsewhere at a lower wholesale price (Weissman and Johnson 2012). The utility will see some harder-to-quantify benefits, such as reduced transmission and distribution losses, lower use of utility equipment, and potentially lower peak demand due to solar production.

Utilities and industry groups in the United States are currently discussing possibilities of "unbundled" electricity charges by splitting the cost of generation from transmission and distribution. "The utility argues that solar customers are not paying for transmission and distribution costs such as maintenance of the wires, public use charges, and other charges. (CPUC 2012)" This change would not eliminate net metering, but would reduce the incentive provided. It would allow utilities to add a "network use charge" for net metering customers for using the energy grid as an interconnection point and would effectively reduce the subsidy or benefit provided by net metering policies.

\subsection{Time-of-Use Utility Metering}

Under time-of-use (TOU) pricing, utilities charge consumers for energy use based on when the energy was used. In general, the utility charges a higher rate per $\mathrm{kWh}$ when demand is higher. For example, a utility could set both a winter rate and a summer rate and could set a rate that varies from nighttime (when demand is lowest) to mid-afternoon (when demand is highest). Time-of-use pricing is meant to reflect the actual cost of producing electricity at various times throughout the day. By having a varied pricing scheme, consumers are encouraged to lower their electricity use when the cost of production is high, reducing loads on the utility and improving grid stability and efficiency.

Although TOU is not typically developed as a policy or program for encouraging renewable energy investment and development, it is important to understand the impacts that TOU pricing has on renewable energy. For example, because PV produces energy throughout the day when demand is often highest, the return-on-investment to a property owner could be higher under TOU utility metering than it would be under a flat-rate paradigm. However, in general, a TOU rate across the utility's service territory could encourage more people to consider installing distributed generation such as solar.

Similarly, utilities often offer discounted or more inexpensive utility rates during off-peak hours when demand is low and the utility has ample low-cost generation capacity. By understanding the various rates charged, it is possible to incentivize investment in a wide variety of renewable energy technologies.

\subsection{Interconnection Policies}

Local policy regarding interconnection of renewable energy generation is directly associated with net metering. ${ }^{3}$ Across the U.S., policies vary widely on encouraging the use of distributed

\footnotetext{
${ }^{3}$ In general, the Federal Energy Regulatory Commission has jurisdiction over large (>20 MW) power generation interconnection. It has designed specific interconnection rules (grid codes) for variable generation sources such as wind.
} 
generation. Ensuring that the owners of distributed generation have adequate flexibility to install cost-effective and productive systems is critical to enabling sustainable market growth.

A clearly written interconnection process helps to reduce uncertainty and enable distributed generation to be installed within a utility network on a consistent and reliable basis. Creating a policy that enables significant investment in renewable energy while maintaining grid stability is important for renewable adoption. The concerns of the utility for the safe and reliable operation of the grid should be balanced with the benefits from enabling additional renewable generation. In the United States, states that have established reasonable, consistent, and streamlined interconnection processes often also have higher overall renewable energy deployment levels.

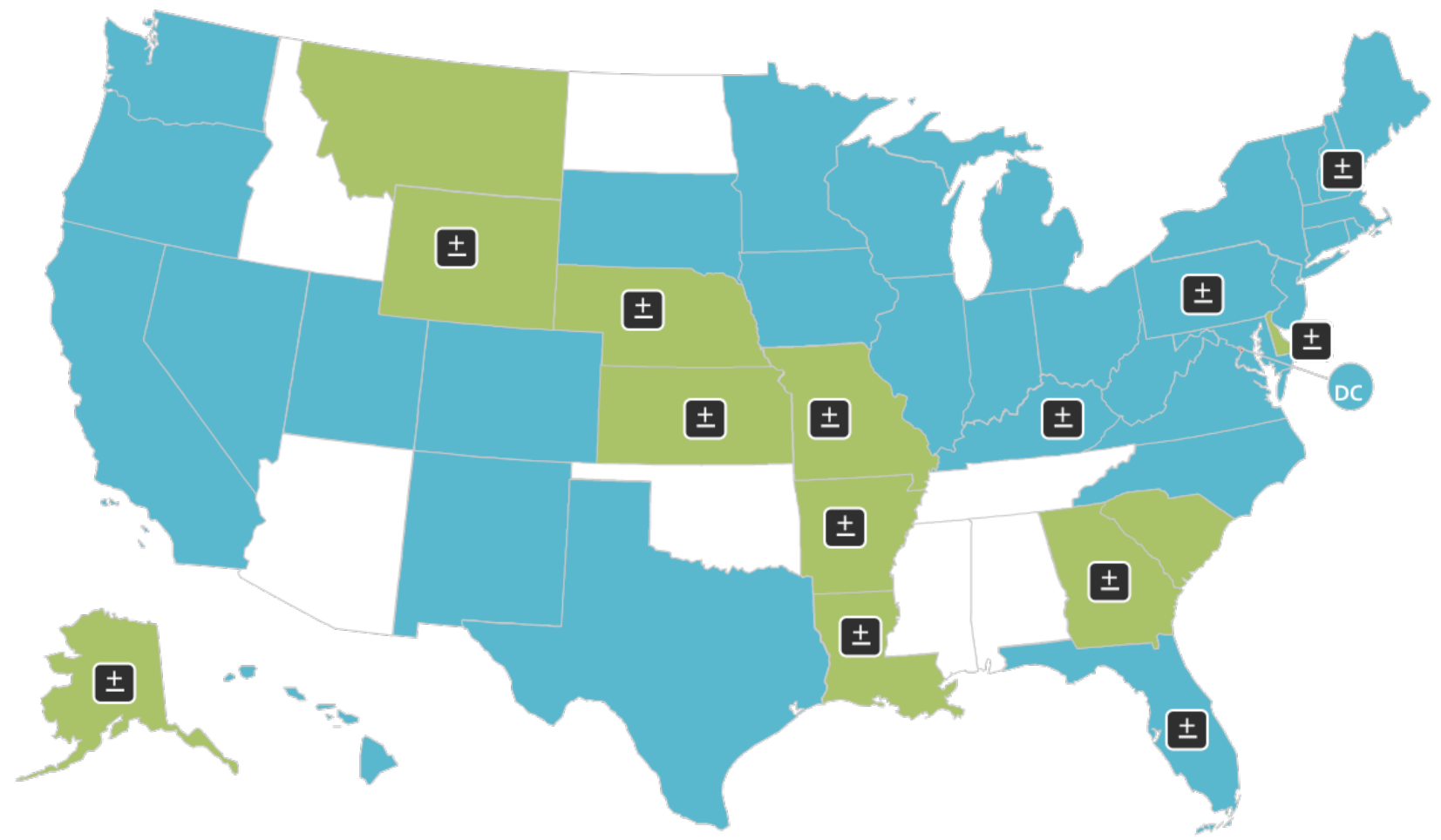

State renewable energy interconnection standards: 31 states + Washington DC

State renewable energy interconnection guidelines: 11 states

\pm Applicable only to net-metered systems

Based on DSIRE interconnection summary map

Figure 4. State interconnection policies in the United States (as of February 2013)

Together, net metering and interconnection policies can serve as an effective approach to encourage property owners and other private businesses to invest in distributed renewable energy. Investment returns are improved and risk is reduced because the distributed energy producer can rely on a purchase price of energy produced that can be calculated and forecasted. The application and use of TOU rates vary greatly depending on a specific building's load profile, function, and size. In addition, interconnection policies help ensure that the distributed generation can legally be connected to the grid. By remaining constant, net metering can serve as a continuous and predicable ongoing stimulus. 


\subsection{Complementary Policy Areas that Impact Renewable Energy}

Beyond specific renewable energy policies that can directly incentivize investment or industry growth, several other areas of government policy can impact the potential growth or interest in renewable energy. It is important to consider these associated areas as complementary, low-cost government policies that can help to prepare the market for easy adoption of distributed generation technology.

In addition, the U.S. Department of Energy (DOE) has invested heavily in developing tools and databases for public use by the solar industry that work to enhance innovation, lower the cost of market entry, and drive clean-energy solutions. For example, NREL has developed the PVWatts Calculator, ${ }^{4}$ a web application that estimates the electricity production of a grid-connected solar system based on a few simple inputs, such as the geographic location of the system, system size, and module type. This free tool, supported by the DOE, is used for estimating performance of solar systems in the preliminary studies stage.

Another example of a renewable modeling tool free to the public is the System Advisor Model (SAM) ${ }^{5}$ which forecasts cost of energy and performance based on inputs such as installation costs, operating costs, and system design parameters. SAM is a user interface built on industryvetted calculations, datasets, and formulas that enable the public to simulate cash flow and performance of a renewable energy project (Blair, et al. 2014).

In addition, DOE has developed the Database of State Incentives for Renewable Energy (DSIRE), ${ }^{6}$ the Utility Rate Database, ${ }^{7}$ Building Performance Database, ${ }^{8}$ and interactive mapping tools that provide information to the public free of charge that can help them develop new solutions and investments strategies. These public resources provide a common platform for basic research and data, reducing the duplicative efforts and resources of individual companies in creating these tools and databases.

Permitted land-uses can also limit, or enable, renewable energy system adoption. Zoning ordinances that either allow or prohibit the installation of large-scale renewable energy such as wind farms, concentrating solar power, or utility-scale solar arrays serve as an initial decision point as to whether or not renewable energy can be considered for the site.

The NREL Benchmarking of Non-Hardware Balance-of-System Costs Summary recently identified that soft costs account for a majority of total installed PV system prices in the first half of 2012: $64 \%$ of the total residential system price, $57 \%$ of the small (less than $250 \mathrm{~kW}$ ) commercial price, and 52\% of large commercial system prices (Friedman, et al. 2013).

\footnotetext{
${ }^{4}$ PVWatts calculator is available at: http://pvwatts.nrel.gov/pvwatts.php

${ }^{5}$ More information on System Advisor Model is available at: https://sam.nrel.gov/

${ }^{6}$ DSIRE is available at: http://www.dsireusa.org/

${ }^{7}$ Utility Rate Database is available at: http://en.openei.org/wiki/Utility Rate Database

${ }^{8}$ Building Performance Database is available at: http://energy.gov/eere/buildings/building-performance-database
} 


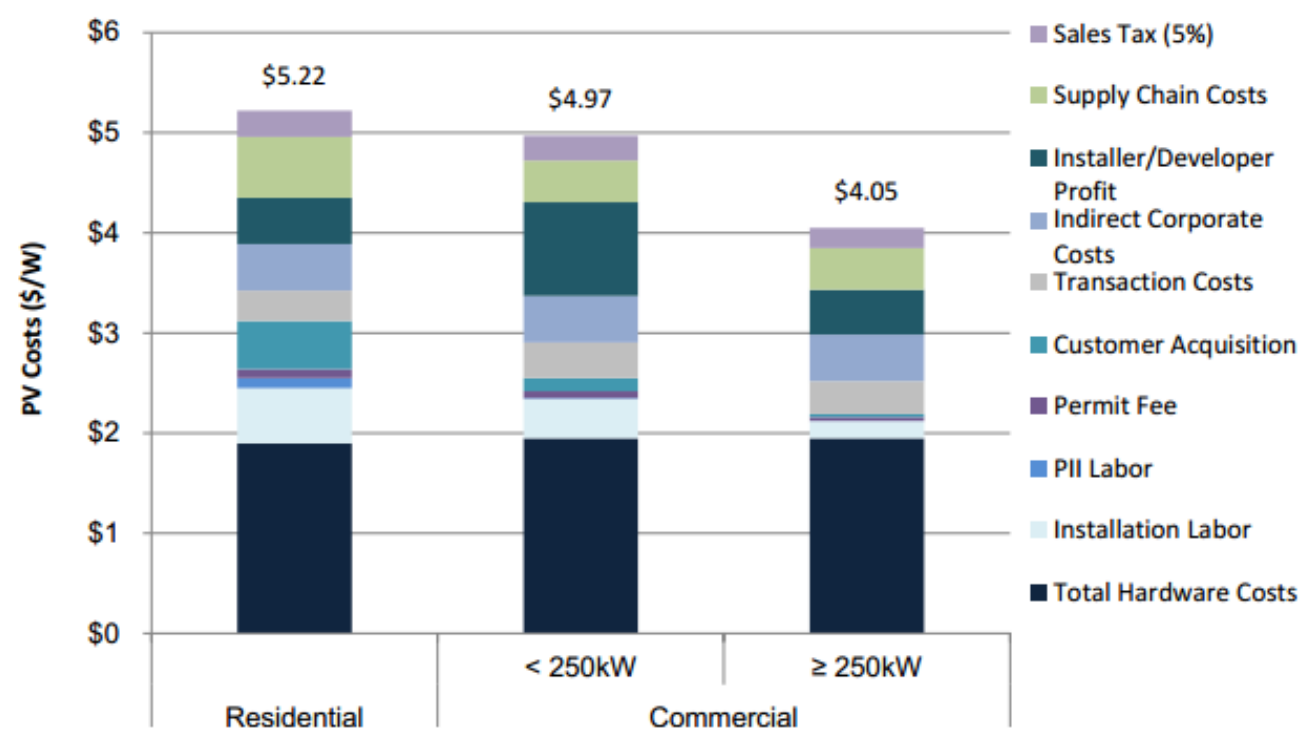

Source: Friedman et al. 2013

Figure 5. Total PV system price, by sector and system size (first half of 2012)

If the government can enact policies that reduce these soft costs, the total installation cost will be reduced and investment will increase. Costs for which a government may have jurisdiction can include permitting costs, siting requirements, sales tax, or management costs associated with the incentive policies described above.

\subsubsection{Improved Permitting and Siting Requirements}

When considering the cost to develop and install renewable energy, the balance-of-system or soft costs associated with installation are as important to consider as the cost of the hardware and the impacts of any policies put in place by government agencies.

One example of an improved approach to permitting requirements would be the inclusion of "solar-ready" language in building-code language. With solar-ready buildings, designers can prepare a building for a future solar system in such a way that adjustments to structural systems, additions to make room for inverters, or electrical conduit lines do not need to be added. This can reduce the implementation cost of solar and can incentivize more systems. Policies, as in Lancaster, CA, have required that new construction be solar ready without actually requiring that a solar system be installed.

\subsubsection{Grid Preparation}

When considering renewable energy, it is always important to consider how it will interact with the established utility grid. The electricity produced must be delivered to the utility in such a way to be manageable and useful. Siting wind or solar generation in an area where there is no demand does not add value to the grid unless sufficient infrastructure exists to deliver the energy to a consumer.

Government policy and utility support can help enable transmission lines to be built and can help prepare the grid for supporting renewable energy. Future investment in renewable energy will be 
better enabled by engaging experienced utility engineers to fully understand the impact of intermittency on the management of utility power structures, the need for peak demand facilities, and the potential upgrades to transmission lines, transformers, and grid control systems. A government planning agency's coordination with utilities is important to ensure that the grid infrastructure is prepared to support distributed renewable energy development as well as remotely located utility-scale generation such as wind, solar, or biomass power plants.

\subsubsection{Energy Parks}

In addition, the government can create "energy parks" that allow independent investors to install distributed renewable energy with low-cost land, easy interconnection, and access to sufficient transmission capacity. This energy park serves as an area that is specifically planned by the government to serve as a site for clean-energy development, such as wind and solar generation (Ciardulli 2013). These locations are often selected due to a high renewable energy resource such as solar, wind, biomass, or geothermal. A government can incentivize outside investment in the actual capital cost of the renewable energy technology by choosing to designate land that it already owns as an energy park and ensuring that the appropriate support areas are in place to enable easy and low-cost deployment of renewable energy.

\subsubsection{Allowable Third-Party-Owned Systems and Roof-Lease Programs}

Another enabling factor for the growth of renewable technologies, specifically distributed solar, is third-party solar financing. Third-party financing allows for-profit companies to own distributed solar systems placed at a property, which is owned by another entity (e.g. residential rooftop or commercial or industrial property). Two popular models that have emerged under third-party ownership are the power purchase agreement (PPA) model and lease model.

Under a PPA model, the customer pays the owner of the solar system for the amount of electricity produced by the solar system, typically at a lower and more predictable rate compared to traditional utility rates. In a lease model, a customer makes monthly payments to the developer at a predetermined rate and maintains ownership of the electricity generated.

In both cases, third-party ownership can enable outsize growth in the distributed generation market because it allows developers with available capital to purchase systems and to secure income from those systems (Kollins, Speer, and Cory 2010). In addition, the developer retains responsibility for the maintenance and operation of the system, which an individual property owner may not be qualified, prepared, or interested in handling.

Regulators may need to declare that third-party-owned systems are not utilities or electrical corporations and are therefore not subject to the same regulation as typical utilities. In certain jurisdictions, solar leases may be permitted while PPA models are not because the consumer is not technically purchasing power from the developer, but rather, is buying the right to use the equipment.

Alternatively, it is possible for a utility to own the distributed generation equipment and the resultant power through a roof lease with the property owner. In this situation, the solar energy system is installed on the utility side of the meter such that the renewable energy is never considered as part of the property owner's utility bill. In this case, the utility would simply 
provide payment to the property owner for the lease of the used roof area at the property. This can enable utilities to expand distributed generation without purchasing land or property.

\subsubsection{Focus on Energy Efficiency}

NECs should recognize that the cleanest and least-cost energy is that which is never needed at all. The government should consider incentives to encourage reductions in energy use in tandem with incentives that encourage new renewable energy development. Detailing specific opportunities for incentivizing energy efficiency is beyond the scope of this report. However, governments should consider developing building energy codes, utility rebate programs, and integrated plans incorporating both renewable energy and energy efficiency.

\subsubsection{On-Bill Financing}

Often used for energy-efficiency retrofits, on-bill financing administered by utilities can offer an effective incentive for consumers to invest in the energy performance of their properties. Such programs leverage the existing relationship between the electric utility and the consumer to provide convenient access to funding, low default rates, and minimal complicated relationships (ACEEE 2012). They allow customers to invest in energy improvements and repay the funds through a separate charge on their monthly utility bill. This type of simplified transaction can encourage development, increase the ability to track system performance, and reduce risks associated with renewable energy or energy-efficiency deployment.

\subsection{Renewable Portfolio Standards}

A renewable portfolio standard is a policy or regulation that requires utilities to produce a certain percentage of their energy from renewable energy sources. These renewable energy sources are defined as part of the policy and can include technologies such as wind, solar, biomass, or geothermal. Depending on how the RPS is written, the requirement could apply to all renewable energies in total or there could be specific requirements for each type of generation, often called "carve-outs" or "set-asides." Set-asides can also exist to require that a particular percentage of generation be provided by distributed generation. Distributed generation is often defined as consumer-scale generation installed at a utility customer's address. Sizes of distributed generation can vary significantly; however, it is typically tied to the actual energy use of the site where the renewable energy system is installed. The design of an RPS may vary, but at its core, an RPS will require electricity suppliers to source a certain quantity of renewable energy. This quantity can be defined as a percentage or as a particular amount of energy produced in megawatt-hours. Along with these overall production-type requirements, many RPS policies will allow or include the trading of renewable energy certificates to enable utilities to meet their obligations in a variety of ways.

More than half of U.S. states have adopted RPS policies or goals, each of which ranges from about $5 \%$ to as high as $40 \%$ by 2030 . The policies are typically specified as a percentage requirement by a particular year such as $25 \%$ by 2025 . In the United States, each state sets its own policy and the specific details will outline the requirements of utilities, whether investorowned or government-owned, to meet the policy requirements. 


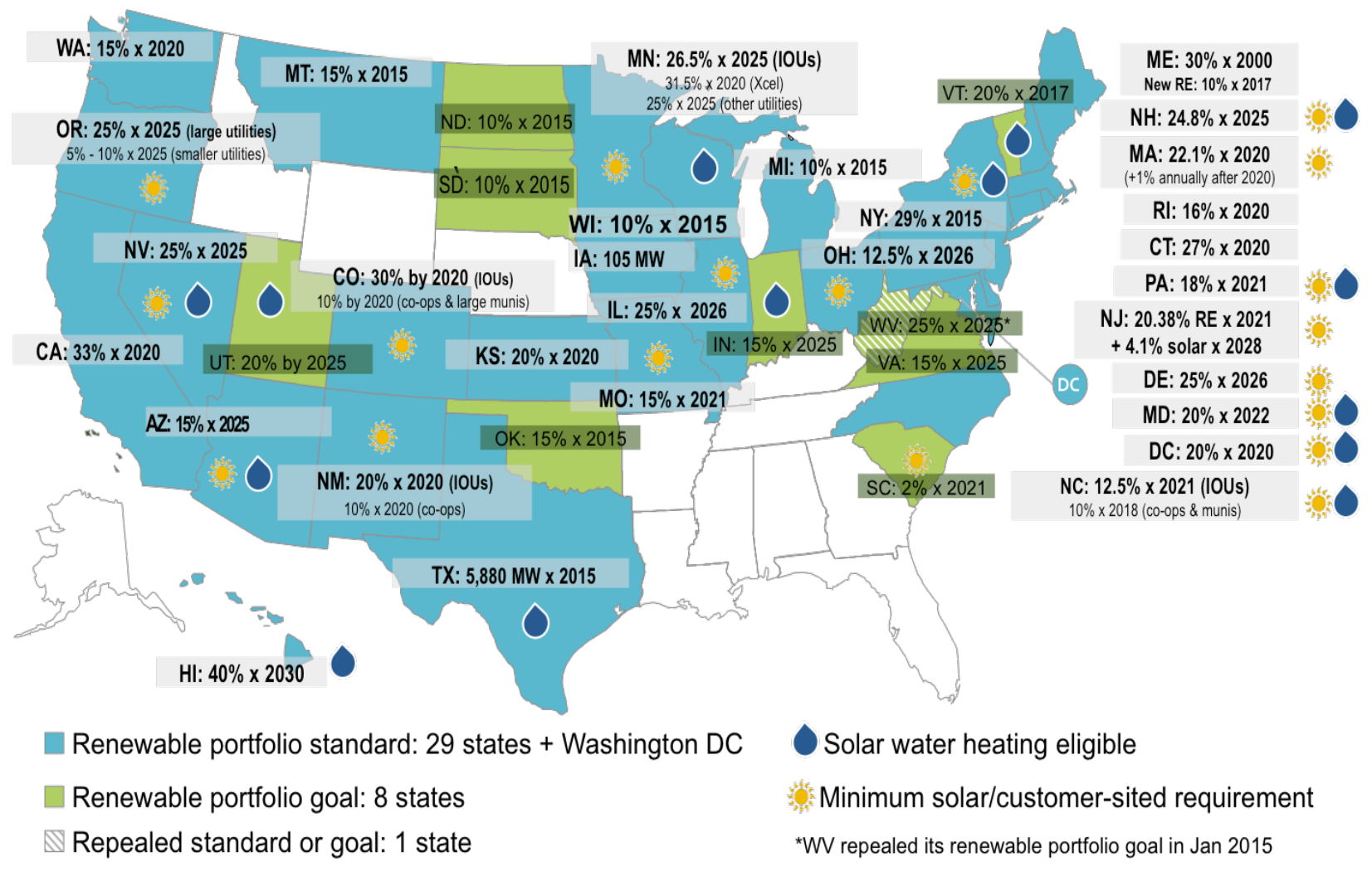

Updated from DSIRE RPS summary map

Figure 6. Summary of RPS policies (as of January 2015)

An RPS can serve as a clearly defined target for an entire state to work toward and can serve as a positive political statement that the government is committed to supporting renewable energy development and deployment. The adoption of an RPS also serves as a high-level way for states to require action by utilities.

Often, the primary impact of an RPS policy being adopted will be on the major utilities within the jurisdiction. These utilities will need to find the most cost-effective way to meet the requirements of the policy. This could involve the development of utility-owned, large-scale, renewable energy developments such as large wind farms or solar plants, the development of PPAs with large-scale energy producers such as owners of wind farms or megawatt-scale solar installations, or the purchase/trading of renewable energy credits (RECs) from owners of distributed generation renewable energy systems.

In 2013, NREL and Lawrence Berkeley National Laboratory (LBNL) conducted a survey of several existing state-level RPS policies to better understand the cost and benefit estimates of each policy (Heeter, Barbose, et al. 2014). Figure 5 summarizes the incremental costs of meeting RPS targets, where the incremental cost is the cost in excess of what would have been incurred if the RPS did not exist. These costs are determined by considering the cost of RECs and alternative compliance payments (ACPs). 


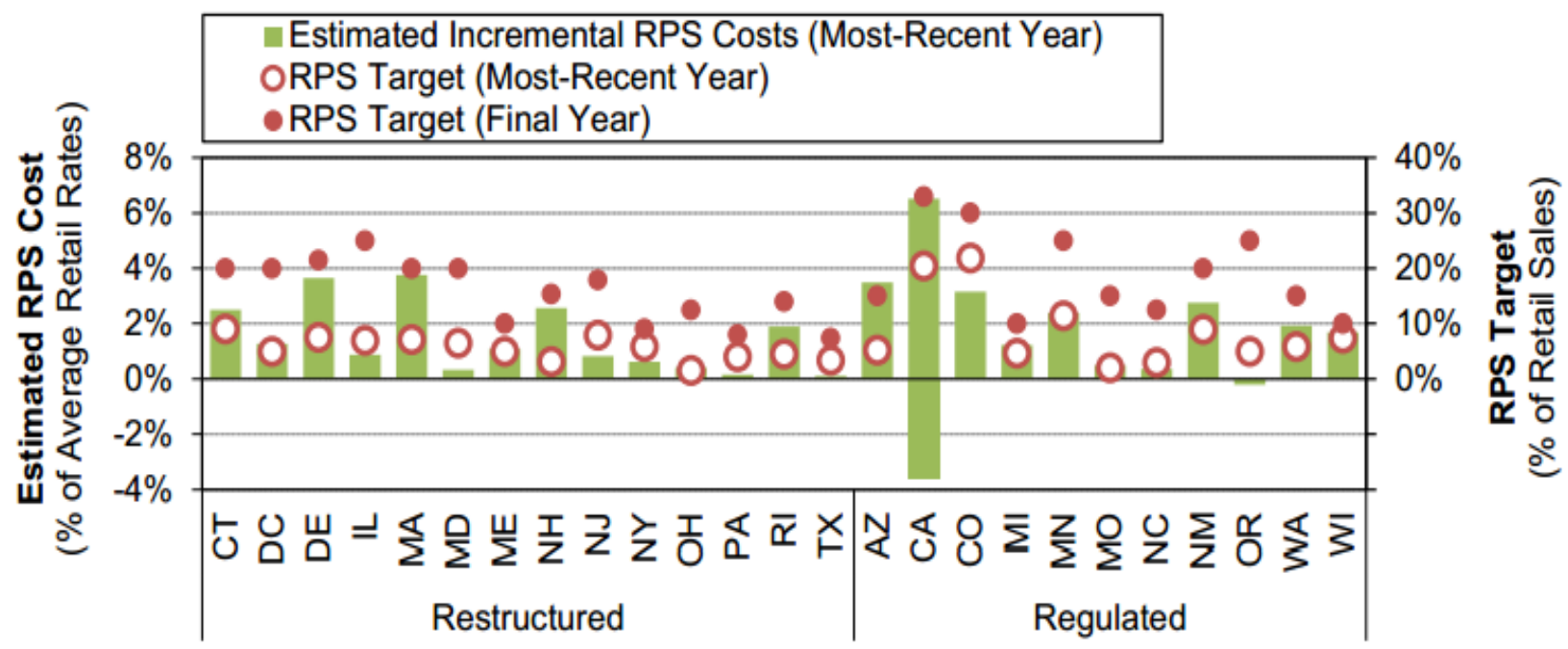

" For most states shown, the most-recent year RPS cost and target data are for 2012; exceptions are CA (2011), MN (2010), and WI (2010). MA does not have single terminal year for its RPS; the final-year target shown is based on 2020. For CA, high and low cost estimates are shown, reflecting the alternate methodologies employed by the CPUC and utilities. Excluded from the chart are those states without available data on historical incremental RPS costs (KS, HI, IA, MT, NV). The values shown for RPS targets exclude any secondary RPS tiers (e.g., for pre-existing resources). For most regulated states, RPS targets shown for the mostrecent historical year represent actual RPS procurement percentages in those years, but for MO and OR represent REC retirements (for consistency with the cost data).

Source: Heeter, Barbose et al. 2014

\section{Figure 7. Estimated incremental RPS costs compared to recent and future RPS targets}

The study found that the estimated incremental RPS compliance costs were about $0.9 \%$ of retail electricity rates when calculated as a weighted average. The same study also concluded that RPS "policies have been a significant driver of development of new renewable capacity additions in the United States, with roughly $46 \mathrm{GW}$ or two-thirds of all non-hydroelectric renewable energy capacity additions since 1998 occurring in states with active or impending RPS targets." When considering RPS policies, it is typical to consider not just the costs (or savings) that may be borne by the utilities, but also, systemic benefits such as lowered emissions, energy-source diversity, lowered price volatility, and increased economic development. It is also important to realize that many RPS policies include provisions that require costs of RPS compliance to remain below $2 \%-4 \%$ of retail electricity rates (Heeter, Barbose, et al. 2014).

RECs, mentioned above, are a method by which utilities can purchase the environmental attributes of renewable energy capacity installed and use those attributes and associated production to meet the requirements of the RPS. The rates paid for RECs can vary widely from year to year depending on demand, production makeup, and whether a utility is behind or ahead of RPS targets.

Overall, an RPS works as a policy that attempts to allow the market, through utilities, to determine the most efficient way to produce renewable energy. Without any carve-outs, the utility is incentivized to produce electricity as cheaply as possible while still meeting compliance with the RPS. As such, the enactment of an RPS policy will typically encourage utility-scale renewable energy investment, either owned by the utilities themselves or built by private entities, which then sell the electricity and associated RECs to the utility through a PPA. 


\subsection{Feed-In Tariffs}

Feed-in tariffs are a policy mechanism that guarantees that customers, who own a feed-in tariff (FIT) eligible renewable electricity generation facility, will receive a set price from the utility for the electricity they generate and provide to the grid (EIA 2013a). FITs are similar to net metering in that the utility is required to buy electricity from the producer, but they separate the purchase price from the retail rate of electricity typically borne by the consumer.

FITs are not very common in the United States, but are used widely internationally. Historically, FITs have been government-mandated rates at which the utility must buy electricity produced by distributed renewable energy facilities; however, in the United States, some models have emerged where utilities choose to independently create a FIT to help meet government mandates that may exist through an RPS or other policies. For example, Dominion Virginia Power created a voluntary FIT where participants will receive $\$ 0.15$ per kilowatt-hour for a specified contract term lasting 5 years. Participants would still pay retail rates for any electricity consumed. This FIT rate is significantly above the $\$ 0.105 / \mathrm{kWh}$ residential and $\$ 0.078 / \mathrm{kWh}$ commercial rates for that utility. Similarly, any FIT can have adjustable purchase prices that respond to market conditions and reduce the incentive as technologies become more commonplace.

\section{U.S. states and utilities with feed-in tariffs or similar programs}

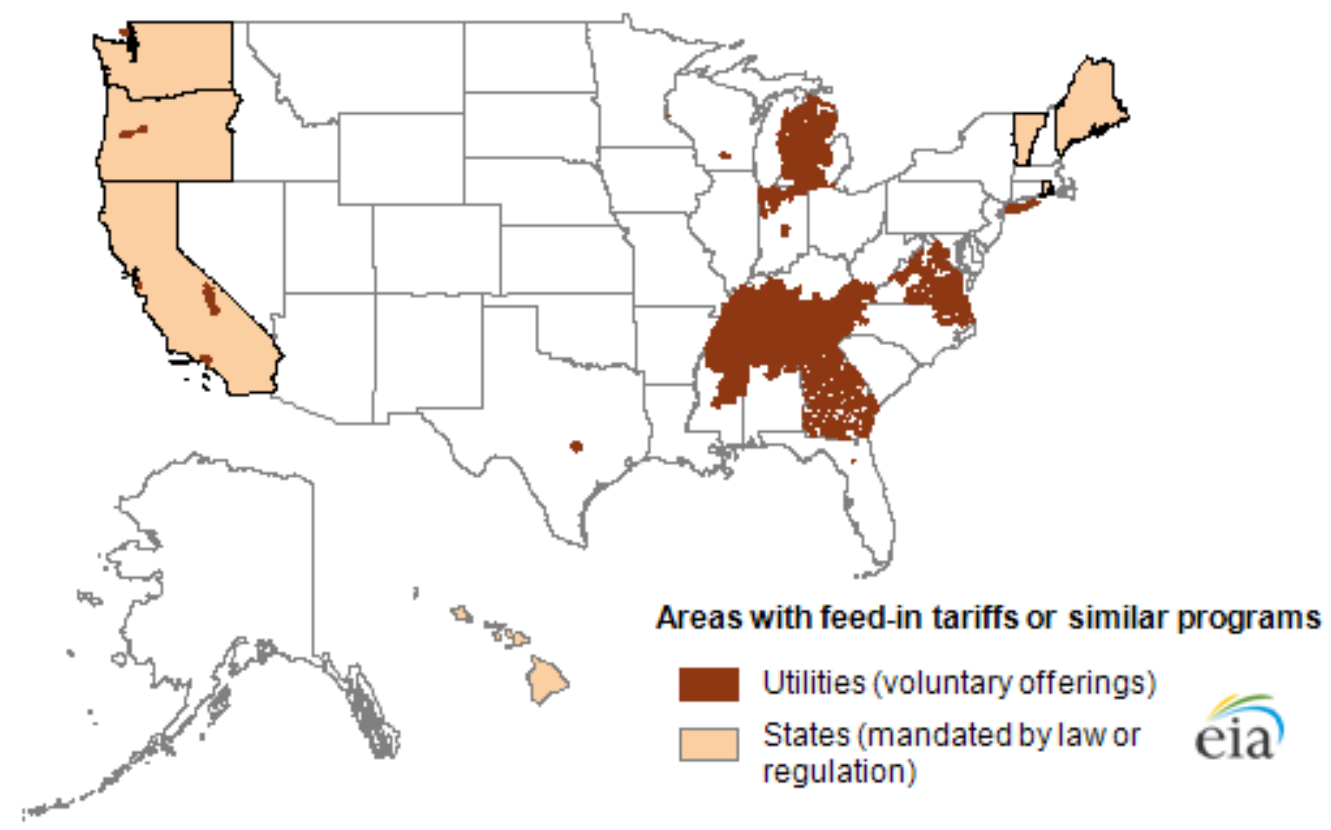

Source: EIA

Figure 8. Areas with feed-in tariffs in the United States

Similar to the RPS policy described previously and the associated RECs, FITs are performancebased incentives that depend on the continued performance of the system over time, rather than on the initial investment in the technology. 
Because FITs are not directly linked with the retail rate of electricity, which is the case in net metering, the rate paid per $\mathrm{kWh}$ can vary over time. The FIT could require payment of aboveretail rates when a technology is new to the market, but could be reduced to better reflect the value added to the utility once renewable energy is established. Much like the net metering policy, one must present a clear and consistent approach to encourage investment and reduce overall project risk. Coinciding with this, most successful FITs use long-term contracts of 10-20 years to help assure project owners of a stable and measurable revenue stream.

Setting FIT rates requires careful consideration to ensure that the rate is not set too high as to over-stimulate the market or set too low as to fail as an incentive. The EIA publishes a table ${ }^{9}$ that summarizes many FITs used in the United States because the policies enacted vary widely from state to state. Most, however, specify the eligible technologies, the rate and contract terms, system size and type restrictions, and total program size limitations to ensure that the FIT cost and impact remain within expectations.

A variation on a traditional FIT is a value-of-solar tariff (VOST), where the tariff received is based on the benefit of solar to the grid. This is calculated using an agreed-upon formula developed not only by the utility but also by third-party organizations or a public utility commission to help ensure that the value is evaluated fairly. When calculated correctly, the incremental cost to a utility or government to adopt a VOST can be marginal; however, it may incentivize solar and adequately account for the benefit that renewable distributed generation can have for a community as well as the utility itself. VOST is an alternative to net metering that utilities can use to compensate solar.

In 2012, the city of Austin, Texas implemented a VOST policy. Under this scheme, solar customers cannot use the power generated by their solar systems but sell it back to the utility at a price while still purchasing all the electricity from the utility. As of 2014, Minnesota has been the only state to allow utilities, through legislation, to voluntarily implement a VOST.

Overall, FITs can be understood best as a production-based incentive similar to net metering that can use higher-than-market rates to incentivize the investment in and development of renewable energy generation. FITs can be used in conjunction with other policies, such as RPS or tax credits.

\subsection{Tax Incentives}

To help encourage investment in renewable energy and energy efficiency, government agencies throughout the United States often offer a variety of tax credits, rebates, and other incentives. Similar to the policies described above, each incentive is designed to encourage investment in renewable energy by making project economics more favorable.

\subsubsection{Investment and Production Tax Credits}

The U.S. federal government has historically used several key incentives to encourage renewable energy development. These include the investment tax credit (ITC), production tax credit (PTC), and accelerated depreciation for renewable energy property (Modified Accelerated Cost Recovery System and bonus depreciation). The ITC and PTC are similar in that they provide

\footnotetext{
${ }^{9}$ EIA's Feed-in Tariff table is available at: $\mathrm{http}: / /$ www.eia.gov/electricity/policies/provider programs.cfm
} 
financial incentives in the form of tax credits that can be used, in the future, to offset taxes paid on a company's profits (Steinberg and Porro 2012).

The federal renewable electricity PTC, originally enacted in 1992, is a per-kilowatt-hour tax credit for renewable electricity generated and sold by a taxpayer. The PTC amount was set, generally, as $\$ 0.015 / \mathrm{kWh}$ in 1993 dollars, indexed for inflation. The credit typically lasts for 10 years past the date that the facility was placed in service, and unused credits could be carried forward for up to 20 years. The PTC allowed several different technologies to be used, including wind and geothermal, but not solar.

The federal business energy ITC is a policy that reduces the tax liability for individuals or businesses that invest in qualifying technologies. This tax credit is, generally, equal to $30 \%$ of the qualified costs for solar, fuel cells, and small wind and $10 \%$ for geothermal, micro turbines, and combined heat and power. The ITC also sets maximum incentives and limits eligible system size for some technologies. This incentive enables the federal government to reduce the upfront capital costs of investment in renewable energy technologies.

Because tax credits are simply a reduction in the tax base, they do not require forward funding or a government appropriation to enact. The costs must be considered when planning future spending, but the money does not need to be available immediately.

Both the ITC and PTC serve as incentives for renewable energy investment, but operate in different ways. The ITC is an initial credit toward the initial capital required to build a project, whereas the PTC is a credit over time based on production of energy. The ITC rewards high capital cost. This can incentivize expensive third-party financing structures. Because the ITC depends on cost, applicants are less incentivized to pursue the lowest-cost option, or the highest overall value. The PTC, or other production-based subsidies, incentivizes the highest potential production at the lowest possible cost. Independent financial analysis of each project could identify which incentive would yield the highest return on investment. The greater the amount of projected energy production, the more likely that the PTC will make more financial sense than the ITC.

\subsubsection{Cash Payment In Lieu of Tax Credit (Treasury 1603 Program)}

Between 2005 and 2008, the U.S. renewable energy industry experienced substantial growth and progress toward adoption. However, when the economy contracted and entered a recession, a reduced supply of available capital led to decreased opportunities to realize planned projects. In response to this downturn - and to act as both an economic stimulus and a renewable energy incentive - the U.S. government established the Treasury 1603 program. In addition, the U.S. government recognized that many renewable energy companies or property owners are relatively small such that their tax liability is lower than the value of the tax credits received and the incentive does not work as intended. Historically, to counteract this disconnect, project developers would rely on third-party tax-equity investors to monetize the value of tax credits. However, as the economy collapsed, so did the pool of tax-equity investors investing in the market. As such, the Treasury 1603 program was designed as a technology-neutral solution that allows taxpayers to receive a cash payment in lieu of the already-existing ITC. This one-time payment is equal in value to the ITC, calculated as $30 \%$ of total eligible costs for renewable energy projects. 
As of January 8, 2015, the Treasury 1603 program has funded 98,993 projects through a total government funding of $\$ 23.7$ billion and estimated private, regional, state, and federal investment of $\$ 84.5$ billion. This directly led to an installed capacity of $31.7 \mathrm{GW}$ and an estimated annual electricity generation of $78.7 \mathrm{TWh}$, an amount roughly equivalent to the usage of 7.9 million homes. The cash grant has supported more than 97,000 solar projects with a total installed capacity of $6.6 \mathrm{GW}_{\mathrm{DC}}$ and more than 1,000 wind projects with a combined capacity of 21.6 GW. Although fewer in number, wind projects accounted for nearly $\$ 13$ billion in awards versus $\$ 7.8$ billion for solar (Department of Treasury 2015).

The Treasury 1603 program was successful in encouraging the deployment of renewable energy systems. By enabling project owners to take the immediate benefit of the ITC, upfront capital requirements were reduced and returns on investment became attractive. However, the Treasury 1603 program did not work in isolation from other policies. Overall, tax incentives have enabled the U.S. government to enact policy that incentivizes renewable energy development beyond any incentives that local governments or states choose to adopt. The PTC and ITC provide both a production-based incentive over time and an investment-based incentive at the time of construction that together encourage the deployment of the most cost-effective renewable energy systems available. Although this still represents a subsidy above normal market conditions, the policies encourage developers to maximize their returns by optimizing their system designs and technologies selected. When combined with other policies, both the ITC and PTC are recognized as significant influencers of renewable energy development.

\subsubsection{Tax Exemptions}

In addition to providing federal tax incentives such as those described above, local governments can choose to incentivize renewable energy development by waiving or reducing tax liability such as property tax or sales tax associated with renewable energy systems. For example, governments could create policy that removes requirements to collect sales tax for the sale of renewable energy systems, effectively reducing the cost to the owner of the system of the complete installation. Alternatively, a government could enact policy that reduces the property tax liability, either wholly or partly, due to the installation of a qualified renewable energy system.

\subsection{Renewable Energy Rebates}

Renewable energy rebates, also known as buy-down programs, subsidize renewable energy development by providing a rebate, refund, or discount on the cost of new installations. These programs are typically run by local utilities or smaller government agencies such as the city or state. Rebates are typically given following installation and the system owner is required to complete an application for the rebate. Payments can be structured with limitations such as the value per watt, maximum rebate, transfer or renewable energy credits, or maximum system size (Lantz and Doris 2009). Utilities and government agencies may choose to implement a renewable energy rebate in concert with other policies to help stimulate market growth and investment.

When developing rebate programs, utilities or government agencies should consider the current market cost of the technology, the expected return on investment without subsidies, the total size of the market and expected number of participants in the rebate program, and the expected 
impacts on overall market growth. To ensure that the incentive and market conditions are compatible, a rebate program should consider building a timeline for adjusting the rebate value based on changes in technology costs and expected deployment rates.

Because the rebates are associated with individual systems, a procedure must be in place to review applications and approve payments. Thus, rebate programs can require substantially larger administrative costs and commitments. The other potential downside of an installation payment based on installation cost is that it does not necessarily incentivize or guarantee longterm system performance.

A NREL study summarizes the ideal conditions and applications for the successful implementation of state and local government renewable energy rebate programs as follows (Lantz and Doris 2009):

- Appropriate technology for the market. Rather than applying broadly to a variety of technologies, a rebate program should recognize the unique market condition of each technology and the need for varied rebates across each type of system to be successful.

- Small markets with limited growth. Rebates are encouraged not as an incremental market-driver, but rather, as an incentive that causes technologies to be adopted early in its market deployment. By creating a rebate early, programs can limit free ridership and optimize investment.

- Market-ready technologies. Rebates are best applied to technologies that are ready for consumer adoption and investment-grade activity but for which the prices are not quite low enough to grow without incentives.

- Available workforce. If a specific government agency recognizes an underutilized workforce that could quickly adapt to the technology being supported, then rebates can better support market growth and sustained markets following the conclusion of the rebate.

- Appropriate energy markets. Rebates for renewable energy should be enacted in areas where there is a demand for the solution, even if it is not quite investable. The rebate should not force a market to be created, but rather, encourage investment where it is already appropriate.

Overall, rebates can be a successful strategy when used for an appropriate technology and an appropriate time. Rebates should be carefully designed to ensure that the value provided by the government does not exceed what would otherwise be required to develop investment. Unlike tax credits described above, a rebate program will require that funding is available to deliver rebates soon after installation of the systems. Unlike FITs, which make payments over time, rebates are typically one-time payments that are front-loaded to when the system is installed.

Rebates can be used as a complement to other policies such as net metering or TOU rates. The rebate could encourage the system to be built while the net metering or TOU rates help ensure that operating the system remains profitable into the future (Lantz and Doris 2009):

Rebate programs may be most effective when well designed and implemented as one component in a suite of policies. Under this scenario, rebates can be applied 
to jumpstart or rapidly expand a specific renewable energy technology while additional policy measures may be put in place to capture the full value of renewable energy resources and ensure that institutional barriers, technical barriers, and public awareness are also addressed.

\subsection{Cap-and-Trade Systems}

In general, a cap-and-trade policy is a system in which a government agency enacts a mandatory cap on emissions. The emissions producers will then have flexibility in how they comply with the requirements. Producers comply with cap-and-trade policies by ensuring that their allowances are equal to or greater than their total emissions, and are able to buy or sell allowances or "bank" them to use in future years. As one potential way of meeting the requirements, energy producers may choose to invest in renewable energy technologies. Beyond work to reduce emissions of the power plants currently in operation, investing in alternative technologies can be part of a successful strategy for meeting cap-and-trade requirements. The policy acts as an outside influence that encourages reductions in emissions and adds value to renewable energy systems.

\subsection{Utility Programs}

Across the United States, dozens of different utilities offer many different incentive programs that attempt to encourage adoption of renewable energy. Designing appropriate incentives - and, more importantly, tracking the expenditure of utility funds - is difficult, yet supremely important. In 2012, NREL published a report focusing on recent experiences and best practices for design and implementation of solar incentives (Bird, Reger and Heeter 2012). The report is based on interviews with program administrators, regulators, and industry representatives. It found that utilities can effectively manage rebates to help reduce upfront costs, performancebased incentives tied into individual utility bills, and competitive procurement mechanisms for investing in solar. By tying incentives directly to the existing business practices of the utilities, tracking can be simplified and incentives can be constantly tailored to the timely demands of the market. In addition, because of the pre-existing relationship between the consumer and the utility, as well as the expectation that the utility will continue to operate for the foreseeable future, incentive programs led by a utility can help to ensure consumer protection, equitable access to incentives, and transparent, up-to-date communications.

\subsubsection{Administration of Utility Programs}

To successfully implement any incentive program, administrators must balance opposing requirements to keep the process simple enough to encourage investment while retaining enough review and verification to ensure that systems are installed and operate as intended.

"Administrators need to consider how to provide equitable access to incentives; manage the queue of projects; and minimize overall administrative costs of the program" (Bird, Reger and Heeter 2012).

In particular, program administrators must work to enable equal and reasonable access to available incentives. This will help both the perceived and actual program success by ensuring that those qualified for the incentives are able to take advantage of it. In addition, it is recommended that programs choose to charge a nominal yet consequential application fee. This will help to limit applicants to only those legitimately interested and qualified for the program 
and help to prevent the program administrators from being overwhelmed with applications. Incentive schedules should also be designed to support a stable and forecastable renewable energy market and rebate program. To help verify that incentive funds are spent appropriately, program administrators should require inspections to ensure proper system design and implementation. For production-based incentives, a longer-term administration function will be necessary to ensure that proper payments are made for production over time.

When considering utility programs, it is important to separate out incentives from other existing programs and program management because the incentives are usually directly funded from government policy and simply administered by utilities. This will help to establish accurate measurement of adoption and a clear understanding of the full costs associated with each incentive.

In the United States, some software solutions have been developed to help reduce the administrative burden of many years of reporting requirements. Overall, it is important for utilities and program administrators to plan incentives not just for the impact on the market, but also for the administration plan for the entire duration of the incentive.

\subsection{Impacts of Uncertainty}

Risk and uncertainty play a significant role in determining the required expected return on investment. In the United States, a pattern of repeated expiration and short-term renewal of the PTC described above led to a boom-and-bust cycle of investment in wind power (Barradale 2010). This cycle hurts the industry due to additional ramp-up and ramp-down costs and the overall impact on uncertainty. Within this scenario, it has often been assumed that the severe downturn in investment during "off" years indicated the necessity of the PTC. However, a paper written by Merril Jones Barradale of the Copenhagen Business School found that it was actually the "dynamic of power purchase agreement negotiations in the face of PTC renewable uncertainty that drives investment volatility" (2010). Long-term certainty of government support of particular technologies, policies, and incentives can lower the uncertainty and risk associated with renewable projects, thus driving down financing costs and increasing investment..

\section{City/State Examples}

The following U.S. city and state examples are meant to provide insight into policy decisions and the impacts on renewable energy development taken across a variety of climates, geographic locations, political environments, and economic conditions. The examples illustrate best practices in cities and states with high penetrations of renewable energy sources. These summaries attempt to analyze the concepts, definitions, evaluation criteria, objectives, policies, and measures adopted in each locale. Each section is structured to outline the overall goals and philosophy of the local government, summarize the renewable energy development measures adopted, and summarize the overall impacts on the city.

Each example identifies a variety of policies implemented, including the compliance and monitoring methods used by the relevant government agency for each set of policies. Although the United States does not currently have any examples of a large-scale city that sources $100 \%$ of its power from renewable energy, several examples exist of cities working toward that goal. 


\subsection{New Jersey}

\subsubsection{Overview}

New Jersey is a geographically diverse state with coastal areas to the east, the Appalachian Mountains to the north. New Jersey primarily generates its electricity from nuclear power and natural gas, with power consumption mainly concentrated in the transportation, residential, and commercial sectors (EIA 2013b). New Jersey has implemented energy policies that focus on natural gas as a less carbon-intensive fossil fuel, with intentions of expanding deployment of various renewable resources.

New Jersey lacks abundant natural resources such as crude oil, natural gas, solar radiation, and high wind regimes. However, its high connectivity to transmission access and distribution hubs provides sufficient access to energy. Despite having only moderate solar resources, New Jersey has become a national leader in solar power development with the third-largest installed solar capacity in the country as of the end of 2013 (SEIA 2014). This was achieved through an aggressive RPS, net metering programs, the country's first solar renewable energy credit (SREC) market, and other favorable policies. Biomass, including municipal solid waste and landfill gas, provides the majority of the state's renewable electricity generation (EIA 2013b). After Hurricane Sandy in 2012, New Jersey launched a series of financial incentives to develop distributed generation (DG) and renewable energy as measures to increase the state's energy resiliency (Hotchkiss, et al. 2013).

\subsubsection{Background}

\subsubsection{Economic and Demographic Context}

The state of New Jersey is located in the Northeastern and Middle Atlantic regions of the United States. According to the 2013 census, New Jersey has a population of 8,899,339. With a land area of just 8729 miles $^{2}\left(22,608 \mathrm{~km}^{2}\right)$, New Jersey ranks the most densely populated state in the country, with 1210 persons per square mile (The U.S. Census Bureau 2013).

New Jersey had the eighth-largest gross domestic product (GDP) in the United States, with $\$ 543.1$ billion (in current dollars) in 2013 . The top five industries, all within the service sector, contributed to $66 \%$ of the total GDP (BEA 2013).

New Jersey is the third-wealthiest state nationally by both median household income and per capita personal income (PCPI) (The U.S. Census Bureau 2013). However, New Jersey has some of the highest tax burdens in the country.

Table 1 summarizes New Jersey's population and economic indicators. 
Table 1. New Jersey Demographic and Economic Indicators

\begin{tabular}{llll}
\hline & New Jersey & USA & National Ranking (2013) \\
\hline Total Population & $8,899,339$ & $316,128,839$ & 11 \\
\hline Area (miles ${ }^{2}$ ) & 8,722 & $3,805,943$ & 47 \\
\hline Area (km $^{2}$ ) & 22,591 & $9,857,306$ & 47 \\
\hline Population per mile & (1,210 & 991 & 1 \\
\hline Population per km ${ }^{2}$ & 467 & 34.2 & 1 \\
\hline Median Household Income (\$) & 71,637 & 53,046 & 3 \\
\hline Per Capita Personal Income (\$) & 55,386 & 44,765 & 3 \\
\hline Current-dollar GDP (\$ billion) & 543.1 & $16,768.1$ & 8 \\
\hline GDP Per Capita (\$) & 57,203 & 53,001 & 7 \\
\hline $\begin{array}{l}\text { Carbon Intensity of the Economy } \\
\text { (million metric tons per million\$ }\end{array}$ & 258.1 & 410.7 & 40 \\
GDP)(2011) & & & \\
\hline
\end{tabular}

Sources: The U.S. Census Bureau 2013 data http://quickfacts.census.gov/qfd/states/34000.html;

The U.S. Bureau of Economic Analysis (BEA) 2013 data http://bea.gov/regional/bearfacts/action.cfm

\subsubsection{Energy and Resource}

\subsection{Oil and Gas}

Located between major metropolitan areas of New York City and Philadelphia, New Jersey has access to key trading ports and sufficient energy supply. Shipping hubs and connected pipeline, rail, and air facilities have enabled New Jersey to become a major distribution center for petroleum products. Despite having no crude oil production, New Jersey has three refineries and hosts the terminus of the largest U.S. petroleum pipeline. New Jersey is also a major petroleum consumer, with the transportation sector leading in energy consumption. Although the state hosts energy-intensive petroleum and chemical manufacturing industries, the service-focused economy makes New Jersey one of the most-efficient states in energy intensity (EIA 2013b).

New Jersey has no natural gas production and relatively low natural gas potential, but imports natural gas for heating and electricity. According to the EIA, the state consumed an estimated 670.8 trillion Btu of natural gas in 2012, which supported the heating needs of about threefourths of the state's households and $43 \%$ of the state's electricity generation.

\subsection{Renewable Resources}

New Jersey receives, on average, $4.5-5 \mathrm{kWh} / \mathrm{m}^{2} /$ day of total solar radiation, relatively low compared to sunny states such as California, Arizona, and Florida. NREL estimates that New Jersey has the potential to generate $15,768 \mathrm{GWh} /$ year from $14 \mathrm{GW}$ of rooftop solar PV and about 484,000 GWh/year from $276 \mathrm{GW}$ of utility-scale solar plants (Lopez, et al. 2012).

The state lacks abundant wind resources suitable for power generation. With average wind speed at $80 \mathrm{~m}$ falling mostly below $6 \mathrm{~m} / \mathrm{s}$, New Jersey has an estimated installed capacity potential of $131 \mathrm{MW}$ (Lopez, et al. 2012). The Atlantic coast presents much more favorable conditions, with the potential to install an estimated $102 \mathrm{GW}$ of offshore wind. 
Having some of the highest waste per capita generation in the country, New Jersey has abundant biomass potential. The state defines biomass as both "agriculturally derived fuel" and waste material used to produce energy (State of New Jersey 2011). A study commissioned by the state through Rutgers University estimates that about 4.32 million dry tons (MDT) annually, or 58\%, of New Jersey's biomass resources could be available to provide $692 \mathrm{MW}$ of generation capacity by 2025 (New Jersey Agricultural Experiment Station 2014).

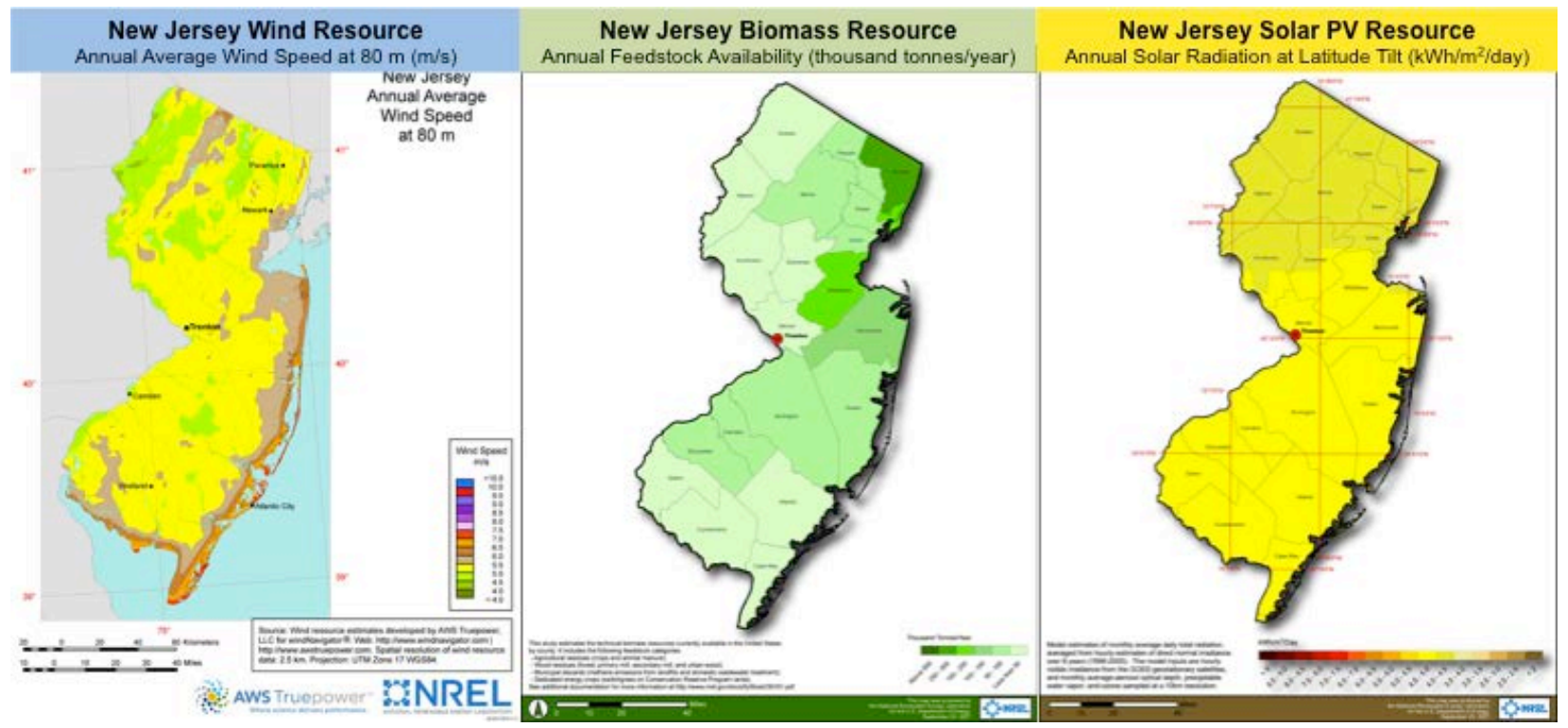

Figure 9. New Jersey renewable energy resource maps

Table 2. New Jersey Renewable Resource Potential

\begin{tabular}{llll}
\hline & $\begin{array}{l}\text { Potential installed } \\
\text { capacity (GW) }\end{array}$ & $\begin{array}{l}\text { Annual generation } \\
\text { (GWh) }\end{array}$ & Available land/resource \\
\hline Urban Utility-Scale PV & 25 & 44,307 & $527 \mathrm{~km}^{2}$ \\
\hline Rural Utility-Scale PV & 251 & 439,774 & $5,232 \mathrm{~km}^{2}$ \\
\hline Rooftop PV & 14 & 15,763 & - \\
\hline Onshore Wind & 0.13 & 317 & $26 \mathrm{~km}^{2}$ \\
\hline Offshore Wind & 102 & 429,808 & $20,387 \mathrm{~km}^{2}$ \\
\hline Biomass & 692 & 5,628 & $\begin{array}{l}4.32 \mathrm{million}^{2} \text { dry tons/year } \\
\text { (MDT) }\end{array}$
\end{tabular}

Source: based on Lopez et al. 2012 and the New Jersey Agricultural Experiment Station 2014

\subsubsection{Electricity Generation and Electric Industry}

New Jersey sources its electricity predominantly from four in-state nuclear power plants, which supply more than $50 \%$ of the state's total generation. Coal and renewables account for about $5 \%$ of total electricity generation. The large proportion of nuclear and natural gas in the net electricity generation mix places New Jersey's electric power industry among the lower third of states in terms of carbon intensity (271 ton $\mathrm{CO}_{2} / \mathrm{MWh}$ in 2013) (EIA 2013b).

\footnotetext{
${ }^{10}$ Includes biogas and landfill gas quantities converted to dry tons, based on New Jersey Agricultural Experiment Station 2014.
} 


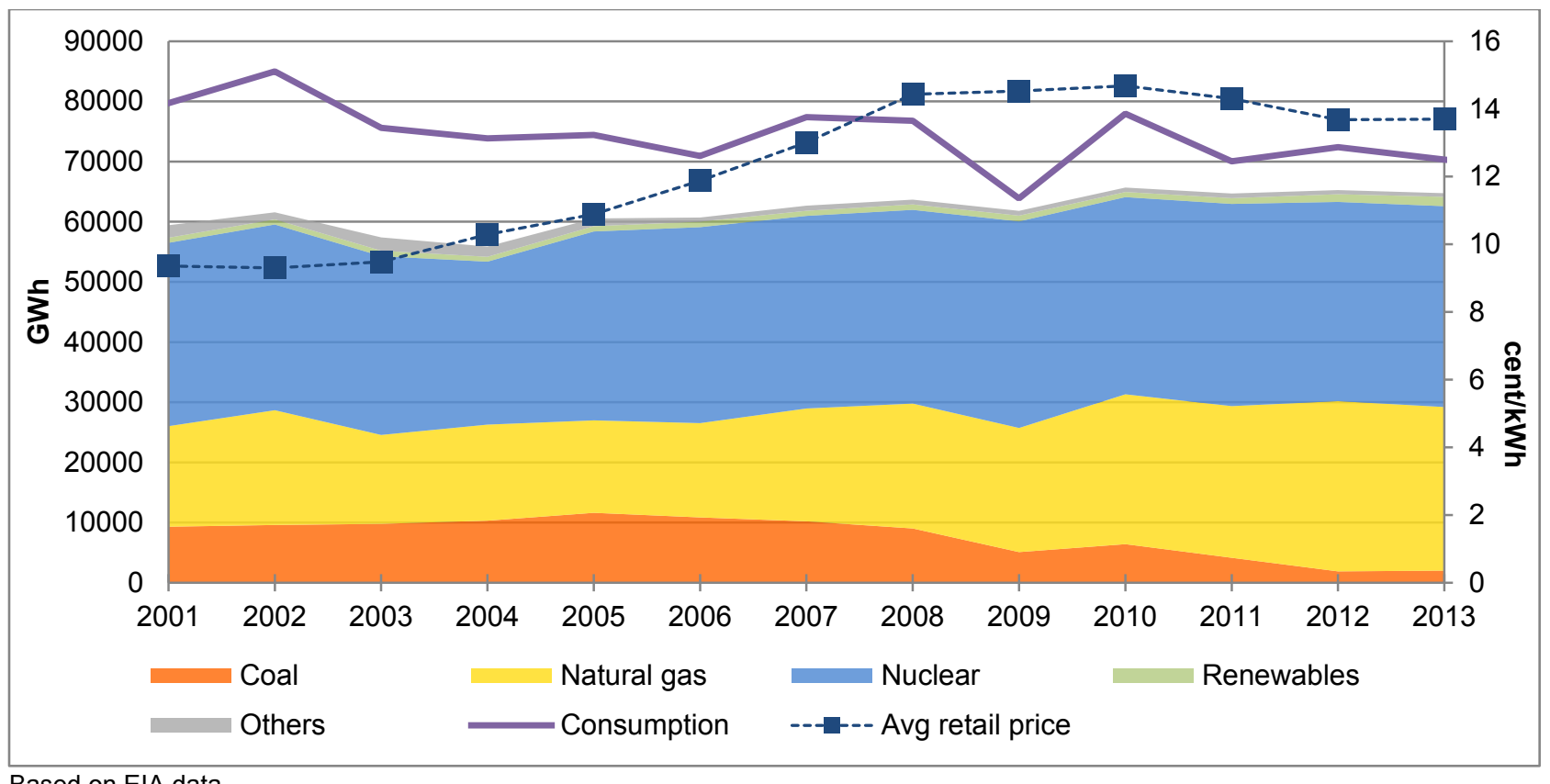

Figure 10. Electricity generation in New Jersey

Others include petroleum liquids, petroleum coke, gases (excluding natural gas), conventional hydroelectric, and hydroelectric pumped storage (as capacity credit). Retail Electricity Price averages residential, commercial, and industrial sectors.

\subsection{Price}

New Jersey has sustained some of the highest retail electricity rates in the continental United States, reaching 14.68 cents/kWh in 2010. The state's electricity prices exhibit a high correlation to natural gas prices, since natural gas plants typically set the locational marginal pricing. An increase in natural gas supply had driven down electricity price in 2010, and sustained a 3-year average price of 13.89 cents/kWh between 2011 and 2013. ${ }^{11}$ Nevertheless, residential and commercial electricity prices are more than $20 \%$ above the U.S. average, while the industrial price reached 50\% above the national average price in 2014 (EIA 2013b).

\subsection{Import/Export}

In addition to being a net importer of crude oil and natural gas, New Jersey also imports about one-third of its electricity. The majority of New Jersey's electricity is supplied through PJM, the largest regional electricity market in the country. New Jersey is highly connected through transmission systems with neighboring PJM states, which provides flexibility in pursuing costeffective supply options. The state also has a number of high-voltage transmission links with New York, to which it exports electricity (State of New Jersey 2011).

\footnotetext{
${ }^{11}$ EIA average retail price of electricity, annual data for New Jersey
} 
Table 3. New Jersey Power Market Summary

\begin{tabular}{lll}
\hline & New Jersey & US (Share) \\
\hline $\begin{array}{l}\text { Net Electricity Generation } \\
\text { (thousand MWh) }\end{array}$ & 64,848 & $4,058,209(1.6 \%)$ \\
\hline $\begin{array}{l}\text { Electricity Consumption } \\
\text { (thousand MWh) }\end{array}$ & 74,404 & $3,691,789(2.0 \%)$ \\
\hline $\begin{array}{l}\text { Net Generation from } \\
\text { Renewables (thousand } \\
\text { MWh) }\end{array}$ & 1,549 & $253,328(6.1 \%)$ \\
\hline $\begin{array}{l}\text { CO }{ }_{2} \text { Emission from Electric } \\
\text { Power Industry (metric tons) }\end{array}$ & $64,481,324$ & $8,627,499,108(0.7 \%)$ \\
\hline $\begin{array}{l}\text { Electricity Price (Q3 2014) } \\
\text { (cents/kWh) }\end{array}$ & 14.35 & $10.91(131 \%)$ \\
\hline $\begin{array}{l}\text { Three-year Average Retail } \\
\begin{array}{l}\text { Electricity Price (2011-2013) } \\
\text { (cents/kWh) }\end{array}\end{array}$ & 13.89 & $9.94(139 \%)$ \\
\hline
\end{tabular}

Note: Electricity price in this table is the average value of residential, commercial, and industrial.

Source: EIA

\subsubsection{Stakeholders}

The New Jersey Board of Public Utilities (BPU) is a state agency with the authority to oversee the regulated utilities (including electricity, water, gas, telecommunications, and cable television) in the interest of the public. It addresses consumer protection, energy reform, deregulation, and structure of utility rates. The entity is currently situated within the NJ Department of the Treasury. The BPU oversees the development of renewable energy, administers the Clean Energy Program, and approves ratepayer supported utility programs.

New Jersey has four electric distribution utilities that provide distribution services to more than 3 million electric customers in New Jersey. These providers include Public Service Electric \& Gas (PSE\&G), Jersey Central Power \& Light (JCP\&L), Atlantic City Electric (AE), and Orange \& Rockland Electric (O\&R). These are investor-owned utility companies that compete with retail suppliers to supply electricity to end users. As regulated utilities, they are required to purchase long-term energy contracts to insulate customers from price fluctuations.

Other prominent stakeholders in New Jersey include the New Jersey Governor's Office, which sets long-term energy objectives and implementation plans by commissioning the Energy Master Plan. The document is drafted by an inter-agency task force consisting of many departments, such as agriculture, community affairs, environmental protection, and transportation.

Rutgers, the State University of New Jersey, partners with the state government agencies and industry in clean-energy research. It serves as a research center, outreach platform, and business incubator through basic and applied research in clean energy, as well as energy policy. 


\subsubsection{Policies and Development}

New Jersey established several policies that have encouraged an investment in renewable energy larger than peer states with comparable electricity prices and solar resources. Most notably, electricity generation from solar energy increased from $3 \mathrm{GWh} /$ year in 2008 to $546 \mathrm{GWh} /$ year in 2013.

In 1999, New Jersey became the $14^{\text {th }}$ state in the United States to deregulate its electric market by enacting the Electric Discount and Energy Competition Act (EDECA). With the goal of lowering energy cost and improving service to consumers, EDECA mandated vertically integrated utilities to separate supply and distribution charges and provide consumers with retail supplier choice.

This deregulation provided the initial framework that would allow for renewable energy deployment in the state. EDECA also aimed to encourage the development of renewable sources of electricity. It set renewable energy goals in the state, requiring a percentage of net electricity sales from investor-owned utilities and retail electric suppliers to come from qualified renewable energy resources, including specific solar and offshore wind requirements. EDECA compelled the BPU to adopt the standards and granted the BPU broad authority and discretion to oversee, adjust, and implement the RPS as the electric sector transitions from a regulated to a competitive market.

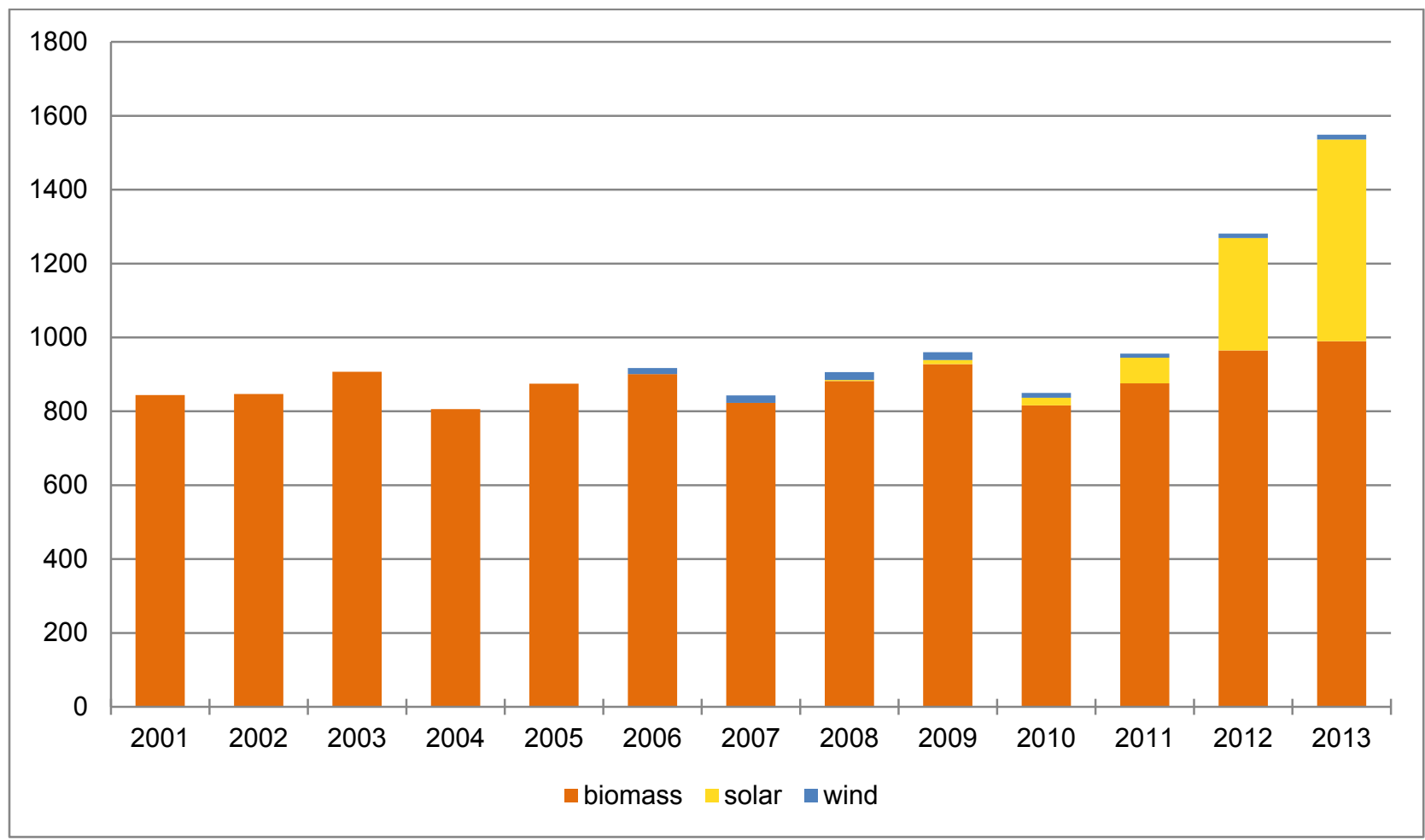

Based on EIA data

Figure 11. New Jersey renewable electricity generation by source 2001-2013 (GWh) 


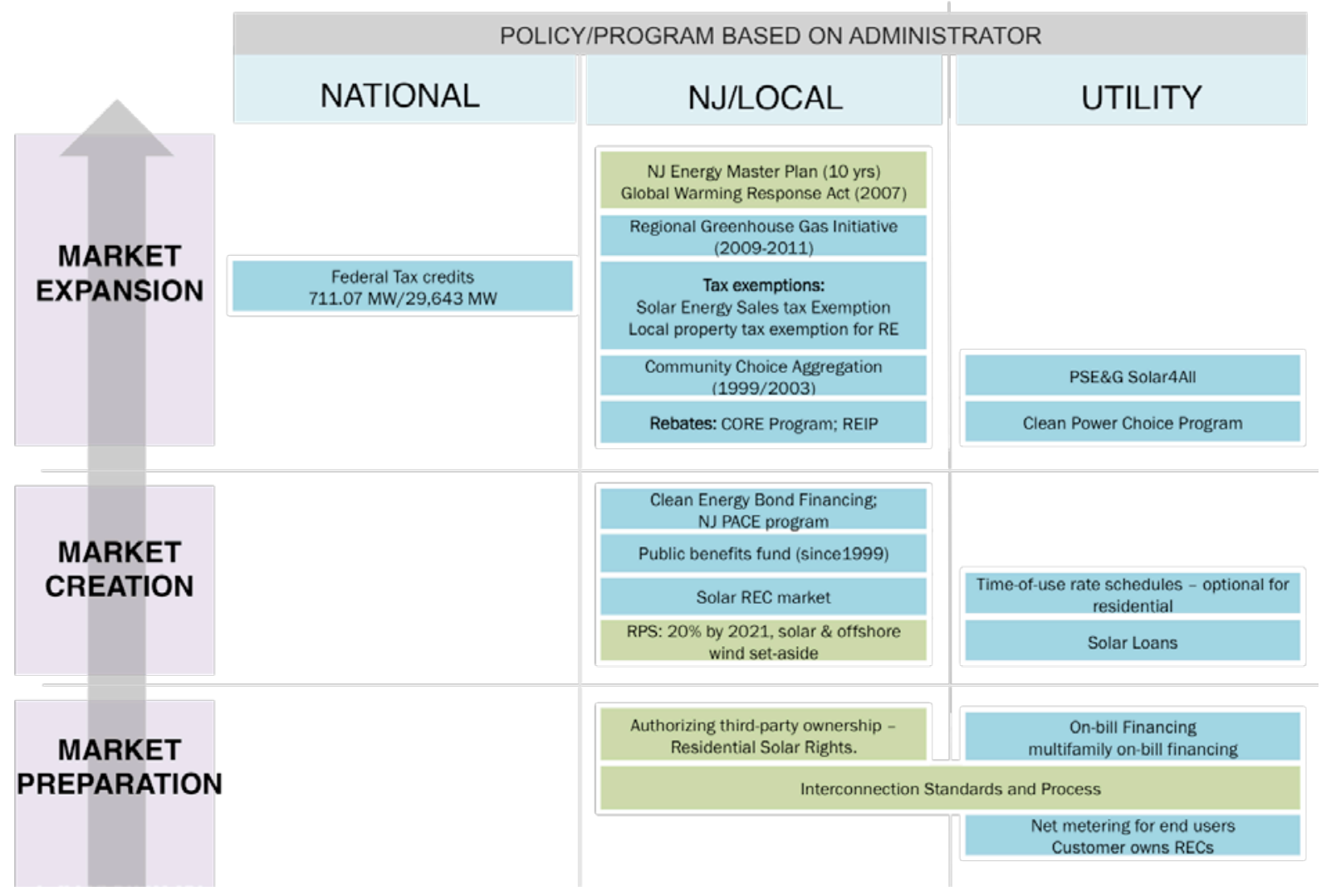

Figure 12. Summary of policies under the stacking framework for New Jersey

\subsubsection{Market Preparation}

\subsubsection{Net Metering and Interconnection}

The EDECA framework prepared the market for distributed generation growth. Along with the RPS, EDECA established net metering and interconnection standards in New Jersey. It required the state's investor-owned utilities and energy suppliers to offer net metering for all retail customers with electric generation systems using Class I renewable resources (solar, wind geothermal, wave tidal, landfill gas, or sustainable biomass). It enables customers to obtain full retail credits on their utility bill for each $\mathrm{kWh}$ that the system produces, up to $100 \%$ of their electricity usage over the course of a year (BPU 2014a). In addition, the generators can retain ownership of all RECs associated with electricity generated from renewable systems. This effectively created two revenue streams for customer generators under two separate meters: the RECs generated and the commodity provided through the interconnection.

In 2010, the Solar Advancement Act eliminated the individual system size cap of $2 \mathrm{MW}$, allowing larger-scale systems for commercial, industrial, or community aggregate programs to participate in net metering. The net metering policy does not contain an aggregate capacity limit for the state. Instead, it has stipulated a trigger mechanism at $2.5 \%$ of peak demand, which prompts a regulatory discussion without requiring the utilities to suspend net metering. Although New Jersey became the only state to surpass its statewide trigger, the BPU has not instructed utilities to cease net metering programs (Heeter, Gelman and Bird 2014). 
Having an established net metering policy prior to the RPS taking effect was instrumental in incentivizing early adoption of distributed solar systems. However, the initial net metering measures included provisions to ensure safety and facilitate administration that unintentionally resulted in high installation costs and long lead times. A notable example is the requirement of an external disconnect switch on a PV system to ensure that electricity does not feed back into the grid during a power outage. Although this serves as an extra precaution for utility workers' safety, it significantly increased solar installation costs. Recognizing these barriers, the BPU initiated a cost-benefit study in 2003 to evaluate the necessity of the requirements. After the study uncovered that switches were infrequently used and did not necessarily ensure safety, the BPU revised net metering and interconnection rules in 2004, mandating that utilities eliminate many unnecessary provisions and capping the length of the interconnection process at one month (NREL 2005). The improved process provided a foundation for market creation and expansion policies to stimulate the market.

\subsubsection{Third-Party Ownership}

The net metering requirements established under EDECA did not provide regulatory language that determines whether third-party owners are allowed to net meter. However, the changes to net metering and interconnection rules defined a "customer generator facility" as the equipment used, but not necessarily owned, by a customer generator. This clarification allowed third-partyowned systems to participate in net metering, improving the financial returns for systems and helping to grow the solar market. Third-party-owned systems have made up more than $90 \%$ of New Jersey's residential solar market since Q2 2013 (SEIA 2014). At the end of January 2015, $75 \%$ of all behind-the-meter installed projects were third-party-owned and more than $80 \%$ of residential behind-the-meter installations were third-party-owned.

\subsubsection{Residential Solar Rights}

Homeowner associations can set a variety of restrictions on their member homeowners. In 2007, New Jersey enacted legislation to prevent homeowner associations from prohibiting the installation of solar PV and thermal technologies on rooftops on property not considered community or public. More specifically, it prohibits associations from imposing any regulations that would incur costs greater than $10 \%$ of the installation and maintenance cost of the solar equipment or impact its operating efficiency (DSIRE 2014).

\subsubsection{Market Creation}

\subsubsection{RPS}

In 1999, EDECA set an initial renewables target of 4\% "Class I" and 2.5\% "Class I or Class II" resources by 2012. The RPS clearly defines and classifies qualifying renewable technologies into two classes, with specific requirements aimed to accelerate the growth of "newer" technologies while maintaining existing renewable generation capacity. ${ }^{12}$

The BPU has made subsequent adjustments to the RPS and relevant measurements based on market conditions and state goals. After amendments in 2004, 2006, 2010, and 2012, the RPS currently requires at least $23.85 \%$ of the total electricity generation to come from renewables by

\footnotetext{
${ }^{12}$ Class I renewables included electricity derived from solar, wind, wave or tidal, geothermal, landfill gas, anaerobic digestion, renewable fuel cells, certain sustainable biomass (with approval of the state Department of Environmental Protection), as well as certified in-state hydroelectric facilities of $3 \mathrm{MW}$ and less. Class II renewable energy included hydroelectric facilities $3 \mathrm{MW}-30 \mathrm{MW}$ in generation capacity and waste-to-energy facilities.
} 
2021. Although the ramping requirements for Class I resources is scheduled to increase from $0.74 \%$ in 2004 to $17.88 \%$ in $2028,{ }^{13}$ Class II requirements remains at a constant $2.5 \%$ under the same period. ${ }^{14}$ The technology-specific provisions required electric suppliers and providers to procure at least 5,316 GWh of sales from qualifying solar electric generation facilities by 2026 and $1,100 \mathrm{MW}$ of generation capacity from offshore wind projects. ${ }^{15}$

New Jersey's RPS remains one of the most advanced among states in both goal and structure, and it was the first to establish a SREC market under the solar carve-out.

\subsubsection{Solar Transition: Rebate Phase-Out}

To incentivize market-based development of renewables, EDECA stipulated the creation of a renewable energy trading program featuring RECs. The electrical power generated by each technology is measured or categorized into credits to satisfy specific RPS requirements. ${ }^{16}$

Nevertheless, early market deployment depended on a combination of federal tax credits, income from SRECs, and rebates provided by the BPU's Clean Energy Program to offset the cost of installation. The Clean Energy Program, created in 2001, provided solar rebates which drove rapid growth. The Customer On-site Renewable Energy (CORE) rebate program offered a solar rebate that was as high as $\$ 5.00$ /watt. The rebate scheme that succeeded CORE, known as the Renewable Energy Incentive Program, reduced the upfront incentive to a maximum of $\$ 1.75 /$ watt for residential systems less than $10 \mathrm{~kW}$ and $\$ 1.00 /$ watt for commercial systems up to $50 \mathrm{~kW}$ (BPU 2014b).

\footnotetext{
${ }^{13}$ Based on current requirements in 2014. 1999 interim goals set the ramp schedule for Class I requirements from $0.5 \%$ in 2001 to $4 \%$ in 2012.

${ }^{14}$ More information about PJM EIS is available at http://www.pjm-eis.com/

${ }^{15} \mathrm{~A}$ timeline has not been established for the offshore wind specific requirement in the EDECA in 1999.

${ }^{16}$ Any excess credit beyond solar set-aside requirements can be used for Class I or Class II requirements.
} 


\section{New Jersey's Rebates and Solar Transition}

Between 2001 and 2007, the state spent more than $\$ 170$ million in rebates to support $40 \mathrm{MW}$ of installed solar capacity. The state estimated that sustaining the same level of rebate to support the solar RPS requirement by 2021 would require $\$ 9.6$ billion, resulting in a $6.5 \%$ increase in electricity prices. (BPU 2007.)

As a result, the BPU initiated the Solar Transition in 2006 to change New Jersey's solar rebate-based program to a market-based incentive structure reliant on SRECs. The multi-year process ended with the closing of the last rebate program in 2010 , although remaining payments continued until 2013. In 2009, the BPU significantly increased the alternative compliance payment for solar from $\$ 300$ to over $\$ 700$ per MWh. This boosted demand for SRECs in New Jersey and aided the transition from a rebate system to a market-based system. By the end of 2014, New Jersey had added $1.3 \mathrm{GW}$ of solar capacity relying on SREC without state rebates.

New Jersey Solar Rebate Programs:

\begin{tabular}{|l|l|}
$\begin{array}{l}\text { Customer On-site Renewable Energy (CORE) } \\
(2001-2008)\end{array}$ & $\begin{array}{l}\text { Renewable Energy Incentive Program (REIP) } \\
(2009-2010)\end{array}$ \\
\hline $\begin{array}{l}\text { Administrator: State Clean Energy Office } \\
\text { Rebate value > \$5/Watt; moderate scale-down over time. }\end{array}$ & $\begin{array}{l}\text { Administrator: State Clean Energy Office } \\
\text { Rebate value } \$ 1-\$ 1.75 / \text { Watt; rates vary according } \\
\text { to system size and market segment } \\
\text { Total rebates: } \$ 317.58 \text { million }\end{array}$ \\
$\begin{array}{l}\text { Total installation supported: } 37.54 \mathrm{MW} \\
\text { Total rebates: } \$ 45.48 \text { million }\end{array}$ \\
\hline
\end{tabular}

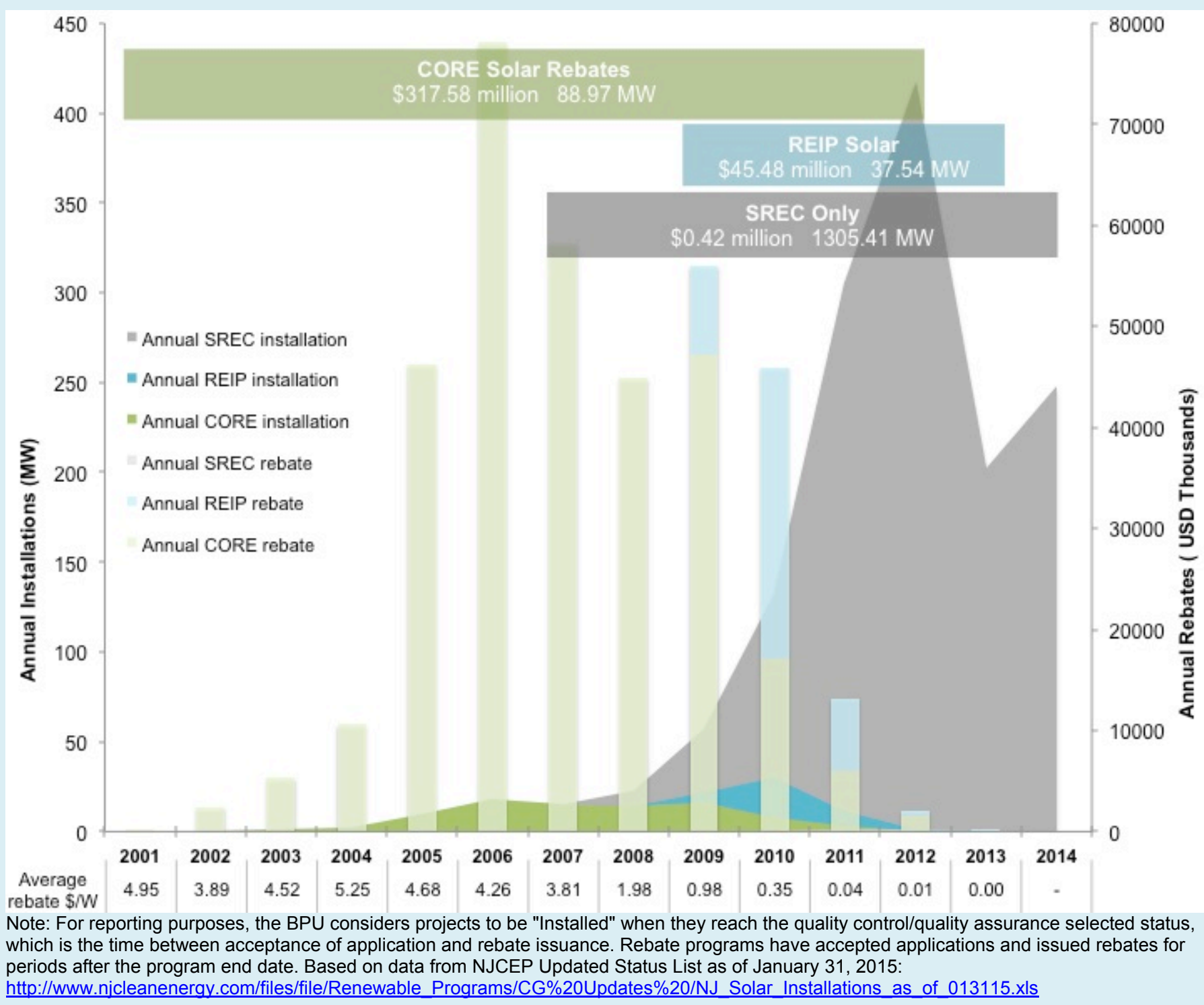

Figure 13. New Jersey's solar installations and rebates 2001-2014 


\subsubsection{Utility Financing Programs}

As part of the Solar Transition, the BPU directed New Jersey's four regulated electric distribution companies to develop solar financing programs to support installation of distributed PV systems in 2008 (BPU 2014c). By working directly with the utilities, the BPU has been able to promote solar development at a lower cost.

Two utility financing models emerged from this initiative: 1) a solar loan program and 2) utility auctions. PSE\&G modified its existing "Solar Loan I" Program, which provided customers a portion of the upfront cost of a PV system. The customers will then repay the loans with either SRECs or cash over 10-15 years. SREC prices for the purpose of repayment are equal to or greater than the prevailing market price or pre-established floor price for SRECs. The PSE\&E Solar Loan II program was approved with a cap of $51 \mathrm{MW}$ for residential and commercial customers. Since then, the BPU has extended approval for subsequent solicitations.

\section{PSE\&G Solar4All Program}

In addition to three Solar Loan programs, PSE\&G's Solar4All Program aims to develop $125 \mathrm{MW}$ of solar PV across its jurisdiction focusing on underutilized spaces such as utility poles, landfills and brownfields. Unlike the Solar Loan programs, which help customers finance solar systems, PSE\&G owns the generation capacity under the Solar4All Program.

Installations under the program include $85 \mathrm{MW}$ of centralized utility-scale solar and 40 megawatts of "neighborhood" solar systems attached to utility poles. The centralized solar portion includes $42 \mathrm{MW}$ of gridconnected projects (greater than or equal to 1MW on PGE\&G's distribution grid) on landfills and brownfields, as well as $3 \mathrm{MW}$ of pilot projects on warehouse roofs, underutilized facilities, and large parking lots.

More information on Solar4All is available through PSE\&G: https://pseg.com/family/pseandg/solar4all/index.jsp

The other three large utilities-JCP\&L, AE, and O\&R - elected to offer 10-15-year long-term SREC contracts to net metered residential and non-residential systems up to $500 \mathrm{~kW}$. The utilities can then resell the certificates to competitive retail electricity suppliers (Wiser and Barbose 2010).

When utility solar financing programs expired in 2011, the utilities filed their intentions in the following year to participate in an extended SREC program. In 2013, the BPU approved an extension of the utility finance programs. The authorization of all the utility programs support the development of up to $225 \mathrm{MW}$ of solar from 2014-2016.

Table 4. Potential MW Contribution from Utility Solar Programs

\begin{tabular}{lllll}
\hline & PSE\&G Solar Loan & PSE\&G Solar4All & Utility Auctions & Total \\
\hline 2014 & 32.5 & - & 27.5 & 60 \\
2015 & 32.5 & 20 & 27.5 & 80 \\
2016 & 32.5 & 25 & 27.5 & 85 \\
\hline
\end{tabular}

Source: Meister 2014 


\subsubsection{SREC Market}

The SREC market has served as a major driver for the solar industry boom in New Jersey after the Solar Transition. Nevertheless, despite measures to mitigate SREC price risk, the marketbased incentive system experienced some setbacks in price volatility.

To address the volatility of the market, BPU commissioned a study (Meister 2014) to make short- and long-term policy recommendations. Some of the mitigation measures recommended by the report include: expanding utility programs, green bank finance, competitive procurement, SREC price floor, and standard offer contracts with interim quantity limits and volumeresponsive pricing.

\section{REC Registration in New Jersey}

To be eligible for SRECs, NJ BPU requires owners of solar projects to register under the SREC Registration Program. This process provides transparency for market participants on the number and size of planned projects as well as insight into future SREC pricing. After the project completes registration and construction, the electric distribution companies need to authorize energization before SRECs can be generated. The project owner reports energy production to the PJM Environmental Information Services (EIS) Generation Attribute Tracking System (GATS), which issues SRECs in the form of electronic certificates that can be sold as a commodity through the same SREC Tracking System as a commodity.

Prior to switching to PJM-GATS, all solar projects participated in the NJ Behind-the-Meter REC System established by the BPU under the SREC Registration Program. To track production, the BPU requires all solar systems to install a revenue-grade meter that meets the American National Standards Institute Standard to qualify for behind-the-meter SRECs. Before 2012, systems below $10 \mathrm{kV}$ could use energy production estimates from the PVWatts Calculator (for more information on PVWatts, see section 2.4)

Originally developed to facilitate RPS compliance, these tracking systems have also increasingly been used by voluntary markets. PJM-GATS can be accessed: http://www.pjm-eis.com/getting-started/about-GATS.aspx

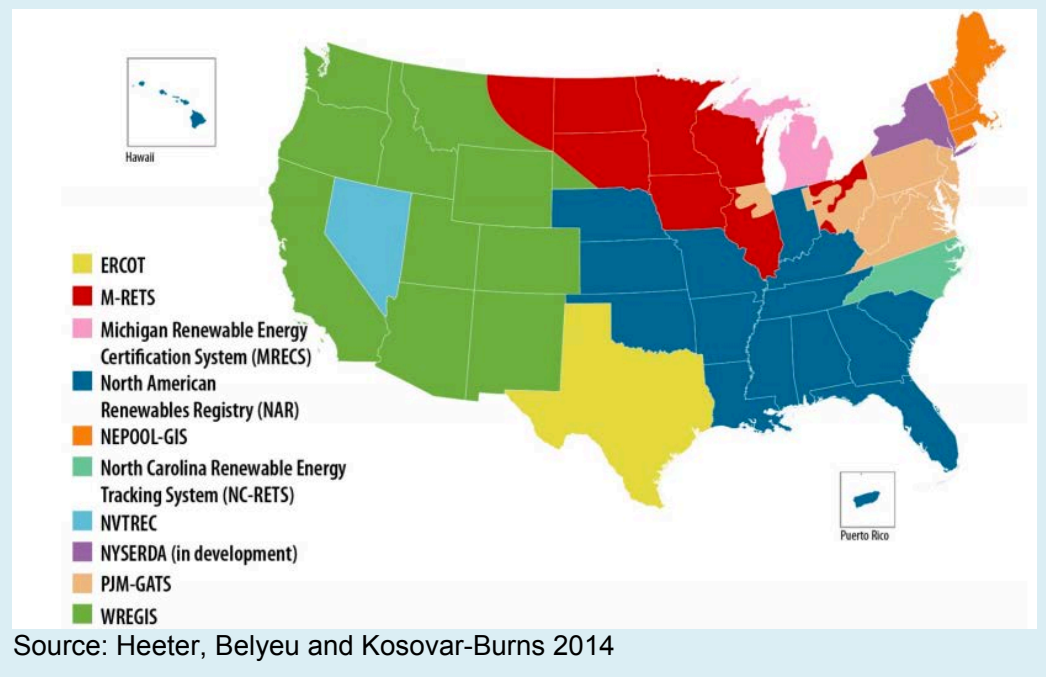

Figure 14. U.S. renewable energy tracking systems

PJM-GATS is one of ten regionally based electronic REC tracking systems in the US. The tracking system serves as a provider of public market information. PJM publishes data on RECs retired to meet RPS compliance in PJM states (Heeter, Belyeu, and Kuskova-Burns 2014). 


\section{New Jersey SREC Market Volatility}

The mandatory RPS adoption incorporated an alternative compliance payment (ACP) at \$50/MWh and a significantly higher 15-year solar alternative compliance payment schedule (SACP) set by the BPU. The SACP was originally set at $\$ 300 / \mathrm{MWh}$. In 2007, the BPU passed an amendment establishing an eight-year schedule, starting at \$711/MWh in energy year 2009.

Acting as a maximum price for SRECs in the market, the high SACP price contributed to a surge in solar investments, some of which would not have been economically sensible without the high penalty price. By 2012, the market became oversaturated with SRECs following market investment in solar systems spurred by the high cost of electricity, various state and federal incentives, decrease in global solar module price, and the high non-compliance cost. The value of SRECs dropped dramatically at the end of 2011 to 2012 , from $\$ 670$ to $\$ 225$. This led to a deep decline in market activity (Meister 2014).

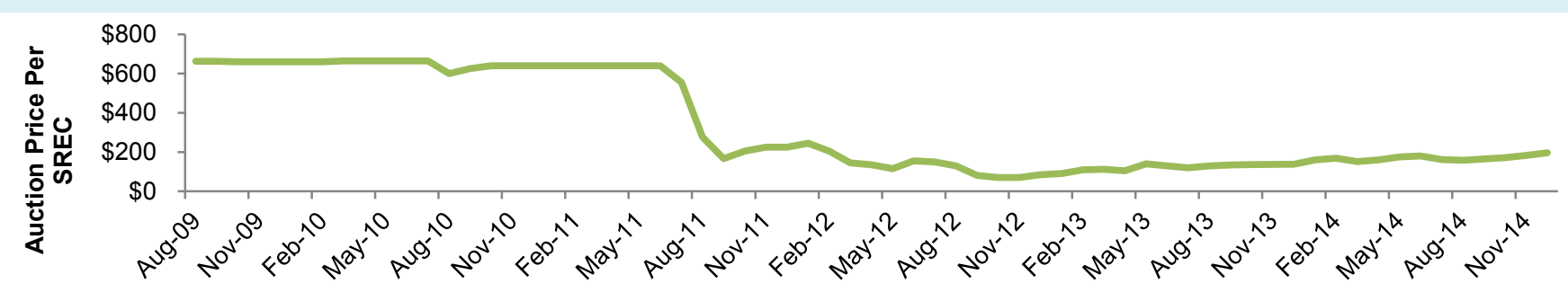

Source: SRECTrade

Figure 15. New Jersey SREC auction prices

To resurrect the solar market and address the volatility of the SREC market, the New Jersey legislature established Assembly Bill A2966 in 2012, also known as the Solar Act of 2012, which attempted to re-align program requirements to allow the market to absorb high demand in earlier years while reducing the solar RPS in future years. The legislation accelerated the RPS by four years and shifted from a MWh-based requirement to a percentage of total energy use requirement. In addition, the legislation modified the SACP price to better reflect the dramatic declines in the cost of installing solar energy. The SACP was dropped from \$641 for the 2013 compliance period to $\$ 339$ for the 2014 compliance period. In 2013 and 2014, the SREC market began to recover, but still experienced fluctuating capacity additions on a quarterly basis.
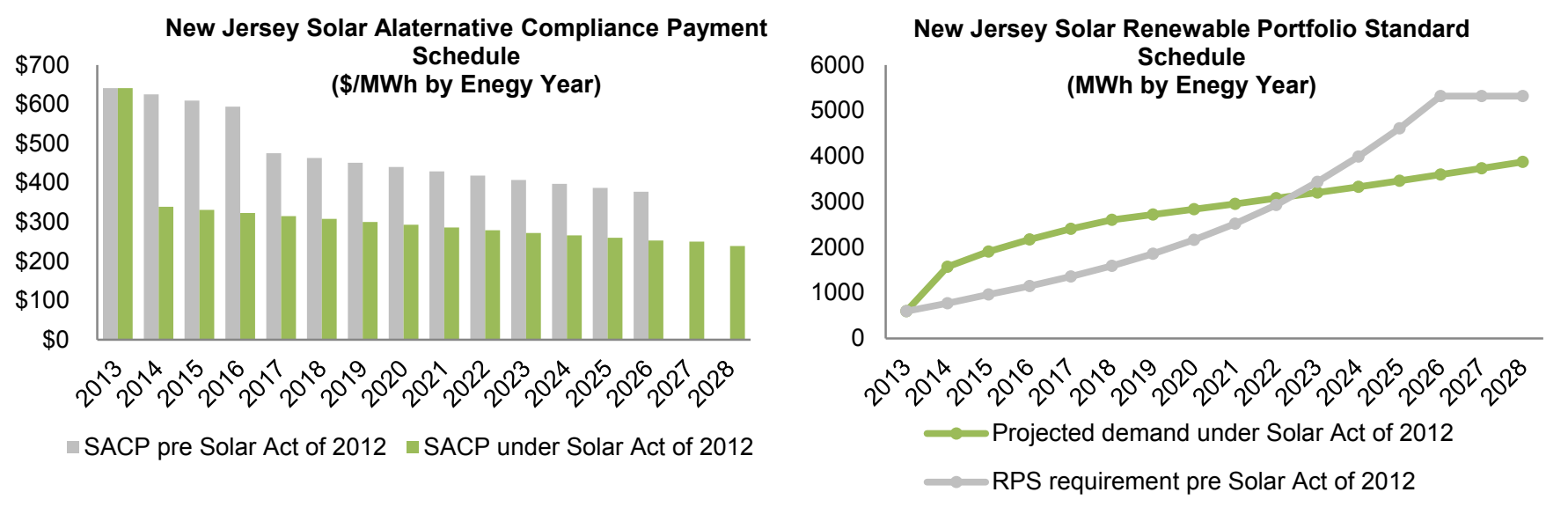

Data source: http://www.srectrade.com/srec_markets/new_jersey, accessed Feb. 20, 2015

Note: Projected demand of SRECs comes from SRECTrade using RPS solar requirement multiplied by projected electricity sales based on EIA electricity data (assuming an average $1.5 \%$ annual growth rate).

Figure 16. New Jersey solar requirements under Solar Act of 2012 vs. previous legislation 


\subsubsection{Bond-PPA Hybrid Financing Model}

Ownership of distributed solar projects has generally fallen into two categories: self-ownership or third-party ownership through a lease or PPA. Morris County, NJ, created a bond-PPA model to innovatively finance solar projects on government sites. It has been used to finance solar projects on schools, colleges, and administrative buildings.

Under this model, a public agency issues a request for proposals for private contractors to build, own, and operate a project on public property. The public agency issues a bond at a low interest rate, and then uses the funds to pay the developer. The contractor or developer will then pay lease payments back to the government entity to retain ownership of the system. This step enables the developer to reap the benefits of low financing costs. In return, it issues an attractive PPA price to the government (Kreycik 2011).

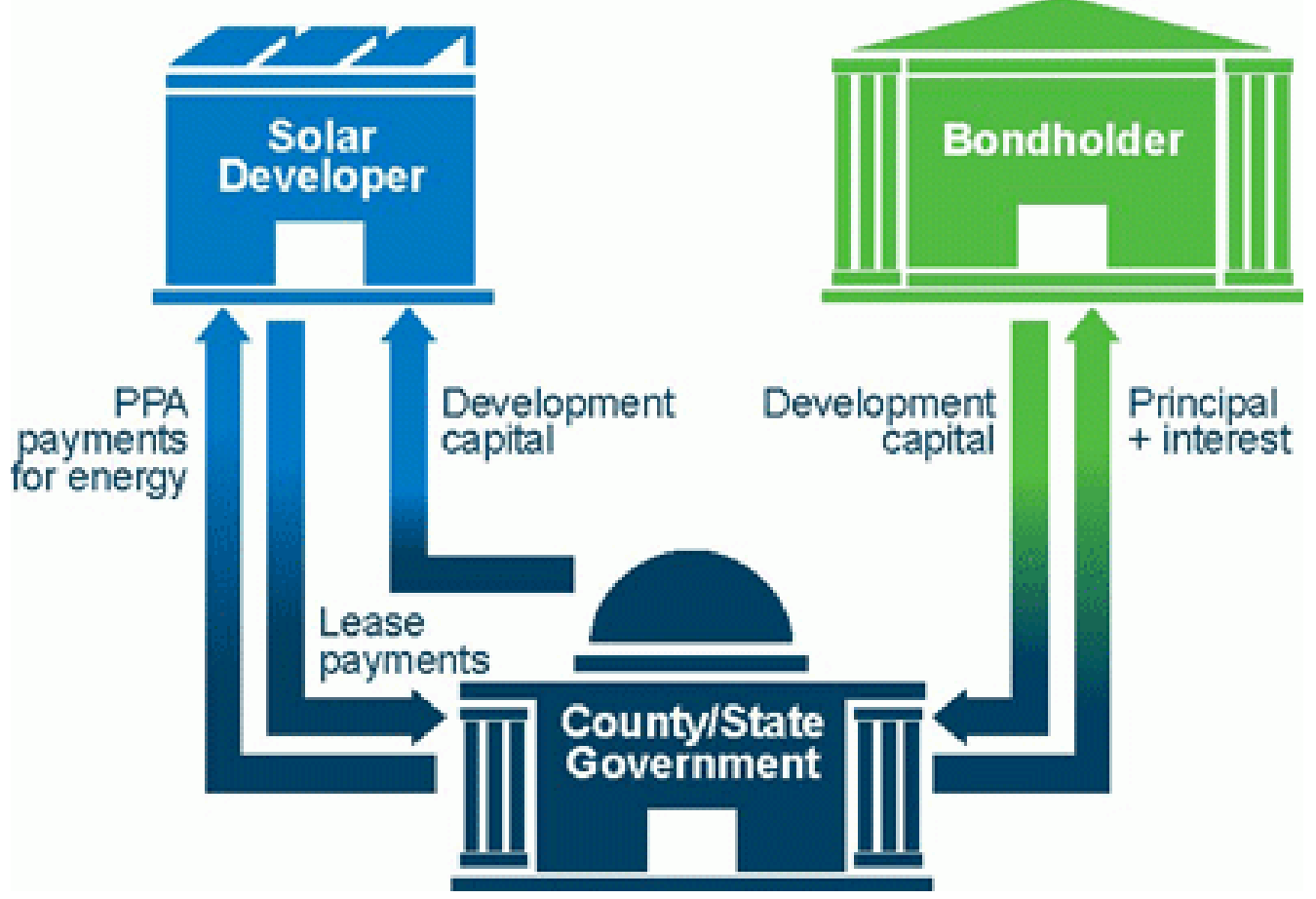

Source: Kreycik 2011

Figure 17. Transactions in the bond-PPA hybrid model on government property

\subsubsection{Market Expansion}

As the solar market became increasingly mature in New Jersey, a number of policies served to expand renewable energy adoption. Although some of these are incentives, others aim at creating voluntary markets and choices to allow more participants in renewables projects.

\subsubsection{Tax Exemptions}

New Jersey offers residential homeowners who invest in solar energy systems exemption from the state sales and use tax. The state also enacted legislation exempting from local property taxes any renewable energy systems used to meet on-site electricity, heating, cooling, or general energy needs. This lowers the upfront cost of the system and encourages additional investment throughout the state. 


\subsubsection{Community Choice Aggregation}

New Jersey is one of six states with community choice aggregation (CCA), which authorizes entities to act on behalf of customers in a community to bargain for choices in electricity supply. In 2003, New Jersey passed the Government Energy Aggregation Act, which eliminated the optin provision for residential customers if the program's rate is lower compared to that offered by the local utility or if the contract contains a higher percentage of renewable energy than is required by the state's RPS. In late 2013, Lambertville and West Amwell municipalities in New Jersey elected First Energy Solutions as their supplier. The company offers an opt-in "100\% green" contract for a premium (Heeter, Belyeu and Kuskoca-Burns 2014).

This type of option enables consumers to invest in renewable energy without physical installation of a system on their own roof. This could be beneficial for consumers who are renters, who live in multifamily dwellings and do not have access to their roof, own houses that are unsuitable for solar, or who do not want to make the long-term commitment associated with the installation of a solar energy system.

\subsubsection{Long-Term Energy and Climate Plans}

Since 1997, New Jersey has been required by law to create long-term goals and interim measures in the Energy Master Plan. It serves as a decade-long strategic planning document outlining how the government plans to meet its energy needs. The 2011 Energy Master Plan's key objectives include driving down the cost of electricity, maintaining an RPS of $22.5 \%$ by 2021 , promoting in-state clean energy generation and emerging technologies, and reducing peak demand through efficiency and conservation.

New Jersey enacted the Global Warming Response Act in 2007. This law requires stabilization of statewide greenhouse gas emissions to 1990 levels by 2020, followed by a further reduction to $80 \%$ below 2006 levels by 2050 .

\subsubsection{Cap and Trade}

From 2009 to 2011, New Jersey participated in the Regional Greenhouse Gas Initiative (RGGI), a market-based cap-and-trade regulatory program in the Northeast and Mid-Atlantic regions of the United States and the first mandatory cap-and-trade program for greenhouse gas emissions. RGGI applies to carbon dioxide emissions from electric power plants with generation capacities of $25 \mathrm{MW}$ or more. The ten participating states agreed to adopt individual shares of the overall program carbon emissions cap by implementing state-level carbon budgets. After the first control period from 2009-2011, New Jersey withdrew from RGGI, citing that the state's carbon dioxide emissions were already below its 2020 emissions targets and that the cost makes in-state generators uncompetitive (Bifera 2013). During the three-year period, the carbon dioxide auctions generated $\$ 119$ million in proceeds after program administration costs for New Jersey, $\$ 65$ million of which was used to reduce the state budget deficit and \$54 million were invested into energy efficiency and renewable measures as well as other climate-change-related efforts (Ramseur 2014).

\subsubsection{Brownfield Development}

To compensate for its high population density and limited space, New Jersey supported the development of solar PV projects on brownfields under the Solar Advancement Act of 2012. 
Solar systems located on brownfields and landfills are automatically qualified for SREC. The passage of this regulation enabled PSE\&G to pursue its $\$ 247$ million, $42 \mathrm{MW}$ investment in solar projects on landfills and brownfields. By providing additional value through the default qualification, the state encouraged investment in the areas it preferred-brownfields over greenfields.

\subsubsection{Summary}

The combination of an aggressive RPS and one of the most favorable net metering standards in the country have been a significant driver in the investment of renewable energy throughout New Jersey. However, it is important to recognize how New Jersey was required to respond to changes in the overall market. New Jersey found it had to reduce, and eventually discontinue, its rebate programs due to rapidly changing market conditions and increasing costs. In 2012, it redesigned the previously issued solar RPS, as a direct response to the dramatic fall in installation costs and surge in demand. With management and notice, however, the renewable energy market in New Jersey has not dried up. Rather, it has become more self-sustaining following initial investment and support by government policy.

The New Jersey BPU also fostered a collaborative relationship with the large utilities, which helped the load-serving entities to meet the RPS mandate while leveraging their capital resources to develop renewables at a lower cost. This strategy may be particularly fitting for authorities in China as they work with the grid companies to design financing programs for distributed renewable development.

\subsection{Hawaii}

\subsubsection{Overview}

Located in the Pacific Ocean, Hawaii consists of an archipelago with eight major islands. Due to its geographic isolation, high population density, and lack of fossil resources, Hawaii relies heavily on imports of petroleum and coal for its energy needs, resulting in the highest retail electricity prices of any state in the nation (EIA 2014). Richly endowed with renewable resources throughout the island chain, Hawaii represents a state in which renewable energy often makes economic sense without any external policies.

Nevertheless, the state has instituted a strong regulatory framework and established favorable policy to maximize the deployment of cost-effective investments in renewable energy production and promote its energy security. Under Hawaii's Energy Efficiency Portfolio Standard and Renewable Portfolio Standard, the state plans to achieve $70 \%$ clean energy by 2030 , with $30 \%$ from efficiency measures and $40 \%$ from locally generated renewable sources (Hawaii State Energy Office 2011).

\subsubsection{Background}

\subsubsection{Economic and Demographic Context}

Hawaii is one of only two states located outside of the continental United States. It consists of hundreds of islands stretching more than 1,500 miles $(2,414 \mathrm{~km})$ across the central Pacific Ocean, with the eight main islands located at the southeastern part of the Hawaiian Archipelago. Hawaii has 750 miles $(1210 \mathrm{~km})$ of coastline and the highest coastline-to-area ratio in the country (U.S. Census Bureau 2012). 
Hawaii has about 1.4 million inhabitants, with more than $70 \%$ residing on Oahu. Since it became a state in 1959, tourism has been Hawaii's largest industry, accounting for $24.3 \%$ of GDP, followed by U.S. military spending accounting for $18 \%$ of GDP.

Table 5. Hawaii Demographic and Economic Indicators

\begin{tabular}{llll}
\hline & Hawaii & USA & National Ranking (2013) \\
\hline Total Population & $1,404,054$ & $316,128,839$ & 40 \\
\hline Area (miles $^{2}$ ) & 10,931 & $3,805,943$ & 43 \\
\hline Area (km $^{2}$ ) & 28,311 & $9,857,306$ & 43 \\
\hline Population per Square Mile & 214 & 991 & 13 \\
\hline Population per Square Km & 82.6 & 34.2 & 13 \\
\hline Median Household Income (\$) & 59,244 & 53,046 & 13 \\
\hline Per Capita Personal Income (\$) & 45,204 & 44,765 & 21 \\
\hline Current-dollar GDP (\$ billion) & 75.2 & $16,768.1$ & 38 \\
\hline GDP Per Capita (\$) & 49,934 & 53,001 & 19 \\
\hline $\begin{array}{l}\text { Carbon Intensity of the Economy } \\
\text { (million metric tons per million\$ }\end{array}$ & 333.3 & 410.7 & 35 \\
\hline GDP)(2011) & & & \\
\hline
\end{tabular}

Sources: The U.S. Census Bureau 2013 data http://quickfacts.census.gov/qfd/states/15000.html

The U.S. Bureau of Economic Analysis (BEA) 2013 data http://bea.gov/regional/bearfacts/action.cfm http://globaledge.msu.edu/states/hawaii

\subsubsection{Energy and Resource}

About $10 \%$ of Hawaii's GDP is spent on energy, most of which is for imported crude oil and petroleum products. In 2013, 93\% of the energy Hawaiians consumed came from out of state. The transportation sector accounted for over $50 \%$ of energy demand in 2012, largely because of heavy commercial and military aviation fuel consumption (EIA 2014). Partially due to its moderate tropical climate, Hawaii has one of the lowest per capita energy consumptions in the nation. However, it has the highest cost of energy, with an average cost of electricity more than triple that of the national average.

\subsection{Fossil Resources}

Having no crude oil production and no proven reserves, Hawaii imports from the Pacific Rim and other oil producers. It also imports jet fuel and propane from Asia, Canada, and the Caribbean. The two refineries in Honolulu can meet most of the remaining demand for refined petroleum products. Transport accounts for around $60 \%$ of petroleum consumption, and electricity generation accounts for 30\% (EIA 2014).

Hawaii has the lowest natural gas consumption in the United States, mainly due to the lack of indigenous natural gas production and a limited network for supply and distribution. Propane is being used in remote applications not connected to the gas distribution system. Syngas from naphtha supplies parts of Oahu through Hawaii Gas. The state supports syngas production from biomass feedstock as it aims to incorporate more renewables into the energy mix. 
In 2014, Hawaii received its first shipment of liquefied natural gas (LNG) in standardized cryogenic containers. This was previously unfeasible due to the lack of suitable LNG import terminals. The regasified LNG feeds into Hawaii Gas' distribution lines to its customers.

Hawaii began to use coal in the industrial and electric power sectors in the 1980s as a hedge against petroleum volatility. Without indigenous coal reserves, Hawaii sources its coal via ocean freight to supply its $180 \mathrm{MW}$ operating coal electricity generation plant in Oahu and to support industrial usage (EIA 2014).

\subsection{Renewable Resources}

Although Hawaii has very limited fossil fuels available for extraction, it has abundant natural resources to support renewable energy. However, much of the resources are located away from the majority of the demand in Oahu. Therefore, maximizing and fully developing the potential of these resources will only be enabled through an interconnected undersea grid linking the main islands.

Annual solar radiation at latitude tilt ranges from 4.0 to $6.64 \mathrm{kWh} / \mathrm{m}^{2} /$ day across the state. Hawaii has an estimated potential of $26 \mathrm{GW}$ of solar PV capacity, of which $3 \mathrm{GW}$ is estimated for rooftop PV (Lopez, et al. 2012).

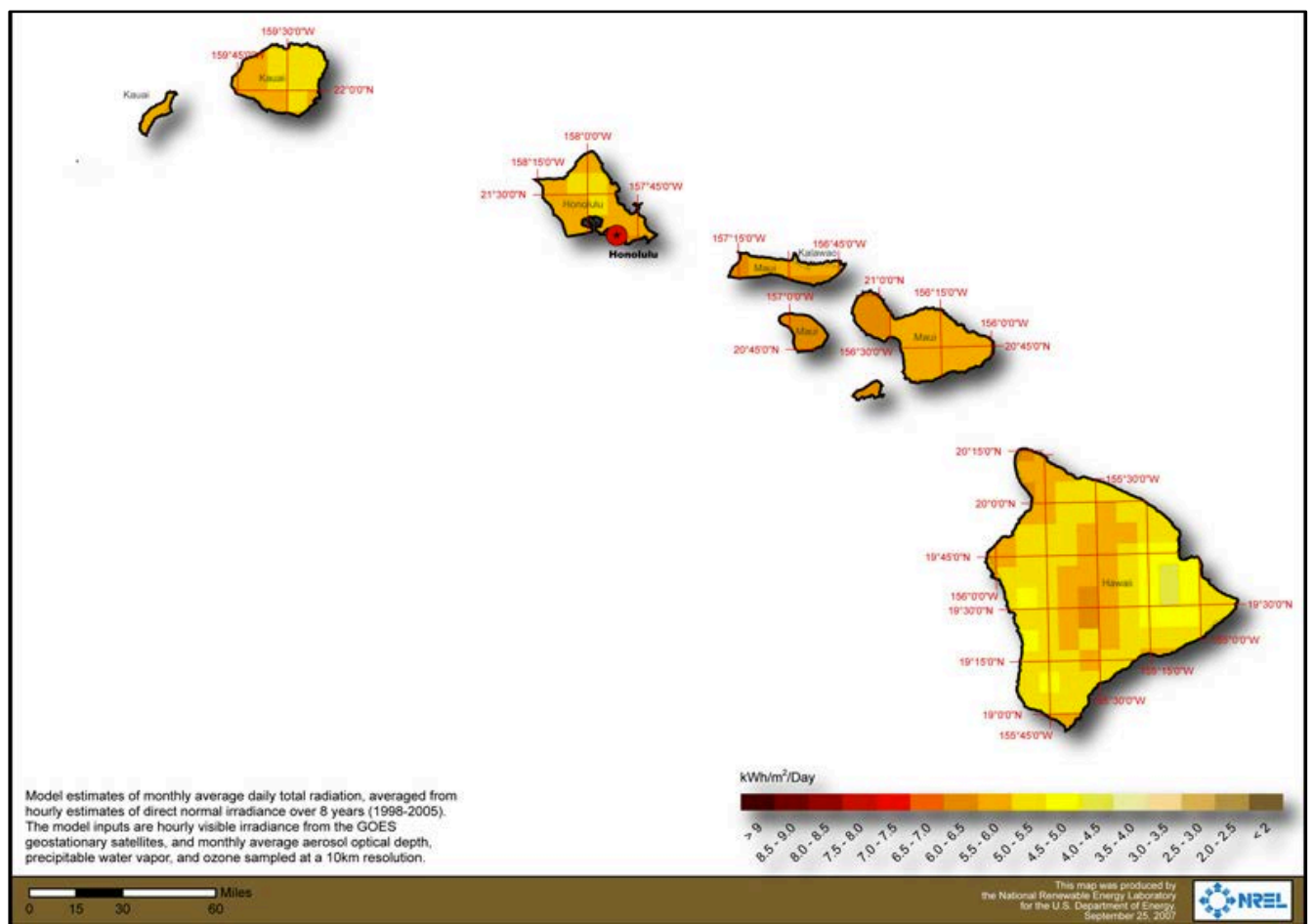

Source: NREL

Figure 18. Hawaii annual solar radiation at latitude tilt $\left(\mathrm{kWh} / \mathrm{m}^{2} /\right.$ day $)$

Hawaii's wind resources are concentrated in the channels between the major islands of Molokai, Maui, and the Big Island (Hawaii Island), mainly due to the blockage of northeasterly trade winds by high mountain ranges. This has created deficits elsewhere on the islands, particularly on the upwind and downwind sides of the major islands (AWS Truewind 2004). Hawaii is estimated to have $2 \mathrm{GW}$ of onshore wind potential, while its coastlines can potentially support $737 \mathrm{GW}$ of offshore wind power. 


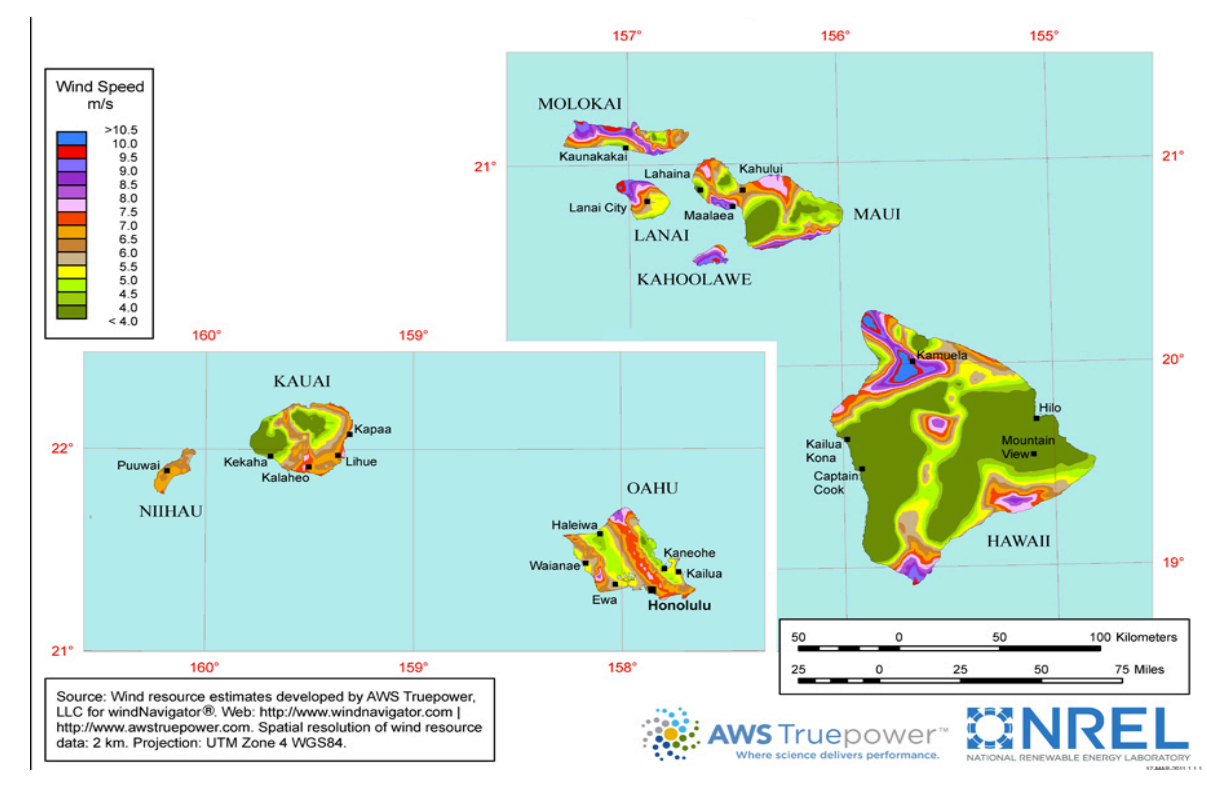

Source: NREL

Figure 19. Hawaii onshore wind resource map at $80 \mathrm{~m}$ (annual average wind speed $\mathrm{m} / \mathrm{s}$ )

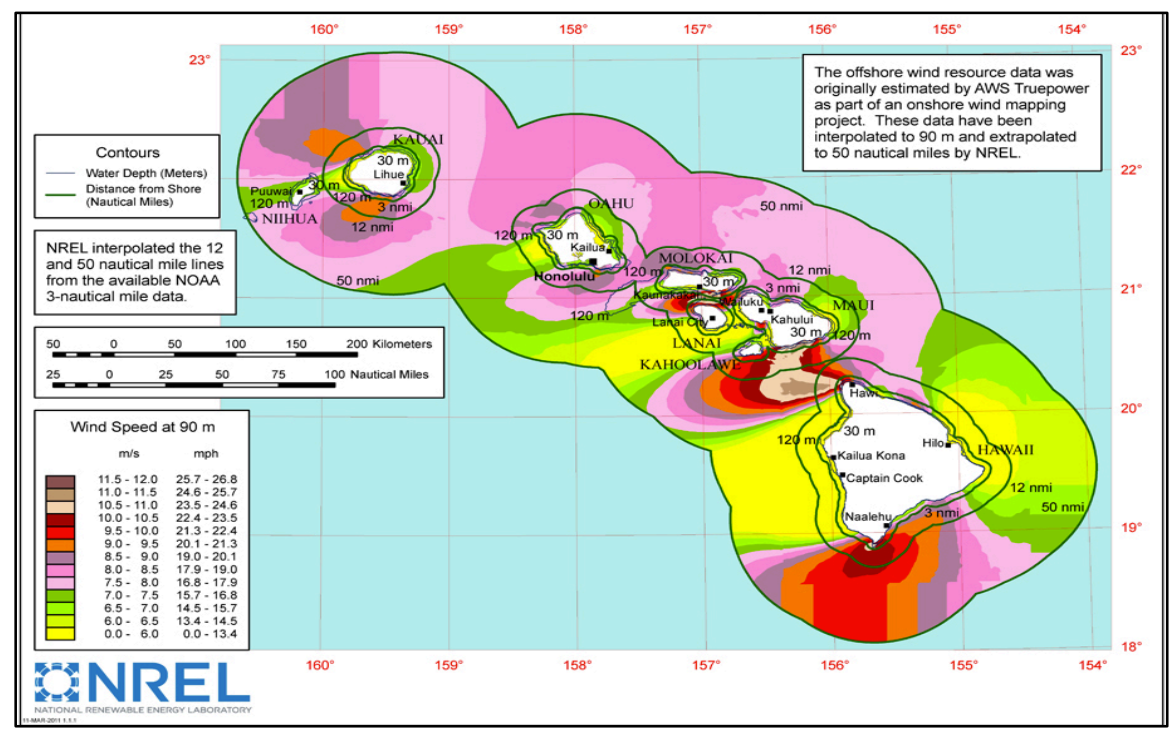

Source: NREL

Figure 20. Hawaii offshore wind resource map at $90 \mathrm{~m}$ (annual average wind speed $\mathrm{m} / \mathrm{s}$ ) 


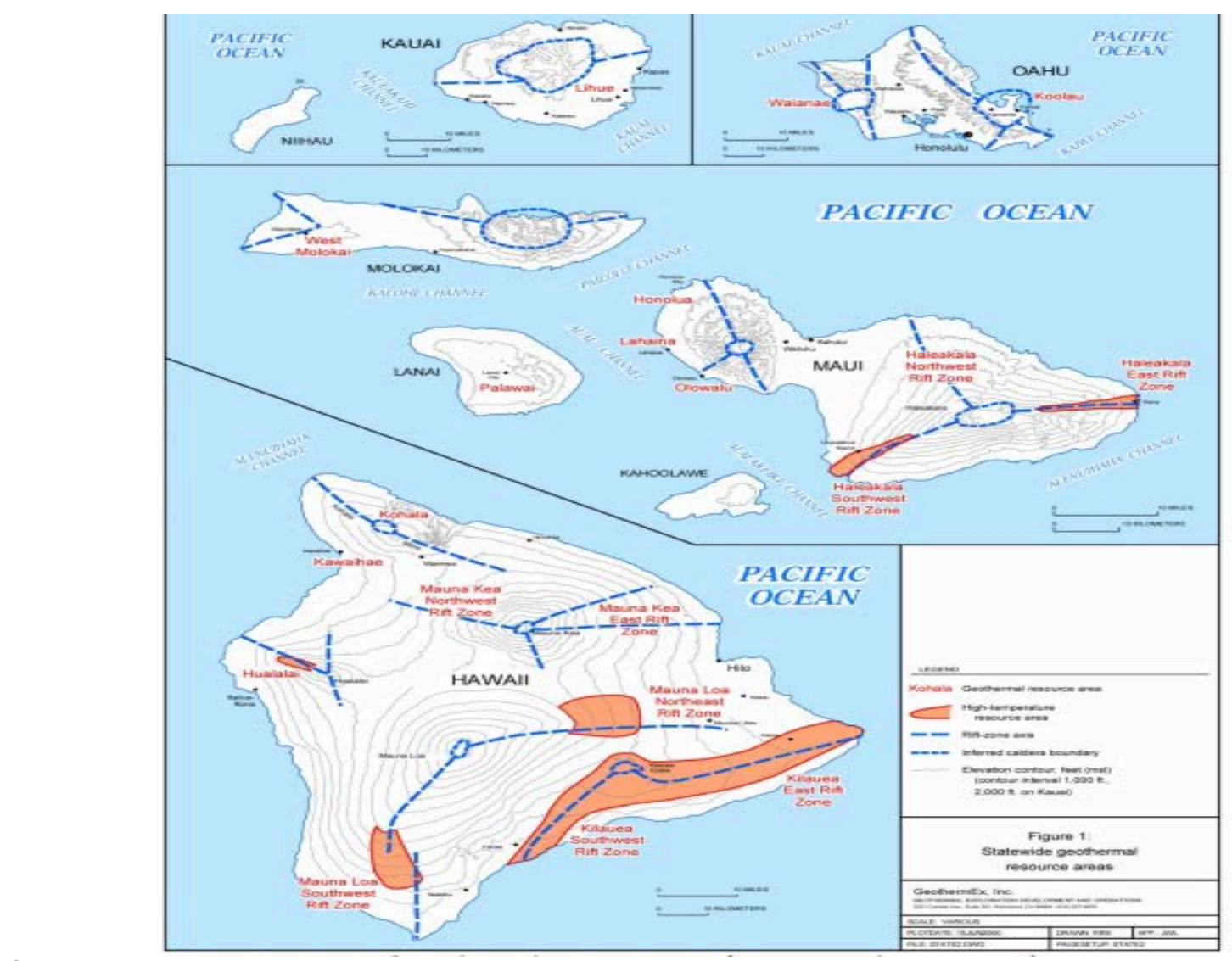

Source: NREL

Figure 21. Geothermal resource areas in Hawaii 
Biopower has traditionally been used to generate electricity in Hawaii, particularly in the form of agricultural waste, to supplement petroleum generation. Bagasse, which is a byproduct of Hawaii's sugar cane industry, entered the energy landscape in Hawaii in the 1970s as an alternative to imported oil for electricity generation. Its consumption increased in the 1980s, generating as much as 5\% of the state's total electricity by $1991 .{ }^{17}$ The agricultural sector's decline in the 1990s caused the electric sector to turn to more biomass energy from municipal solid waste. More recently, Hawaii began to substitute sustainable biofuels for petroleum products. The state plans to ramp up its local biofuel production. In the meantime, biodiesel for its biofuel generation plants is being sourced from the Midwest United States. and Southeast Asia, ${ }^{18}$ at a higher cost compared to that of diesel or oil (DBEDT 2014).

Hawaii is one of the few states in the country with existing geothermal electric generation. Hightemperature resource areas exist along major rift zones on Maui and Hawaii Island. Assessment based on the state exploration studies in the 1970s and 1980s indicates there may be more than $1.5 \mathrm{GW}$ of probable reserves on the islands of Hawaii and Maui (GeothermEx 2005). Supported partially by the U.S. DOE, further exploration has been undertaken to assess the viability of heat recovery at drillable depth along the Haleakala Southwest Rift Zone in Maui. The University of Hawaii is conducting surface exploration using magnetotellurics to obtain geothermal resource data for the public domain (PICHTR 2013).

Hawaii's river steams, which are prone to fluctuating water levels, are not suitable for large hydroelectric dams. However, the islands of Hawaii and Maui have a number of small run-ofriver hydro turbines.

Table 6. Hawaii Renewable Energy Resource Summary

\begin{tabular}{llll}
\hline & $\begin{array}{l}\text { Potential Installed } \\
\text { Capacity (GW) }\end{array}$ & $\begin{array}{l}\text { Potential Annual } \\
\text { Generation (GWh) }\end{array}$ & $\begin{array}{l}\text { Available Land } / \\
\text { Resource }\end{array}$ \\
\hline Urban Utility-Scale PV & 2 & 3,725 & $35 \mathrm{~km}^{2}$ \\
\hline Rural Utility-Scale PV & 21 & 38,033 & $431 \mathrm{~km}^{2}$ \\
\hline Rooftop PV & 3 & -- & -- \\
\hline Onshore Wind & 2 & 7,787 & $494 \mathrm{~km}^{2}$ \\
\hline Offshore Wind & 737 & $2,836,735$ & $147,389 \mathrm{~km}^{2}$ \\
\hline Biopower & $<1$ & $724^{19}$ & Solid: $476,459(\mathrm{BDT})$ \\
& & & Gas: 42,603 (tonnes $\left.\mathrm{CH}_{4}\right)$
\end{tabular}

Source: Lopez, et al. 2012

\subsection{Electricity Generation}

Hawaii is the only state in the United States that depends heavily on petroleum-fired generation as an electricity source. In 2013, petroleum fueled $71 \%$ of Hawaii's net electricity generation,

\footnotetext{
${ }^{17}$ Economic report 2011 Renewable Energy in Hawaii June 2011 State of Hawaii Department of Business Economic Development and Tourism Research and Economic Analysis division.

${ }^{18}$ More information is available at: http://www.hawaiianelectric.com/heco/ hidden Hidden/CorpComm/Hawaii-PUC-approves-

biodiesel-contract-for-HECO's-Campbell-Industrial-Park-Generating-Station?cpsextcurrchannel=1

${ }^{19}$ Generation estimates based on biomass and biogas resource
} 
followed by $14 \%$ from coal-fired power, and $11 \%$ from renewables (mainly wind, biomass, and geothermal) (EIA 2014).

To harness heat from the islands' volcanoes, Hawaii Island built the state's first geothermal plant, the Puna Geothermal Venture, in 1993 to support base-load and dispatchable electricity. With a generation capacity of $38 \mathrm{MW}$, the plant produced $281 \mathrm{GWh}$ in 2013 , providing about one-fifth of Hawaii Island's electricity consumption and $17 \%$ of total electricity generated from renewables in the state (DBEDT 2014).

Biopower generated $445 \mathrm{GWh}$ of electricity in 2013 from a combination of biomass, biogas, and biofuel generators on the islands (HECO 2013a). In Maui, the last sugar plantation in the state continues to produce electricity for the island with a capacity of 10-12 MW. The $46 \mathrm{MW}$ Honolulu H-Power waste-to-energy plant has been converting municipal waste into electricity for Oahu since 1990 (HECO 2013c). In 2010, Oahu inaugurated a 110 MW commercial electricity generator fueled $100 \%$ by biofuel at Campell Industrial Park (HECO 2013b).

The seven operating wind power plants on Oahu, Maui, and Hawaii Islands have a combined installed capacity of $202 \mathrm{MW}$ and generated close to $500 \mathrm{GWh}$ of electricity in 2013, accounting for $31 \%$ of total renewable generation (DBEDT 2014).

Solar PV systems have been installed at a rapid pace. Commercial and residential system capacity has been doubling every year since 2006. In addition, the state has utility-scaled PV plants spread on Lanai, Oahu, Kauai, and Maui. In 2013, Hawaii installed 151 MW of solar electric capacity, and ranked second in solar installations per capita. Hawaii had an estimated $358 \mathrm{MW}_{\mathrm{DC}}$ of solar PV installed at the end of 2013 (Sherwood 2014).

Without an undersea transmission system, each island operates independently to supply and distribute electricity. As the population center of the state, Oahu generates and consumes the most electricity. In 2013, Oahu's utility company, HECO, generated $7561 \mathrm{GWh}$ of electricity, accounting for about $72 \%$ of the state's total generation (DBEDT 2014).

Due to its reliance on imported oil for its electricity needs and the lack of interconnectivity, Hawaii has the most expensive electricity rates in the United States. The average cost of electricity in Hawaii is $\$ 0.3398 / \mathrm{kWh}$, compared to a U.S. total average of $\$ 0.1021$. The cost of electricity in Hawaii is more than double the highest continental state-average cost, New York at $\$ 0.1550 / \mathrm{kWh}$ (EIA 2014b). 


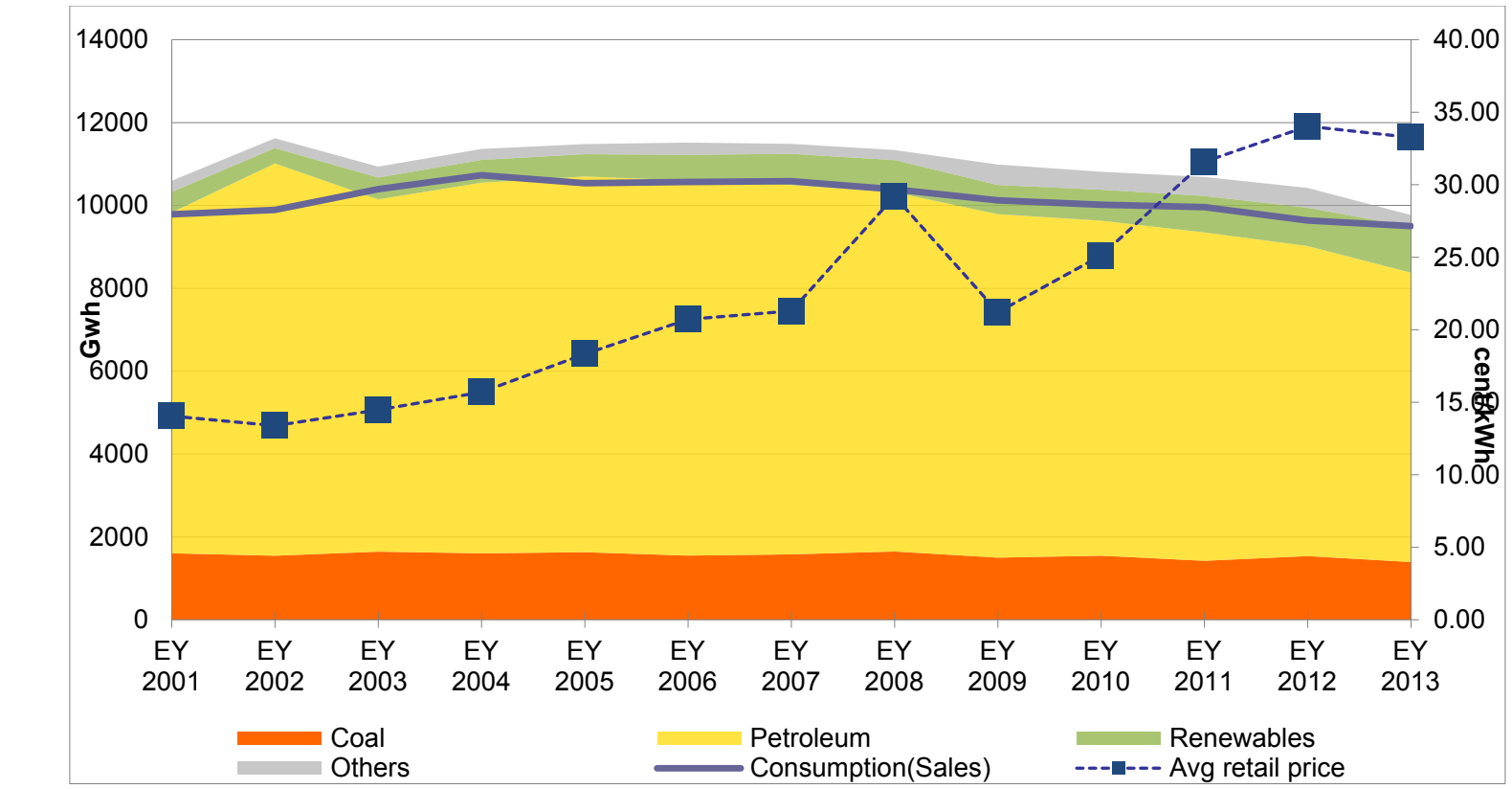

Based on EIA data

Figure 22. Electricity generation in Hawaii

Understanding the makeup of electricity production is becoming increasingly important because of the substantial increase in renewable energy deployment and the fact that Hawaii operates as a series of independent non-interconnected utility grids. Because electricity must be used (or stored) at the instant it is produced, the utility must constantly work to balance production and consumption constantly. Because much of Hawaii's existing electric generation consists of slowreacting base-load generation, intermittent renewable energy across the state has experienced significant curtailment to balance the grid. This introduces risk and income uncertainty to the independent power producers and reduces the likelihood of investment in future systems.

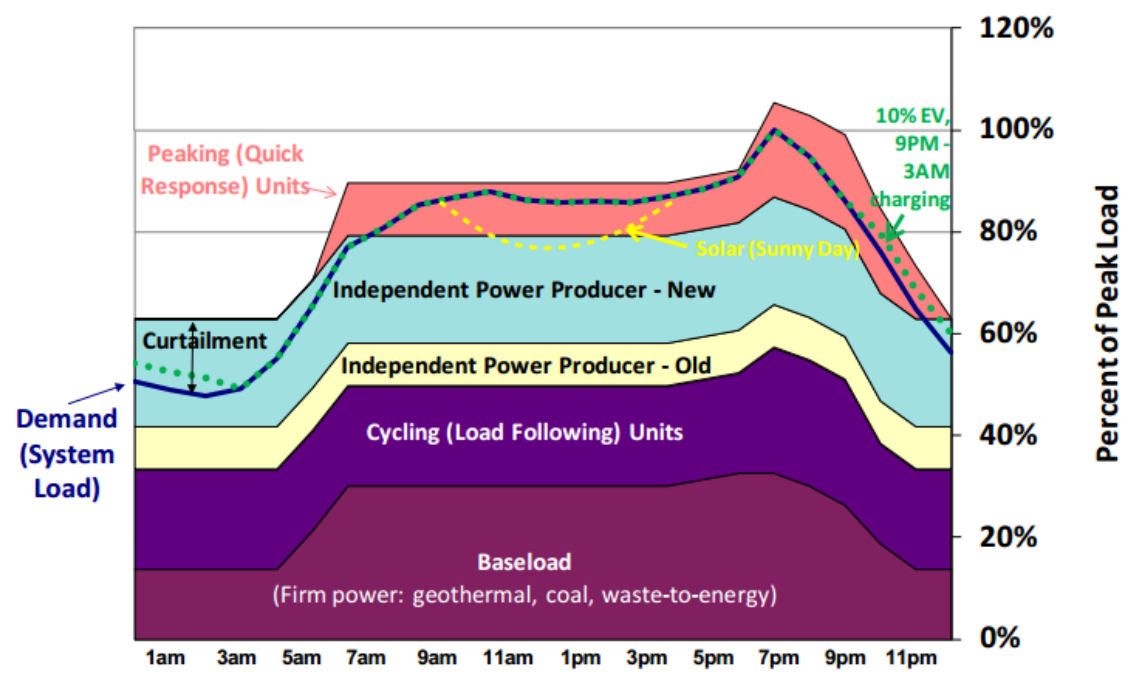

Source: DBEDT 2014

Figure 23. Summary of load generation profile in Hawaii 
The Interisland Cable Grid-tie project is an investigation into the cost and benefits of connecting the electricity grids of Maui and Oahu with a $200 \mathrm{MW}$ high-voltage direct-current undersea cable. This would enable load-sharing and generation-sharing between the islands and has an estimated net benefit of \$551 million. In addition, Hawaii is supporting investment in smart-grid technology that will enable improved energy management systems, demand management, improved electric TOU billing, improved storage, and overall improved grid monitoring and increased stability.

Table 7. Electricity Generation in Hawaii

\begin{tabular}{lll}
\hline & Hawaii & US (Share) \\
\hline $\begin{array}{l}\text { Net Electricity Generation } \\
\text { (thousand MWh) }\end{array}$ & 9,814 & $4,058,209(0.24 \%)$ \\
\hline $\begin{array}{l}\text { Electricity Consumption } \\
\text { (thousand MWh) }\end{array}$ & 9,501 & $3,691,789(0.26 \%)$ \\
\hline $\begin{array}{l}\text { Net Generation from } \\
\text { Renewables (thousand } \\
\text { MWh) }\end{array}$ & 1,112 & $253,328(0.44 \%)$ \\
\hline $\begin{array}{l}\text { CO }{ }_{2} \text { Emission from Electric } \\
\text { Power Industry (metric tons) }\end{array}$ & $30,499,176$ & $8,627,499,108(0.35 \%)$ \\
\hline $\begin{array}{l}\text { Electricity Price (Q3 2014) } \\
\text { (cents/kWh) }\end{array}$ & 33.96 & $10.91(311 \%)$ \\
\hline $\begin{array}{l}\text { Three-Year Average } \\
\text { Electricity Price (2011-2013) } \\
\text { (cents/kWh) }\end{array}$ & 33.77 & $9.94(339 \%)$ \\
\hline Sorce: EIA & & \\
\hline
\end{tabular}

Source: EIA

\subsubsection{Stakeholders}

On the state level, renewable energy development in Hawaii is led by the Hawaii State Energy Office under the Department of Business, Economic Development and Tourism (DBEDT). The State Energy Coordinator, who manages the efforts of all involved parties in Hawaii's Energy Policy and establishes plans for energy conservation and renewable energy, is a designated role of the Director of DBEDT. In addition, DBEDT conducts policy and economic analysis and coordinates and facilitates permits.

The Hawaii Public Utilities Commission (PUC) regulates the four electric utility companies that purchase, transmit, distribute, and sell electricity in Hawaii. In addition to regulating the service and rates of utilities, the PUC has been entrusted by the state legislature to implement and regulate Hawaii's clean-energy policies.

The Hawaiian Electric Company (HECO) serves the island of Oahu, while its subsidiariesMaui Electric Company (MECO) and Hawaii Electric Light Company (HELCO)—serve the islands of Maui, Lanai, Molokai, and Hawaii (Big Island). The three utilities together, known as "the HECO Companies" under investor-owned company Hawaiian Electric Industries, Inc., provide power to $95 \%$ of Hawaii's population, serving more than 450,000 customers. Each island operates independently in terms of energy production and distribution. HECO provides 
service to nearly 400,000 customers with a peak capacity of 1,141 MW in Oahu MW (DBEDT 2014). Aside from the HECO Companies, Kauai Island Utility Cooperative (KIUC), a non-profit cooperative, services 32,000 member-customers throughout the island of Kauai. ${ }^{20}$

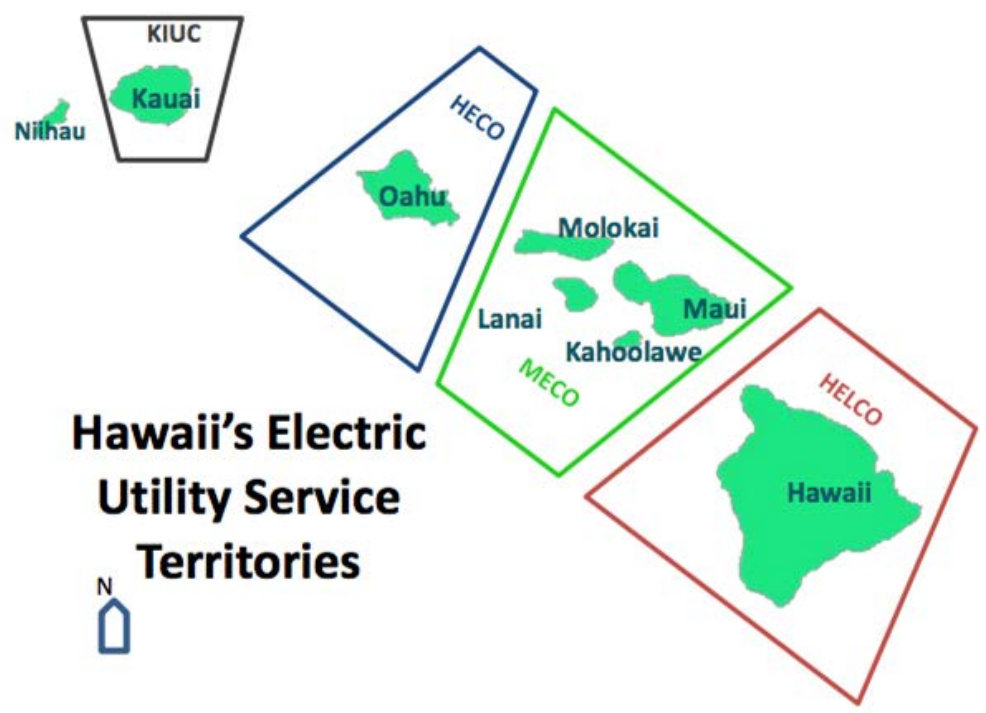

Source: DBEDT 2014

Figure 24. Hawaii utility territory summary

\subsubsection{Policies and Development}

Unique in its energy structure and geographical isolation, Hawaii developed an acute awareness of energy security issues early on. After the OPEC oil embargo in 1973, Hawaii formally articulated its energy goals through the legislature in 1974, with a focus on energy independence and recognition of non-polluting, natural energy potential (Hawaii Statutes $\S 196-1$ ). In the same year, the legislature created the legal basis of the energy program and the position of State Energy Coordinator under the Department of Planning and Economic Development, as well as two research institutes affiliated with the University of Hawaii (i.e., Hawaii Natural Energy Institute and the Natural Energy Laboratory of Hawaii). This was a critical step in advancing energy policy in Hawaii, because it built the foundational institutions and regulatory actors that remain largely in place to this day. The director of the state's economic planning agency overseeing energy policy provided both regulatory continuity and political backing for the success of the state's energy policy.

In 1978, the Hawaii State Plan was signed into law with specific objectives to develop "dependable, efficient, economical" energy systems and to increase self-sufficiency. These objectives were augmented in 1981 and 2000 to include greater energy security and reduction of greenhouse gas emissions to reflect the state's evolving priorities for its energy policy (Hawaii Statutes 226-18).

With the energy regulatory structure set in place and the broader energy policy objectives established, Hawaii was able to push forward a series of energy policies to increase indigenous energy resources in the energy sector. These include issuing the first law offering state tax credit

${ }^{20}$ More information about KIUC is available at http://website.kiuc.coop/ 
for renewable energy (for solar water heaters), funding solar and wind resource assessment studies, and launching geothermal and solar demonstration projects.

Although early renewable energy initiatives served as enabling actions, the initiatives were not designed or implemented within a comprehensive, integrated framework. The first Integrated Energy Assessment in 1981, a joint study between Hawaii's DBEDT and the U.S. DOE, projected energy scenarios as Hawaii transitions to a mix of indigenous, renewable energy resources in 25 years. ${ }^{21}$ From 1991 to 2008 , Hawaii issued a series of long-range integrated energy plans to support the State Energy Objectives by analyzing possible energy scenarios and offering policy recommendations. The plans incorporated renewable energy development and deployment into a comprehensive energy policy that included transport, electricity generation, demand-side efficiency, and energy security.

In 2008, the State of Hawaii signed a Memorandum of Understanding (MOU) with the U.S. DOE to launch the Hawaii Clean Energy Initiative (HCEI), a long-term partnership to reach Hawaii's energy transition goals. The HCEI outlines a roadmap of 70\% clean energy by 2030 through realizing 30\% energy efficiency and $40 \%$ locally generated renewable energy. The MOU calls for the U.S. DOE to provide technical assistance and other resources, helping Hawaii to gain energy independence as well as become a test bed for renewable energy. ${ }^{22}$ Hawaii State government, the HECO Companies, and the State Consumer Advocate signed an energy agreement that set out actions and timetables to realize its energy transition. ${ }^{23}$

Although the MOU was a nonbinding agreement, the 70\% clean-energy goal pushed forward two state mandates for Hawaii's electric utilities: the Energy Efficiency Portfolio Standard (EEPS) with a goal of achieving 4,300 GWh of electric energy savings by 2030, and the RPS of meeting $40 \%$ of electricity sales from renewables by 2030. In addition, it has spurred many policies to implement the aggressive goal. On September 15, 2014, the State of Hawaii and the U.S. DOE reconfirmed their commitment to the Hawaii Clean Energy Initiative. Led by Governor Neil Abercrombie, the agreement continues the state's commitment to renewable energy development.

\footnotetext{
${ }^{21}$ The Hawaii Integrated Energy Assessment (1981) is available at http://evols.library.manoa.hawaii.edu/bitstream/handle/10524/33713/1981\%20-\%20HI\%20Integrated\%20Energy $\% 20$ $\% 20$ Exec\%20Summary.pdf?sequence $=1$

${ }^{22}$ The HCEI MOU is available at http://www.hawaiicleanenergyinitiative.org/storage/pdfs/HI-DOE MOU 9.15.14.pdf

${ }^{23}$ More information about Hawaii Energy Agreement between the state and HECO is available at http://files.hawaii.gov/dcca/dca/HCEl/HECl\%20Agreement.pdf
} 


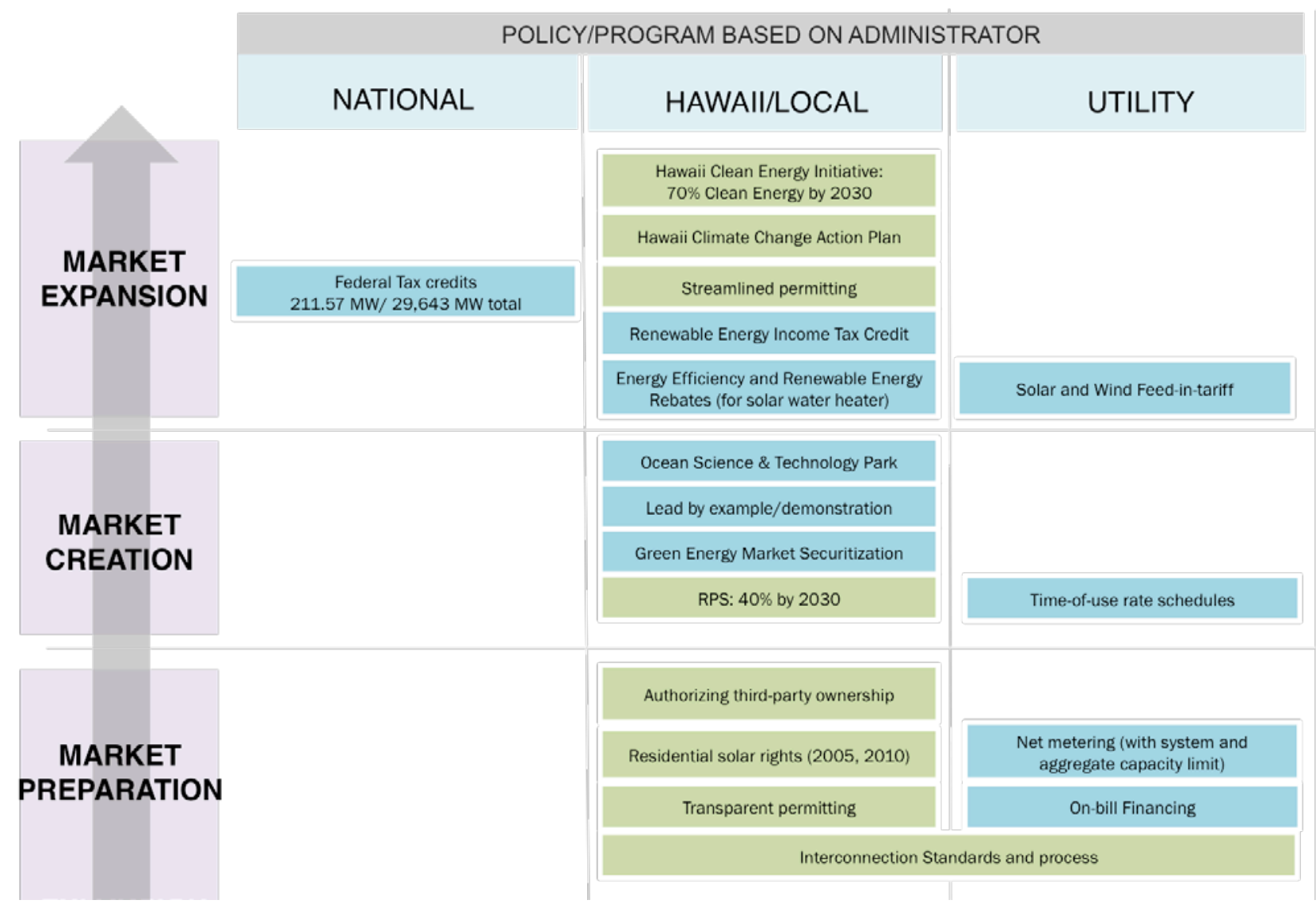

Figure 25. Summary of policies under the stacking framework for Hawaii

\subsubsection{Market Preparation}

\subsubsection{Net Metering and Interconnection}

Hawaii has recognized the impacts that permitting processes and standards can have with regard to total system cost and renewable energy deployment.

Hawaii first enacted law to enable net metering in 2001, which has since evolved with the increasing penetration of distributed generation. Initially set for systems at $10 \mathrm{~kW}$, the eligible capacity limit was expanded to $50 \mathrm{~kW}$ in 2004 , with additional options for increasing limits and the carryover of excess generation to the next electricity bill. In 2008, under the Hawaii Clean Energy Initiative, the state government agencies and the HECO Companies reached an agreement to eliminate system-wide caps and encourage movement to a FIT model.

Hawaii also established simplified interconnection procedures for net metered systems (up to 50 $\mathrm{kW}$ in Kauai and up to $100 \mathrm{~kW}$ for all other islands). In 2010, the PUC created a standard threeparty interconnection agreement, in addition to the two-party interconnection agreement, to improve consistency and expedite the process.

As an early adopter of a net metering policy, Hawaii enabled substantial distributed generation investment where it made the most economic sense for the property owner. As the market continued to grow, however, Hawaiian utilities began reaching the aggregate capacity limits. In 
2006, the PUC established an initial cap on net metering: $0.5 \%$ of system-wide peak demand. By 2008 , the cap increased to $4 \%$ of peak demand.

As distributed solar installations grew in Hawaii, net metering policy became dependent on the penetration of distributed generation per-circuit, per-utility. In 2011, the PUC replaced the system-wide cap with a distribution-level trigger of $15 \%$ of circuit peak demand for the HECO Companies. Once the circuit hits the $15 \%$ threshold, HECO will conduct a supplemental review based on daytime minimum load (DML) threshold ${ }^{24}$ to determine if new distributed generation systems on these circuits need an interconnection requirement study (IRS) or circuit upgrades. ${ }^{25}$ (Heeter, Gelman and Bird 2014). While a supplemental review takes less than 20 days, an interconnection requirement study can take up to four to six months to complete (HECO 2015a).

By the end of 2013, about $10 \%$ of Hawaii's residential electric customers had net metering agreements in place, representing a total capacity of about $312 \mathrm{MW}$ (DBEDT 2014). In the same year, $27 \%$ of the 416 distribution circuits had exceeded $100 \%$ of the daytime minimum load on HECO's distribution network in Oahu. Hawaii Electric Light and Maui Electric had $18 \%$ and $16 \%$ of their respective distribution circuits reaching above 100\% DML (Heeter, Gelman and Bird 2014).

In February 2014, HECO released new interconnection procedures based on different circuit penetration levels (increasing the upper threshold from 100\% DML to $120 \%$ DML) and size of the systems (HECO 2014c). Table 8 summarizes these interconnection policies.

Table 8. Interconnection Policy for HECO (as of February 2014)

\begin{tabular}{|c|c|c|c|}
\hline $\begin{array}{l}\text { Aggregate PV } \\
\text { Nameplate (kW) vs. } \\
\text { Daytime Min Load } \\
\text { (DML) on Circuit }\end{array}$ & $\begin{array}{l}\text { Single-Phase System, } \\
10 \mathrm{~kW} \text { or smaller }\end{array}$ & $\begin{array}{l}\text { Single-Phase System, } \\
\text { from } \\
10 \mathrm{~kW} \text { to } 100 \mathrm{~kW}\end{array}$ & $\begin{array}{l}\text { Three-Phase, } \\
\text { from } \\
10 \mathrm{~kW} \text { to } 100 \mathrm{~kW}\end{array}$ \\
\hline $\begin{array}{l}\text { Greater than } 120 \% \text { of } \\
\text { DML }\end{array}$ & $\begin{array}{l}\text { IRS may be required, } \\
\text { possible upgrades }\end{array}$ & $\begin{array}{l}\text { IRS may be required, } \\
\text { possible upgrades }\end{array}$ & $\begin{array}{l}\text { IRS may be } \\
\text { required, } \\
\text { possible upgrades }\end{array}$ \\
\hline $100 \%-120 \%$ of $\mathrm{DML}$ & $\begin{array}{l}\text { No IRS, possible } \\
\text { upgrades }\end{array}$ & $\begin{array}{l}\text { IRS may be required, } \\
\text { possible upgrades }\end{array}$ & $\begin{array}{l}\text { IRS may be } \\
\text { required, possible } \\
\text { upgrades }\end{array}$ \\
\hline $75 \%-99 \%$ of DML & $\begin{array}{l}\text { No IRS, possible } \\
\text { upgrades }\end{array}$ & $\begin{array}{l}\text { No IRS, possible } \\
\text { upgrades }\end{array}$ & $\begin{array}{l}\text { No IRS, possible } \\
\text { upgrades }\end{array}$ \\
\hline Up to $74 \%$ of $D M L$ & No IRS, no upgrades & $\begin{array}{l}\text { No IRS, possible } \\
\text { upgrades }\end{array}$ & $\begin{array}{l}\text { No IRS, possible } \\
\text { upgrades }\end{array}$ \\
\hline
\end{tabular}

Source: HECO 2014b

\footnotetext{
${ }^{24}$ Daytime minimum load refers to electricity demand from 9 a.m. to 5 p.m. local time.

${ }^{25}$ Cost for circuit upgrades are shared between the utility and the customer
} 


\section{Hawaii's Online Tools for Interconnecting Distributed Solar}

\section{Locational Value Maps}

To facilitate customer-sited generation interconnection, the HECO Companies launched the Locational Value Maps (http://www.hawaiianelectric.com/portal/site/heco/lvmsearch) for its service territories. This online tool includes an address search function demonstrating the level of distributed generation on distribution circuits as a percentage of MDL and peak circuit load. Summary maps, which are updated each weekday, provide visual tracking of DG penetration changes. The tool aims to provide preliminary guidance to customers and contractors considering installation and interconnection.

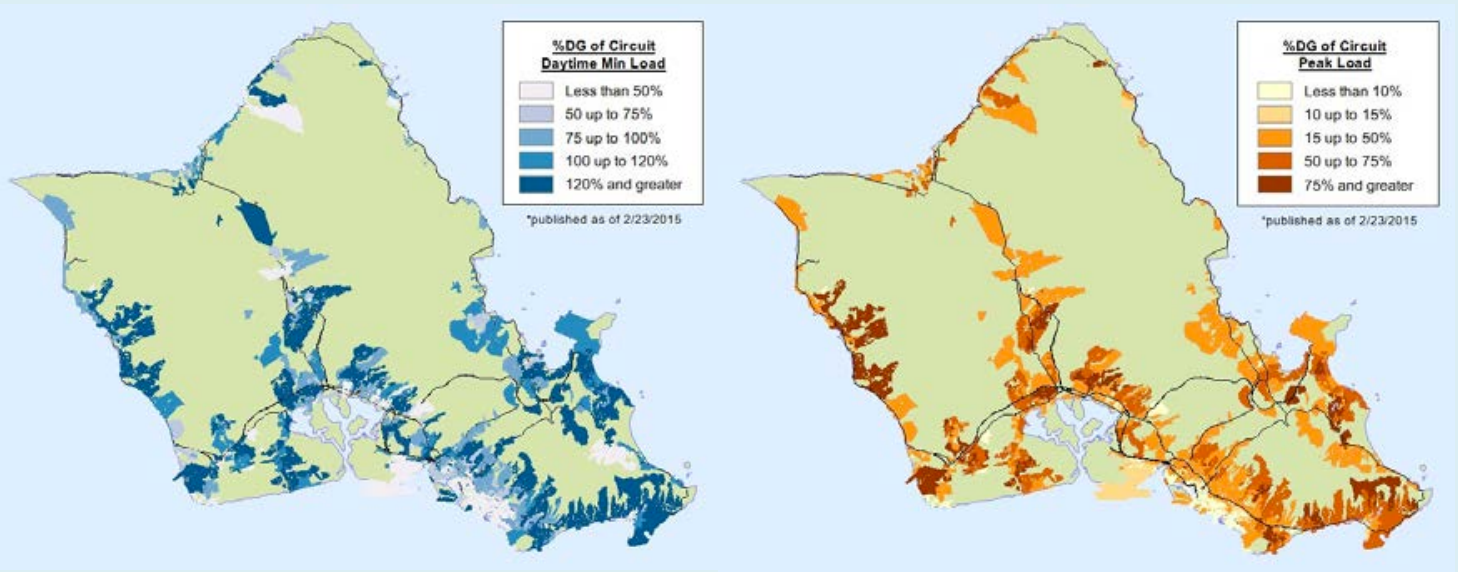

Source: HECO http://www.hawaiianelectric.com/portal/site/heco/lvmsearch

Figure 26. DG interconnection locational value maps for Oahu (2/13/2015).

\section{Integrated Interconnection Queue}

In addition to the Locational Value Maps, HECO has launched the Integrated Interconnection Queue (http://www.hawaiianelectric.com/heco/Clean-Energy/Integration-Tools-and-Resources/Integrated-InterconnectionQueue). The Queue was implemented as one of the measures to alleviate the backlog of DG systems waiting for interconnection. The first public interconnection queue system by a utility to encompass all classes of DG installations, the Hawaii Integrated Interconnection queue shows applications from all DG programs, including net metering and FIT. The online portal increases transparency in how many projects are in the pipeline. However, it does not serve as a publically available tracking system after the interconnection has been complete. (Reiter and Ardani 2015)

Renewable Watch:

REWatch is a visualization tool that combines system load information with variable electricity generation from solar and wind in Oahu. The tool illustrates how different the net system load served by the utility changes throughout the day with changing levels of PV and wind generation.

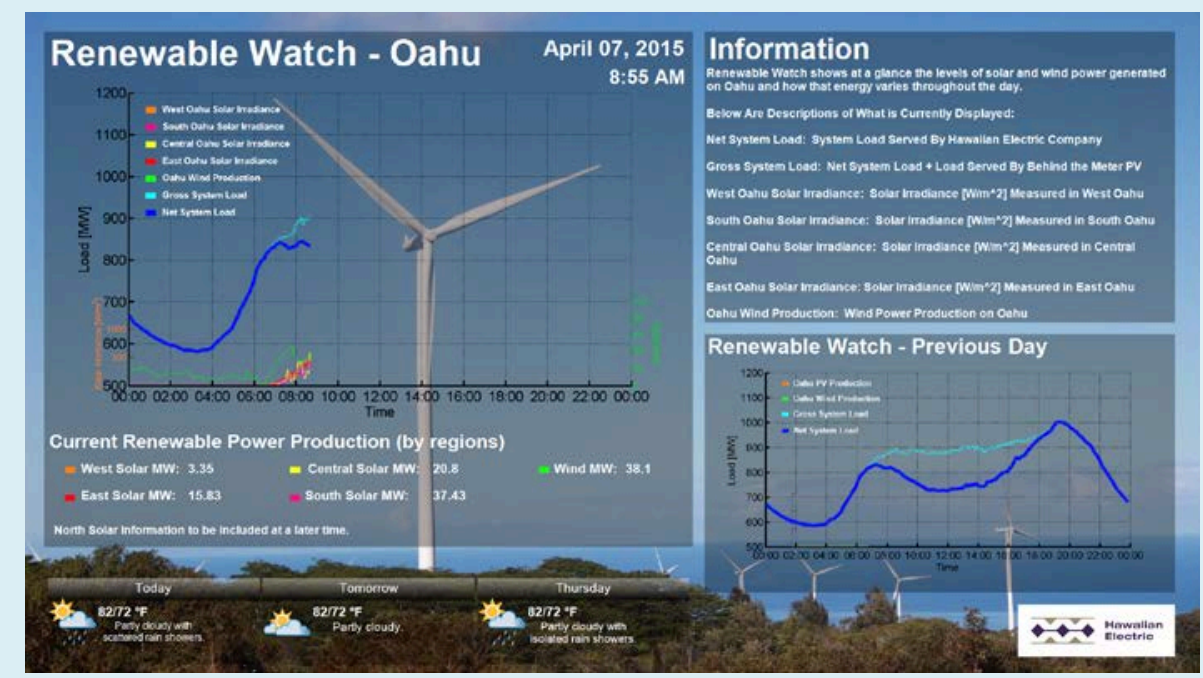

Source: HECO http://www.hawaiianelectric.com/heco/Clean-Energy/Integration-Tools-and-Resources/Renewable-Watch

Figure 27. Renewable Watch (04/07/2015) 
The more extensive interconnection evaluation process has made investment planning more difficult and has caused a backlog for new permits. However, the PUC deems it necessary in order for the utilities to address the technical feasibility of maintaining system reliability and safety risks associated with reverse power flow to accommodate high penetration of PV.

\subsubsection{Transparent Permitting}

Although Hawaii has implemented a transparent fast-track interconnection policy for distributed generation, the long approval process for larger renewable projects remains one of the greatest barriers to renewable energy in Hawaii (Busche, et al. 2013). Large energy projects in Hawaii average 15 unique permits, with some facilities requiring over 40 such approvals. It can take up to 5 years to obtain all permits for a utility-scale renewable energy project in Hawaii due to a myriad of interested parties and overlapping requirements. Permitting costs are estimated to range between $1 \%$ up to $20 \%$ of construction costs, based on project size, location, and technology (DBEDT 2014). These costs and delays can reduce the attractiveness of investing in renewable energy and negatively impact overall industry progress.

To reduce investment uncertainty, the DBEDT and the U.S. DOE (NREL) launched a multi-year project to increase transparency and streamline the HCEI permitting process for renewable projects. In 2009, eleven HCEI Permitting Guidebooks were published, covering seven technologies and permitting requirements in the four main counties in Hawaii. ${ }^{26}$ In 2011, the HCEI launched an online permitting tool—the Renewable Energy Permitting Wizard-based on the information in these guidebooks. ${ }^{27}$ These tools helped to increase the transparency of the permitting process, allowing developers to estimate the expected timeframe pre-construction or alter design or location of the project. However, more actions were needed to streamline the actual permitting process (Busche, et al. 2013). The state has worked with the utilities to create standardized checklists and to implement electronic permitting.

\subsubsection{Third-Party Ownership}

In Hawaii, third-party ownership of systems is permitted across all utilities. In addition, the Hawaiian legislature has passed the "PV Renter" bill, which further removes barriers for landlords installing renewable energy systems. Prior to the passage of the law, there was concern over whether the landlord could be considered a utility selling electricity to another party. This caused additional complications and reduced investment. Clear and precise laws surrounding third-party ownership and the relationship between distributed generation and the utility continue to enable and encourage investment in the field.

\subsubsection{Residential Solar Rights}

Hawaiian laws prohibit any covenant or unreasonable restriction that limits the installation of solar energy systems on residential dwellings or townhouses. Homeowner associations are limited in the regulations they can pass regarding solar systems. Specifically, regulations adopted by homeowner associations cannot render a solar system more than $25 \%$ less effective, increase costs by more than $15 \%$, or require a title encumbrance. These limits help ensure that homeowners who want to install solar on their personal rooftops are able to do so without undue restrictions from a community management association.

\footnotetext{
${ }^{26} \mathrm{HCEI}$ Permitting Guidebooks are available at: http://energy.hawaii.gov/renewable-energy-project-permitting-in-the-state-of-hawaii

${ }^{27}$ The Renewable Energy Permitting Wizard is available at: http://wizard.hawaiicleanenergyinitiative.org/
} 


\subsubsection{On-Bill Repayment}

Beginning with State HB 1520 in 2011, the Hawaii PUC began investigating the viability of an on-bill financing program for utility customers to finance renewable energy or energy efficiency through on-bill assessment of financing payments. In January of 2014, the PUC released a report suggesting that on-bill financing is appropriate for Hawaii. In particular, the report suggested that solar thermal was ideally suited for on-bill financing in Hawaii due to the payback rates of the systems and the current penetration rate of $28 \%$. Enabling on-bill repayment, or financing, of systems helps to establish the market by offering an easy, clear way for saving energy without upfront costs (Hartcourt Brown \& Carey 2013).

\subsubsection{Market Creation}

\subsubsection{RPS}

Hawaii first passed a voluntary renewable portfolio goal in 2001 to generate $9 \%$ of its electricity from renewables at the end of 2010. In 2004, the state extended the RPS to $20 \%$ by 2020 and made the utility companies' obligation compulsory. In accordance with the Hawaii Clean Energy Initiative, the legislature increased the required amount of renewable generation by utilities to $40 \%$ by 2030 .

The RPS defines "renewable energy" as energy generated from the sun, water, biogas, landfill and sewage digester gas, geothermal, ocean water, biomass, wastes, biofuels, wind, and hydrogen produced from renewable energy sources, including customer-sited, grid-connected systems. Prior to January 1, 2015, up to $50 \%$ of the RPS could be met through means other than renewable energy generation, such as energy-efficiency savings.

Hawaii is one of the few RPS states that does not have a REC market and has not established a tracking system. The utilities report their renewable energy production directly to the PUC, which conducts internal verification of the reports (Hamrin 2014). The PUC can assess penalties or issue rulings if the utility does not meet the RPS requirements. For instance, in 2014, the PUC ruled that HECO was not moving fast enough to accelerate PV installations and address customer concerns. Consequently, HECO submitted plans to achieve 65\% renewable energy, reduce consumption by $20 \%$, and triple the amount of distributed solar by 2030 (HECO 2014a).

\subsubsection{Lead by Example and Demonstration}

The Lead by Example Initiative for Hawaiian government agencies began in 2006 in response to state legislative and executive mandates to increase energy efficiency and sustainable practices. In addition to investing in energy savings performance contracts, LEED certification for buildings, and clean vehicle fleets, agencies also participated in PPAs for renewable energy. Through two rounds of PPAs, the Department of Transportation airports have procured over 1 MW of solar PV systems for their facilities, with an additional 2.69 MW planned (DBEDT 2014).

\subsubsection{Hawaii Ocean Science \& Technology (HOST) Park}

Founded in 1974 at the birth of Hawaii's energy policy, the Natural Energy Laboratory of Hawaii (NELH) has supported research and development (R\&D) in alternative energy and related technologies. It conducted the state's first renewable energy resource studies and engaged in R\&D for a variety of alternative energy technologies, including ocean thermal energy 
conversion. In 1985, The Hawaii Ocean Science \& Technology (HOST) Park was established to encourage commercialization of technologies from NELH's research.

Operating under the same entity, HOST and NELH are located at the natural-resource-abundant Keahole Point on Hawaii Island. The 870-acre technology park has supported a variety of renewable R\&D and demonstration projects, including ocean thermal, concentrating solar power (CSP), PV, biofuels, and storage and microgrid, as well as other applications such as agriculture and aquaculture (NELHA 2011). It has also functioned as an incubator for private companies, leveraging its ability to streamline project siting (as a master-permitted park) and partnerships with various government agencies. In 2014, it formed a partnership with Hawaii County and the utility HELCO to become a test bed for energy storage technology. Hawaii's remote and isolated grid serves as a living lab and is one of the few markets in the world with current economic feasibility for energy storage.

\subsubsection{Time-of-Use Rates}

Hawaii does not currently have TOU rates for typical residential customers; however, it is experimenting with TOU options for electric vehicle customers. Under the program, residential households with one meter would pay 6 cents below typical rates for evening charging ( 9 p.m. to 7 a.m.) and either 2.5 or 5.5 cents above typical rates during the day. This encourages the charging of vehicles in the evening when the demand on the electric utility is at its lowest (HECO 2015b).

Should additional TOU rates be established, consumers may find even more incentive to adopt solar technologies to limit their demand when rates are the highest.

\subsubsection{Market Expansion}

As the solar market became increasingly mature in Hawaii, a number of policies served to expand renewable energy adoption. Some of these are incentives, whereas others aim at creating voluntary markets and choices to allow more participants in renewables projects.

\subsubsection{Net Generation}

The PUC in Hawaii has also required each utility to develop a program in which customer generators can be paid for excess generation at the end of the year under a purchase agreement. Kauai Island Utility Cooperative's current pilot program offers $\$ 0.20 / \mathrm{kWh}$ for excess generation under a 20-year term.

\subsubsection{Renewable Energy Technologies Income Tax Credit}

Since 1976, Hawaii Energy Tax Credits have allowed claims of income tax credits for renewable energy technologies. Individuals and businesses can claim $20 \%$ of the cost of a wind system and $35 \%$ of the cost of a solar thermal or PV system, subject to technology and housing-specific maximum credits. This tax benefit supplements the federal ITC or PTC to further encourage investment in distributed generation throughout the state.

\subsubsection{Feed-In Tariff}

To meet the 2008 goals established in the Hawaii Clean Energy Initiative, the PUC established FITs for renewable energy provided by the investor-owned utility companies. The FIT program 
is divided into three tiers based on technology and size, with designated rates for each technology and maximum caps on system size, differentiated by utility. Eligible technologies include solar PV, CSP, onshore wind, and in-line hydro.

The FIT in Hawaii allows renewable electricity suppliers of up to $5 \mathrm{MW}$ to sell electricity to the utility at constant, contracted rates over 20 years. The contracted purchase price ranges from 18.9 to 23.8 cents $/ \mathrm{kWh}$ for solar PV and 12 to 16.1 cents $/ \mathrm{kWh}$ for onshore wind.

\subsubsection{Green Financing}

In 2006, the state legislature created a public benefits fund for energy efficiency and demandside management programs. The public benefits fund's budget is $2 \%$ of each utility's projected revenue and is collected through a surcharge on utility bills of investor-owned utilities on a $\$ / \mathrm{kWh}$ basis. Under the public benefits fund program, the state has pushed forward multiple rebate programs for energy efficiency, demand response, and solar water heaters.

In 2013, legislation was passed to include renewable energy financing in public funding from the utility bill surcharge. DBEDT created the Green Energy Market Securitization Program (GEMS), which provides low-cost capital to finance distributed solar systems for underserved groups such as low-credit homeowners, renters, and nonprofits. (Hawaii State Energy Office 2014).

\section{Hawaii Green Energy Market Securitization (GEMS) Program}

GEMS employs on-bill repayment through the utility and rate reduction bonds from participating financial institutions. Funding for the loan program comes from a flat green infrastructure fee collected through utility customers, which is accompanied by a reduction in the public benefits fund surcharge. The initial bond secured through this structure, priced at $\$ 150$ million, was the first government-backed green bond to securitize utility fees for solar. (HECO 2014c).

Authorization: SB 1087 passed in 2013

Impact: Expected to fund 40-50 MW of rooftop PV, small amounts of energy efficiency and storage projects

Start date: First fees collected in 2014; loan applications began in 2015

Program administrator: Hawaii Green Infrastructure Authority, new state agency under DBEDT

Structure:

\begin{tabular}{|c|c|c|c|}
\hline & & & \\
\hline $\begin{array}{l}\text { Green Infrastructure fee: } \\
\text { Utility company (HECO) bills } \\
\text { and collects fee from all utility } \\
\text { customers } \\
\text { Rate: Beginning December } \\
2014 \text { at } \$ 1.29 \text { per month }\end{array}$ & $\begin{array}{l}\text { Green Bond Infrastructure } \\
\text { Fund } \\
\text { Cash flow from utility } \\
\text { surcharge are deposited into } \\
\text { a fund and serviced into debt } \\
\text { (initial securitization } \$ 150 \mathrm{M} \text { ) }\end{array}$ & $\begin{array}{l}\text { Hawaii Green Infrastructure } \\
\quad \text { Authority } \\
\text { State agency issues loans } \\
\text { and/or credit enhancement to } \\
\text { customers }\end{array}$ & $\begin{array}{l}\text { Customers: } \\
\text { - } \quad \text { Low-income home } \\
\text { owners } \\
\text { - } \quad \text { Non-profits } \\
\text { - Renters }\end{array}$ \\
\hline
\end{tabular}

Tranches:

\begin{tabular}{|c|c|}
\hline Tranche A-2 & Tranche A-1 \\
\hline \$50 million & \$100 million \\
Tenor: 8 years & Tenor: 16 years \\
Coupon: $1.47 \%$ & Coupon: $3.24 \%$ \\
\hline
\end{tabular}

- Securitization is on utility payments, not solar assets. The government-backed bond will have higher ratings and lower yield than solar-asset-backed securities.

- By targeting low-income, low-credit-score renters, and non-profits, which are underrepresented in HI's PV installation profile, the program will avoid distribution feeders already saturated with PV generation. 


\subsubsection{Additional Incentives}

Beyond many substantial market preparation and market creation policies and incentives, Hawaii has several smaller opportunities that work together to encourage investment throughout the state. For example, the Green Building Incentive, which often includes distributed generation, provides priority permit processing. Similarly, several special improvement districts exist that allow property-assessed clean energy (PACE) financing. Combined with available loan programs, energy disclosure requirements, and solar contractor licensing, the Hawaiian state government has worked to reduce uncertainty and risk associated with investment in distributed generation (Hawaii State Energy Office 2014).

\subsubsection{Summary}

As a state with both high costs of electricity and high renewable energy resources, Hawaii is an expected leader for renewable energy generation. Although renewables are already economically competitive, Hawaii's pivotal transition from import dependence to local clean energy calls for a well-coordinated regulatory system. Hawaii built a strong regulatory architecture early on to ensure that energy is well-integrated into economic and resource planning.

The planning agencies took an integrated resource approach in designing the long-term policies, as illustrated by the Hawaii Clean Energy Initiative. However, to implement these long-term goals, Hawaii monitored and adjusted to evolving market conditions, as illustrated by its permitting policies that have expanded to accommodate growing penetration levels.

Hawaii leveraged funding and resources from the federal government by establishing partnerships in many of its energy plans - from the 1981 Integrated Resource Study to the 2008 Hawaii Clean Energy Initiative. It also worked within local conditions by working closely with the regulated utilities to develop island-specific targets and policies, such as net metering caps. In addition, Hawaii implemented digital tools — such as the Locational Value Maps, the Integrated Interconnection Queue, and the Renewable Energy Permitting Wizard — to increase informational transparency and efficiency.

An aggressive RPS of $40 \%$ generation from renewables by 2030 , combined with net metering, significant tax incentives, potential FITs, and financing programs, makes Hawaii an attractive state for investment. Although generation has grown substantially over the last decade, Hawaii still faces many constraints in realizing its energy transition. However, the renewable energy target still faces many constraints. For example, utilities are currently struggling to accommodate high penetration of renewables and have been resorting to more and more curtailment, limitations on new distributed generation systems on a per-circuit level, and increased fees on renewable energy generators to compensate for the distribution costs on the grid. Grid solutions, including building an undersea transmission line, are relatively large investments to enable the state's clean-energy goals.

Overall, the state and its residents remain supportive of renewable energy investments and continue to identify incentives and policies that encourage responsible development. 


\subsection{San Francisco}

\subsubsection{Overview}

San Francisco is located on the West Coast of the United States at the north end of the San Francisco Peninsula in California. The climate in San Francisco is characterized by dry summers and rainy, yet mild, winters. Both San Francisco and the State of California have prioritized focusing government resources on developing renewable energy and towards mitigating climate change. Under state and municipal directives, San Francisco has established some of the most aggressive sustainability targets in the country, including renewable energy, energy efficiency, transportation, green infrastructure, and recycling initiatives.

With a relatively high cost of electricity, abundant solar resource, and supportive policies from the State of California overall, renewable energy investment has grown rapidly in the last several years. Already receiving more than $41 \%$ of its electricity from renewable resources due to extensive hydroelectricity, San Francisco chose to embrace a 100\% renewable electricity generation target.

\subsubsection{Background}

\subsubsection{Economic and Demographic Context}

San Francisco, CA, is a city of about 46.9 square miles consisting of a census-estimated 2013 population of 837,442 people. It has a population density of 17,867 people per square mile (6,898 people per square kilometer), making it the second most densely populated city in the United States after New York City.

The city has a diversified service economy, with significant representation by financial services, high technology, and other professional services. The city is part of the San Francisco Bay Area, a metropolitan region renowned for being a hub for clean technology innovation and investment, particularly in the Silicon Valley area. The city of San Francisco itself has more than 200 clean tech companies (SFCED 2013).

San Francisco has one of the top per capita personal incomes in the country, as well as a median household income of $\$ 75,000 /$ year, which is well above the national average. However, it also has an acute and growing wealth gap and high cost of living.

Table 9 shows selected information on San Francisco's demography and economy. 
Table 9. San Francisco Demographic and Economic Indicators

\begin{tabular}{|c|c|c|}
\hline & San Francisco & USA \\
\hline Total Population & 837,442 & $316,128,839$ \\
\hline Area $\left(\right.$ miles $\left.^{2}\right)$ & 46.9 & $3,805,943$ \\
\hline Area $\left(\mathrm{km}^{2}\right)$ & 121.4 & $9,857,306$ \\
\hline Population per Mile ${ }^{2}$ & 17,867 & 991 \\
\hline Population per $\mathrm{Km}^{2}$ & 6,898 & 34.2 \\
\hline Median Household Income (\$) & 75,604 & 53,046 \\
\hline Per Capita Personal Income (\$) & 48,486 & 44,765 \\
\hline Current-dollar GDP (\$ billion) & 388.27 & 16,768 \\
\hline GDP Per Capita (\$) & 78,844 & 53,001 \\
\hline
\end{tabular}

Sources: The U.S. Census Bureau 2013 data http:/quickfacts.census.gov/qfd/states/06/0667000.html

The U.S. Bureau of Economic Analysis (BEA) 2013 data http://www.bea.gov/regional/index.htm

\subsubsection{Energy and Resources}

California has high power demands to meet its large economy, and thus, it imports about onefourth of its electricity from out of state. San Francisco consumes about 6,000 GWh of electricity annually, with a peak load of about 970 MW (Murray 2012). The San Francisco Public Utilities Commission (SFPUC) provides the municipal power supply through San Francisco's hydroelectric power plant, as well as from local solar and biogas facilities. The city shut down the last fossil fuel plant within the city limits in 2011. San Francisco imports some of its power through the investor-owned utility Pacific Gas and Electric (PG\&E), which supplies almost all residential and commercial users in the city. A number of third-party suppliers serve the remaining customers in San Francisco through direct business-to-business sales. Direct Access service is available to all non-residential customers and residential customers.

San Francisco households consume an average of about 4,200 kWh per year, compared to the national average of 11,496 kWh/year (Murray 2012). However, San Francisco area's electric rates are high, with an average residential electricity price of $\$ 0.22 / \mathrm{kWh}$, almost twice the national average of $\$ 0.12 / \mathrm{kWh}$ (U.S. Bureau of Labor Statitics 2014).

San Francisco has relatively good solar potential, with an insolation of average insolation of 4.46 $\mathrm{kWh} / \mathrm{m}^{2} /$ day. ${ }^{28}$ Solar power in California and San Francisco has been growing rapidly because of good resources and favorable policies. In 2013, with 2,746 MW of solar electric capacity and 8,544 MW of solar energy installation, California ranked the top solar state in the country (SEIA 2013). According to the Mayor's office, San Francisco has 15.7 MW of solar generating capacity, including $7.7 \mathrm{MW}$ of municipal generation.

San Francisco's hydropower plants at the Hetch Hetchy reservoir in Yosemite have a generating capacity of 385 MW, providing for 99\% of San Francisco's renewable supply. However, prolonged drought conditions could affect hydropower generation. In addition to solar and hydro,

${ }^{28}$ More information on SF Solar power map is available at: http://www.sfog.us/solar/sfsolar.htm 
SFPUC also provides about 3.1 MW of biomass and biowaste generation from its wastewater treatment plants (San Francisco Public Utilities Commission 2013).

In 2010, San Francisco's electricity supply was already 41\% renewable, consisting of hydroelectric, solar, wind and biogas facilities. A state RPS that required that utilities and electricity service providers meet $20 \%$ of their demand with eligible renewable resources by 2010 and $33 \%$ by 2020 . The chart below shows information on the supply mix from San Francisco's electricity providers.

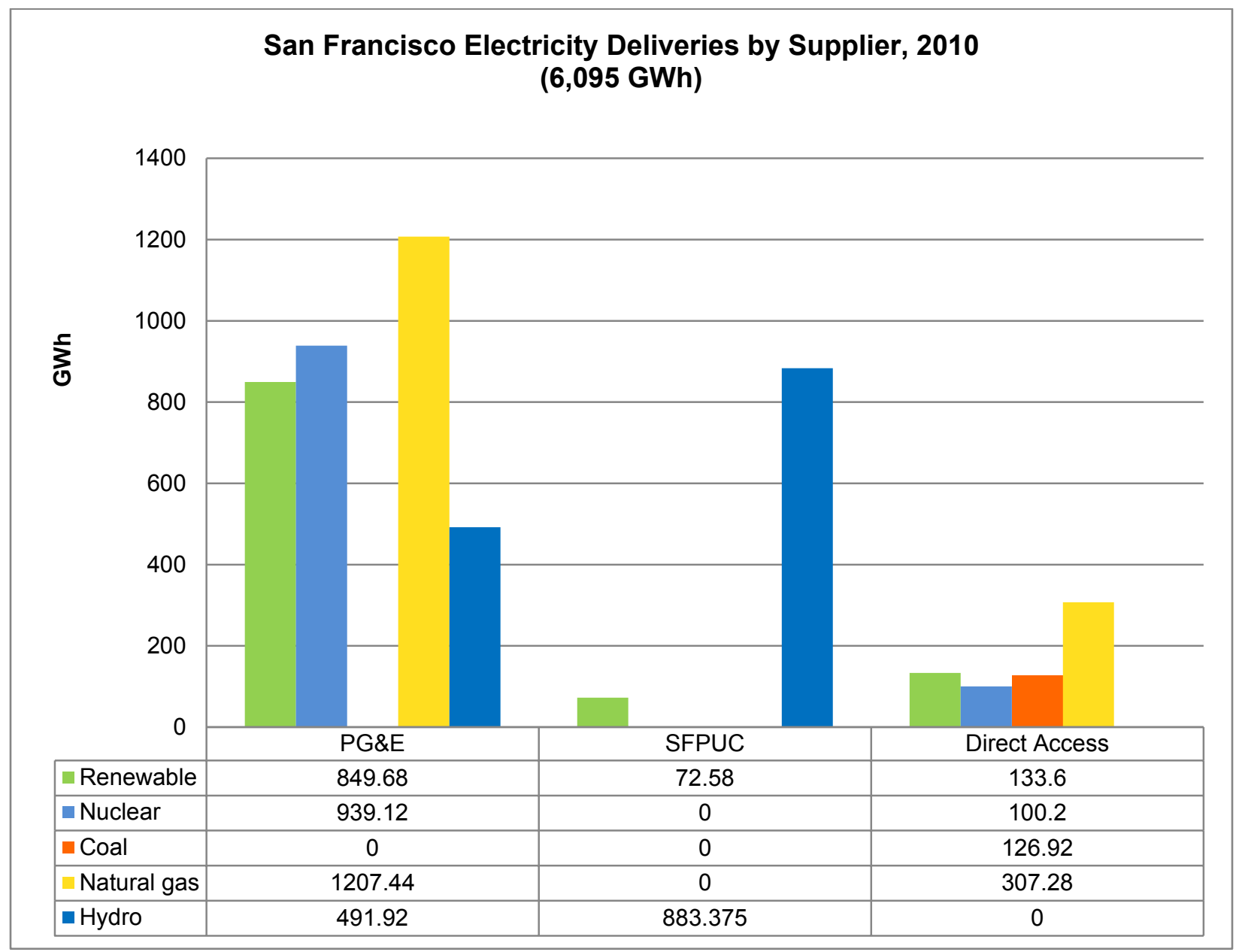

Source: Murray 2012

Figure 28. San Francisco electricity deliveries by supplier

\subsubsection{Stakeholders}

San Francisco is the only consolidated city-county in California. The Board of Supervisors acts as the city council. It is the legislative branch of the city government, responsible for establishing city policies and adopts ordinances and resolutions.

The San Francisco Public Utilities Commission provides and oversees retail water and wastewater services within San Francisco, as well as supplying power to the city's municipal facilities. It owns and operates the City's hydroelectric power plants as well as solar and biogas assets. It has also been selected to administer the CleanPowerCF program. 
The California Public Utilities Commission (CPUC) regulates the state's investor-owned utilities, such as PG\&E, the largest investor-owned utility in California. It creates and administers programs to help the state reach both its RPS goals and greenhouse gas emissions standards.

\subsubsection{Policies and Development}

In 2010, San Francisco Mayor Newsom proclaimed a goal for the city to reach $100 \%$ renewable power within ten years. The aggressive target underscores decades of progressive environmental and sustainability initiatives in San Francisco.

In 2002, the San Francisco municipal government endorsed the 2002 Energy Resource Plan, which set in motion the phase-out of fossil-fuel production within San Francisco by closing down two high-polluting fossil-fuel generators. Other goals in the plan (including reducing greenhouse gas emissions, encouraging renewable development, and increasing energy efficiency) were subsequently adopted by the State of California. The Global Warming Solutions Act (AB 32 2006) set forth a statewide greenhouse gas reduction target to 1990 levels by 2020, representing a $25 \%$ decrease in emissions. The multi-faceted implementation plan incorporated energy efficiency, a cap-and-trade program, transportation and fuel standards, and an RPS.

Meanwhile, San Francisco has adopted a number of city-level initiatives that complement state and federal policy, including the goal of reducing greenhouse gas emissions by $25 \%$ below 1990 levels by 2017 , and $40 \%$ by 2025 (White House 2014). The $100 \%$ renewable electricity target has been incorporated into the city's Climate Action Strategy, ${ }^{29}$ tying its power generation directly to greenhouse gas reduction.

To meet the goal of 100\% renewable energy, the city has identified a need for coordinated effort in three distinct areas: energy efficiency, distributed generation, and a 100\% renewable power purchasing option. The city recognizes that public policy will be necessary to encourage and enable these strategies and that funding will be required to encourage investment in renewable energy citywide.

The first step toward reaching a goal of $100 \%$ renewable energy does not relate to renewable energy itself, but instead, focuses on energy efficiency and a reduction of electricity generation needed. Following a focus on energy efficiency, the city recognized a need to encourage distributed generation. One recognized challenge is that two-thirds of all residential units are in multi-family buildings and over $60 \%$ of households rent. When renters are responsible for energy bills, the property owners have limited incentive to invest in either energy efficiency or solar power. Overcoming these split incentives will be key toward experiencing widespread success with distributed generation. Potential avenues of success include FITs, virtual net metering, and community solar or green leases.

${ }^{29}$ The Climate Action Strategy is available at: http://sfenvironment.org/sites/default/files/engagement files/sfe cc ClimateActionStrategyUpdate2013.pdf 


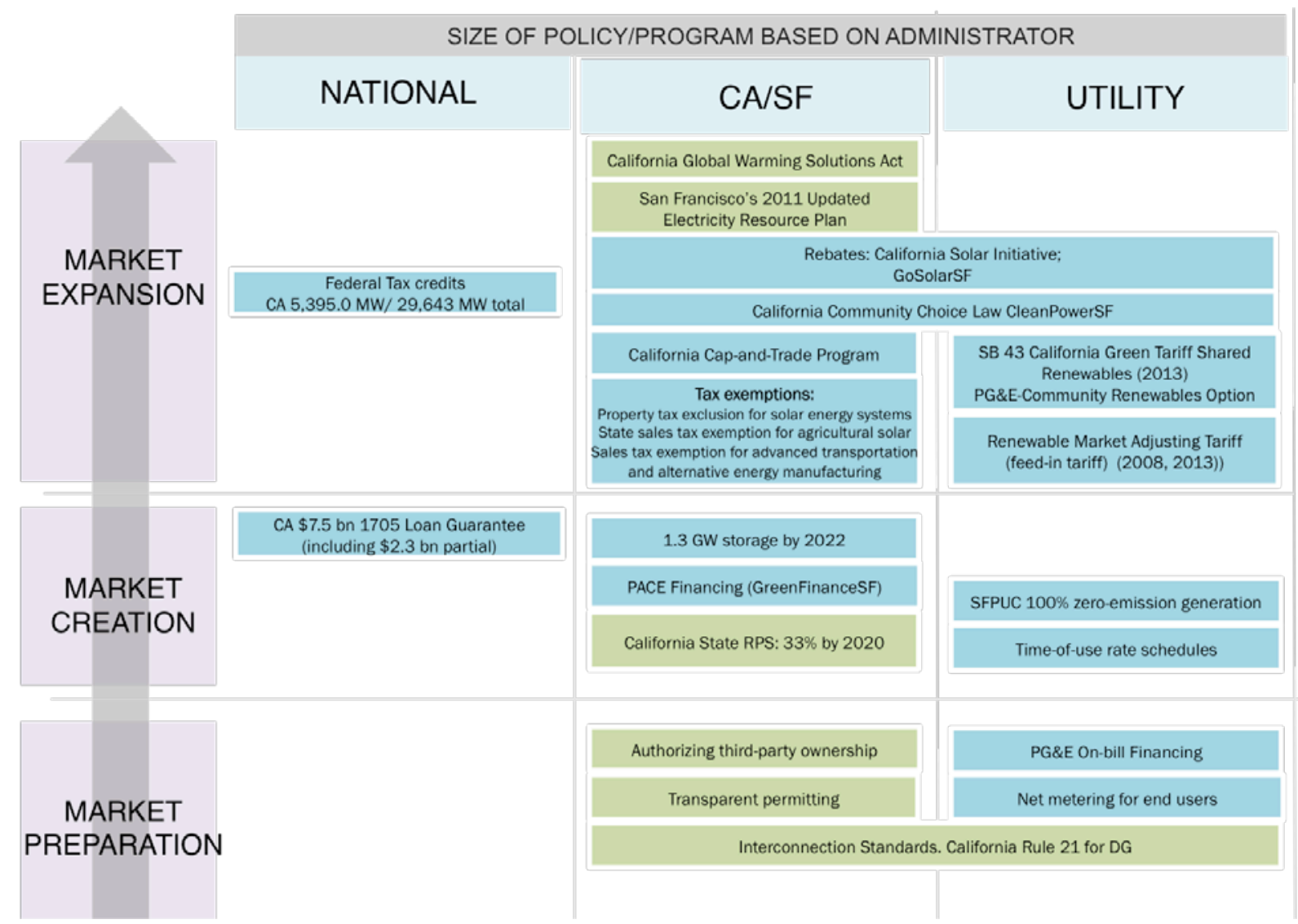

Figure 29. Summary of policies under the stacking framework for San Francisco, CA

\subsubsection{Market Preparation}

\subsubsection{Transparent Permitting}

Beginning in 2004, San Francisco instituted priority permitting for solar installations. The city has since worked to streamline the solar permitting process to reduce transaction time as well as overall installation costs. Policies enacted included over-the-counter permits for qualifying systems under $15 \mathrm{~kW}_{\mathrm{DC}}$, as well as reduced fees and the use of online permitting tools. The city recognized that reducing the pain points from a governmental oversight point of view will increase the likelihood that consumers and investors choose to install renewable energy systems.

In support of this goal, San Francisco adopted the California statewide, publically available California Solar Permitting Guidebook, ${ }^{30}$ which clearly outlines the permitting process, roles, responsibilities, and timelines. By ensuring that installers, financiers, and other solar market players clearly understand the permitting process, risk, delays, and dissatisfaction is reduced.

\subsubsection{Net Metering}

California established a law as early as 1996 requiring almost all utilities to offer their customers the option to net meter distributed generation systems $1 \mathrm{MW}$ and less. ${ }^{31}$ The program limits have

\footnotetext{
${ }^{30}$ The California Solar Permitting Guidebook is developed by the Governor's Office and is available at: http://energycenter.org/sites/default/files/docs/nav/policy/research-and-reports/California Solar Permitting Guidebook 2014.pdf ${ }^{31}$ With the exception of publicly owned electric utilities with more than 750,000 customers that also provide water. Only Los Angeles Department of Water and Power qualifies for this exemption.
} 
evolved since then, with the latest one in 2013 designating a specific MW cap for each of the largest utilities in the state for 2017. Each investor-owned utility designs its own net metering program and rates.

California also allows virtual net metering for all multi-tenant properties with distributed generation. The program was first a pilot at special housing units, but was expanded to include more participants. By allowing bill credits to be distributed across all the tenants' electric bills, virtual net metering opens the market to multi-tenant buildings. Virtual net metering may expand the distributed solar generation market in San Francisco, where about two-thirds of all households live in buildings and nearly all solar installations have been on single-family homes (SFEnvironment 2013).

\subsubsection{Right to Access}

The Solar Rights Act was enacted as early as 1978, prohibiting restrictions by homeowner associations on the installation of solar energy systems. The act was subsequently amended to prevent any public entities from restricting the installation of solar systems.

\subsubsection{Interconnection Standards}

In 2000, CPUC issued "Rule 21," a set of utility interconnection requirements for distributed generation. In 2012, the CPUC approved a redesign of the requirements, which examines the influence of high-penetration PV integration on the grid. In 2015, the CPUC further updated the requirements to include provisions for advanced inverters.

One of the first set of comprehensive procedures for distribution system interconnections, Rule 21 clearly defines the procedures and timelines for approval, as well as the fees and deposits required throughout the interconnection process. It stipulates a "screening process" for utilities to determine the level of study needed, aiming at reducing the cost and increasing the speed of interconnecting distributed systems. A simplified typical interconnection screening process is illustrated in the figure below.

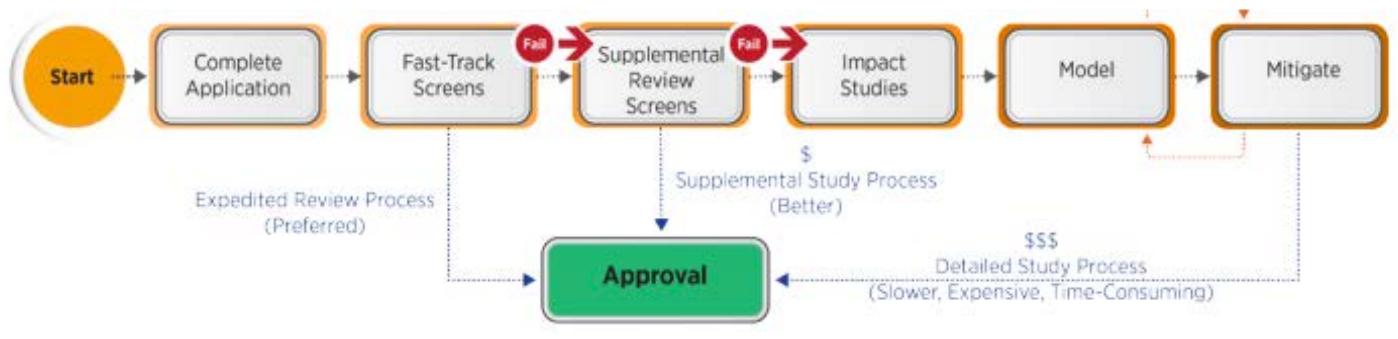

Source: Ardani, Margolis and Nobler 2015

Figure 30. Overview of interconnection screening process used in select states in the United States (simplified)

Under Rule 21, all projects up to $2 \mathrm{MW}$ in size are eligible for fast-track processing. The application review and approval process is required to not exceed a total of 25 days for systems up to $2 \mathrm{MW}$, including 15 days for initial screens and 10 days for completeness review. Investor-owned utilities are required to submit quarterly reports on approval delays to the CPUC. After review of these reports, the CPUC can impose penalties and order changes in process based 
on assessment of the circumstances. A sample of projects from 2012-2014 shows that about 37\% of California's residential projects and $47 \%$ of small commercial projects exceeded the approval times required (Ardani, Margolis and Nobler 2015).

\subsubsection{Third-Party Ownership}

The majority of California's distributed solar installations in recent years have been under thirdparty ownership. California determined that third-party-owned systems are not electrical corporations and are exempt from PUC regulation. It allows third-party owners to sell to residential customers on an individual basis, as well as multi-family housing units that are net metered (Kollins, Speer and Cory 2010).

\subsubsection{Market Creation}

\subsubsection{RPS}

California created the first renewable energy goal in 2002, and subsequently revised it in 2008 before passing it as a law in 2011. The RPS set a goal of 33\% renewables by 2020 for all of the state's electricity retailers, including investor-owned utilities. Interim goals include $20 \%$ by 2013 , and $25 \%$ by 2016.

Renewable energy tracking occurs through the Western Renewable Energy Generation Information System (WREGIS) ${ }^{32}$, which tracks each MWh of electricity generated from a renewable resource used to demonstrate compliance with state RPS policies.

The aggressive RPS has propelled California to become the largest solar market in the United States. For investor-owned utility PG\&E, about $23.8 \%$ of its 2013 retail sales came from nonhydro renewables. This enhances San Francisco's renewable energy mix, but will not be able to meet the $100 \%$ target by 2020 .

\subsubsection{Demonstration Projects Awareness Promotion}

Recognizing that many potential solar users in San Francisco were unaware of San Francisco's solar potential, the city developed resources to provide clear and accessible information to promote the value of solar energy. The San Francisco Solar Map web portal, launched by the San Francisco Department of the Environment, offers a platform for users to find the solar potential of rooftops in the city, evaluate the economics based on site selection, and find information and guidelines on installing a system. It has since evolved into the San Francisco Energy Map, incorporating wind energy and existing installations. ${ }^{33}$

In 2004, through high-profile solar installations on municipal buildings, such as the Moscone Convention Center, the city increased the visibility of the technology and practice. This serves to both create an initial market and educate and promote awareness. The $7.5 \mathrm{MW}$ of total solar installations on city-owned buildings and select communities by SFPUC further expanded this "lead-by-example" strategy.

Already leading the country in energy storage, California sought to solidify its position by announcing a mandate in 2013 requiring the three large investor-owned utility companies to

\footnotetext{
${ }^{32}$ More information on WREGIS is available at https://www.wecc.biz/WREGIS/Pages/Default.aspx

${ }^{33}$ San Francisco Energy Map is available at: http://sfenergymap.org/
} 
procure $1.3 \mathrm{GW}$ of energy storage by 2020. In 2014, California also announced a $\$ 26.5$ million grant to fund microgrid projects to focus on renewable energy integration.

\subsubsection{Financing}

California was the first state to implement a property-assessed clean energy program in the United States. In San Francisco's PACE financing scheme, GreenFinanceSF, ${ }^{34}$ commercial property owners can secure $100 \%$ financing from an investor for an energy efficiency or renewable PPA and repay the cost of the upgrade over time through their property tax. The program enables better financing rates and terms compared to commercial loans.

\subsubsection{Market Expansion}

\subsubsection{Voluntary Markets and Community Choice Aggregation}

California's Community Choice Aggregation (AB 117) was passed in 2002 as a response to the state's energy crisis. While most other states' CCA focused on reducing cost, California's electricity supply option program also placed an emphasis on clean energy.

State legislation SB 43 created the Green Tariff Shared Renewables Program in 2013. It requires California's three largest utilities to develop green pricing programs allowing consumers the option to pay a premium to purchase clean, renewable generation. The policy in place allows customers the option to invest in renewable energy by buying shares of the electricity generated by new-build renewable projects up to $20 \mathrm{MW}$ in size.

Regardless of the amount of energy efficiency savings realized and distributed generation installed, San Francisco will remain reliant on imported power for the foreseeable future. Although California's investor-owned utilities are required to meet the requirements of the statewide RPS, they are not incentivized to reach $100 \%$ renewable power within ten years.

To support the goal of $100 \%$ renewable power, San Francisco turned to its CCA program, CleanPowerSF, which would allow customers to purchase $100 \%$ renewable energy from energy aggregators for a price premium.

San Francisco's CCA effort started in 2004 and obtained approval by the CPUC. However, it has not yet been fully functional due to conflicting interests and disagreement among San Francisco's regulators.

CleanPowerSF, administered by the San Francisco Public Utilities Commission, has been established as an "opt-out" program where consumers are automatically enrolled and must take action to remove themselves from this purchase program. This differs from opt-in programs, requiring customers to take action to subscribe. Study has shown that the enrollment rates for CCA opt-out programs are much higher than those for opt-in programs (Heeter, Belyeu and Kuskoca-Burns 2014).

\footnotetext{
${ }^{34}$ More information on GreenFinanceSF is available at: https://commercialpace.energyupgradeca.org/county/san francisco/overview
} 


\subsubsection{Rebates and Performance-Based Incentives}

CPUC's Self-Generation Incentive Program (SGIP) was first established as a peak-load reduction program to improve system reliability after the 2001 energy crisis in California. In 2009 , the program was modified to focus on technologies that contribute to greenhouse gas reduction, and set rates to incentivize performance. The rates range from $\$ 0.46$ cents $/ \mathrm{W}$ to $\$ 1.83 / \mathrm{W}$ for fuel cells.

Solar is not included among the eligible technologies for SGIP, but is covered under a separate program known as the California Solar Initiative. This program has a budget of $\$ 2.37$ billion over ten years to reach $1940 \mathrm{MW}$ of installed solar capacity by the end of 2016. The main program, known as the "general market program," used a specific budget ( $\$ 1.95$ billion) and goal $(1750 \mathrm{MW})$ to design a ramp-down incentive structure that adjusted to economies of scale. There are two tiers of incentives:

- Expected performance-based buy-down: For smaller systems $(<50 \mathrm{~kW})$ designed for residential and small businesses; capacity-based payment upfront.

- Performance-based incentive: For systems larger than $30 \mathrm{~kW}$ designed for large commercial, government, and nonprofit; payout based on electricity generation over the course of 5 years.

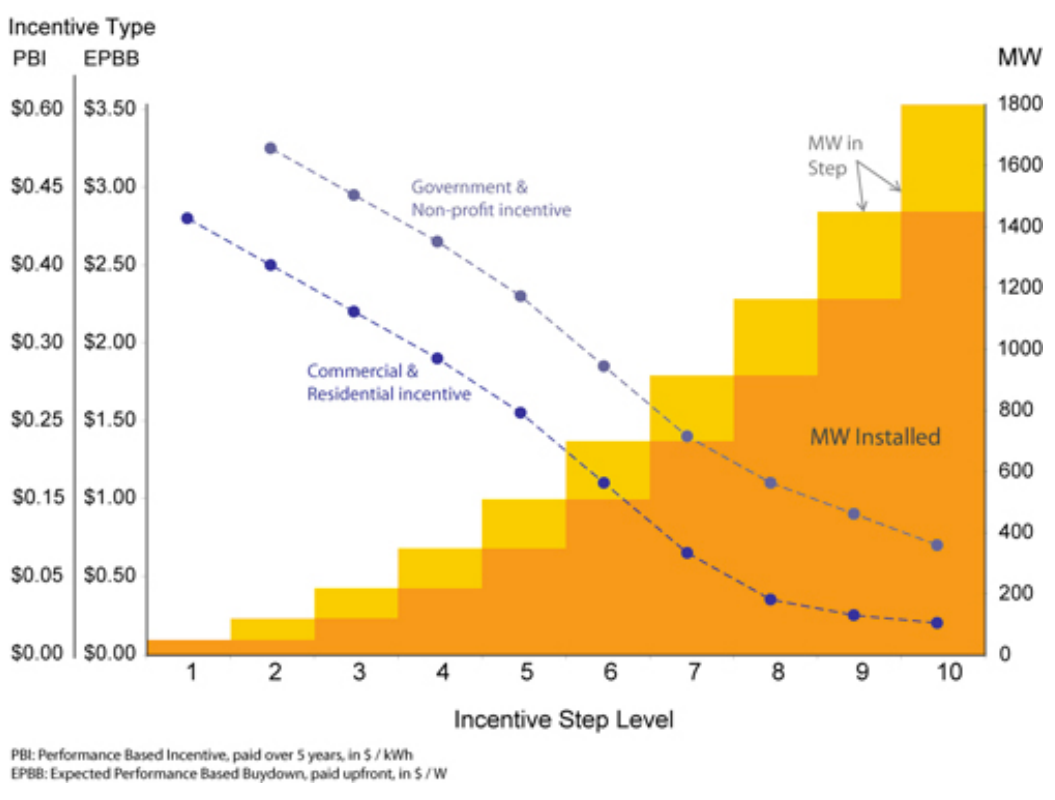

Source: CPUC 2014

Figure 31. Step-level changes under the California Solar Initiative General Market Program 


\section{GoSolar SF}

\section{Program Summary:}

Authorization: Solar Incentive Program ordinance

Administrator: San Francisco Public Utilities Commission Power Enterprise

Budget: 10-year program with annual budget of $\$ 2-\$ 5$ million

Launch date: 2008

Application: Two-step online process

Program cap: $\$ 50,000$, no system size limit

Meter requirement: Basic meter with certified accuracy of $\pm 5 \%$

Installation: 3701 systems (10.1 kW average size) as of April 2014

The City and County of San Francisco, through the SFPUC, has provided one-time incentive payments for installed systems greater than $1 \mathrm{~kW}$ in size under the GoSolarSF program since 2008.

Incentives depend on the property type and system size, ranging from $\$ 500$ per system for a small $1 \mathrm{~kW}$ residential system to as high as $\$ 1,000 / \mathrm{kW}$ (maximum $\$ 50,000$ ) for multi-family residential building owned by a nonprofit. ${ }^{1}$ GoSolarSF is available to residents, businesses, municipal departments, and non-profit organizations, with extra incentives for low-income segments.

\section{INCENTIVE LEVELS FOR FISCAL YEAR 2014-2015}

\begin{tabular}{|c|c|c|c|c|c|c|c|c|c|c|}
\hline Residential & $\begin{array}{l}1 \mathrm{~kW} \text {. } \\
1.24 \mathrm{~kW}\end{array}$ & $\begin{array}{l}1.25 \mathrm{~kW}- \\
1.49 \mathrm{~kW}\end{array}$ & $\begin{array}{l}1.5 \mathrm{~kW} \text { - } \\
1.74 \mathrm{~kW}\end{array}$ & $\begin{array}{l}1.75 \mathrm{~kW} \text {. } \\
1.99 \mathrm{~kW}\end{array}$ & $\begin{array}{l}2 \mathrm{~kW} \text {. } \\
2.24 \mathrm{~kW}\end{array}$ & $\begin{array}{l}2.25 \mathrm{~kW} \text { - } \\
2.49 \mathrm{~kW}\end{array}$ & $\begin{array}{l}2.5 \mathrm{~kW}= \\
2.74 \mathrm{~kW}\end{array}$ & $\begin{array}{l}2.75 \mathrm{~kW} \\
2.99 \mathrm{~kW}\end{array}$ & $\begin{array}{l}3 \mathrm{~kW} \text { - } \\
3.49 \mathrm{~kW}\end{array}$ & $\begin{array}{l}3.5 \mathrm{~kW} \mathrm{\&} \\
\text { larger }\end{array}$ \\
\hline $\begin{array}{l}\text { Select One: } \\
\text { Basic }\end{array}$ & $\$ 500$ & $\$ 650$ & $\$ 1,000$ & $\$ 1,100$ & $\$ 1,300$ & $\$ 1,600$ & $\$ 1,700$ & $\$ 1,900$ & $\$ 2,000$ & $\$ 2.000$ \\
\hline OR & & - & $\cdots \cdots$ & $-\cdots$ & $\ldots-\cdots$ & $\ldots-\cdots$ & - & $\cdots$ & $\ldots-\cdots$ & $\cdots$ \\
\hline $\begin{array}{l}\text { Environmental } \\
\text { Justice }\end{array}$ & $\$ 600$ & $\$ 750$ & $\$ 1100$ & $\$ 1,300$ & $\$ 1,500$ & $\$ 1,900$ & $\$ 2,100$ & 52,300 & $\$ 2,500$ & $\$ 2,800$ \\
\hline $\begin{array}{l}\text { Add on if eligible: } \\
\text { City Installer }\end{array}$ & $\$ 250$ & $\$ 300$ & $\$ 350$ & $\$ 400$ & $\$ 450$ & $\$ 500$ & $\$ 550$ & $\$ 600$ & $\$ 650$ & $\$ 700$ \\
\hline $\begin{array}{l}\text { Add on if elliglble: } \\
\text { Low-income }\end{array}$ & $\$ 2,000$ & $\$ 2,500$ & $\$ 4,000$ & $\$ 4,500$ & $\$ 5,000$ & $\$ 6,000$ & $\$ 6,500$ & $\$ 7,000$ & $\$ 7,000$ & $\$ 7,000$ \\
\hline Nonprofit: & \multicolumn{10}{|c|}{$\$ 1,000 / \mathbf{k W}$. Cap: $\$ 50,000$ cap per service site. } \\
\hline $\begin{array}{l}\text { Nonprofit } \\
\text { residential: }\end{array}$ & \multicolumn{10}{|c|}{ \$1,000/KW. Cap: \$50,000 per service site. } \\
\hline Business: & \multicolumn{10}{|c|}{$\$ 500 / \mathbf{k W}$. Cap: $\$ 10,000$ per meter and $\$ 50,000$ per service site. } \\
\hline $\begin{array}{l}\text { Multi-Unit } \\
\text { Residential } \\
\text { Virtual Net } \\
\text { Metering: }\end{array}$ & \multicolumn{10}{|c|}{$\begin{array}{l}\$ 500 / \mathrm{kW} \text {. Cap: } \$ 500 \text { multiplied by the number of assessed units at the building plus } \$ 10,000 \text {. Under no circumstances } \\
\text { will a service site receive more than } \$ 50,000 \text {. }\end{array}$} \\
\hline
\end{tabular}

Source: San Francisco Public Utilities Commission 2015

Figure 32. GoSolarSF incentive levels 
The incentive can be claimed in addition to any incentive earned through the statewide California Solar Initiative and the federal tax credit. Together, these policies have significantly impacted the growth in the distributed solar market throughout San Francisco over the last several years. By April 2014, GoSolarSF had funded more than 3000 solar systems totaling more than $10 \mathrm{MW}$ in capacity, with about $37 \%$ of residential capacity coming from low-income sites (Jackson 2014).

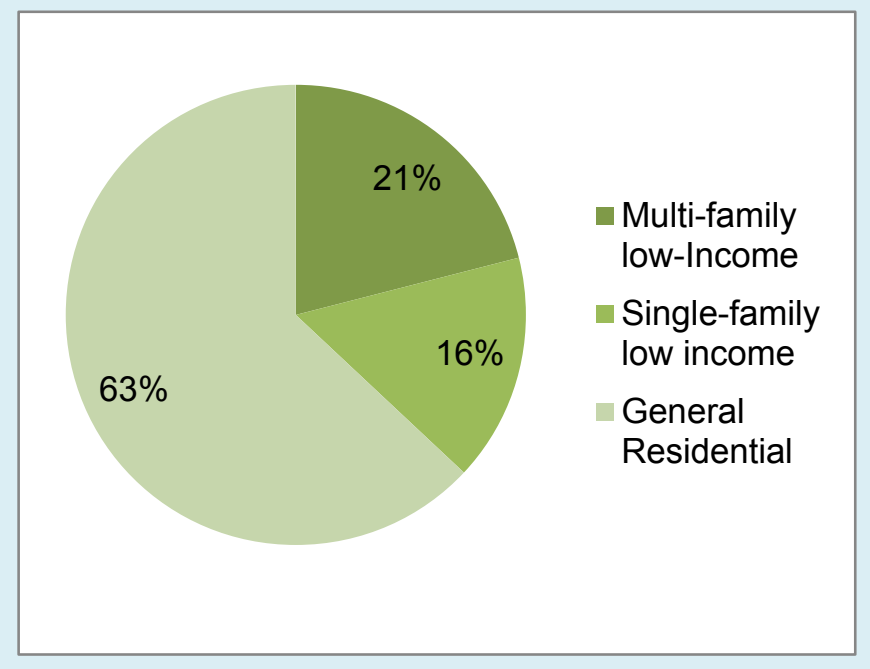

Figure 33. GoSolarSF residential installed capacity by segment

\subsubsection{Tax Exemptions}

California has property tax exclusion for solar energy systems for up to $100 \%$ of the system value. Components also include storage devices. The state also offers a sales tax exemption for agricultural solar systems and for advanced transport technology.

To further bolster its position as a clean tech hub, San Francisco offers up to ten years of payroll tax exclusion for clean technology companies (with less than 100 employees) located within city limits.

\section{Cap-and-Trade}

California's Global Warming Solutions Act of 2006, which called for a return to 1990 levels of greenhouse gas emissions by 2020, gave rise to a statewide cap-and-trade program. The California Air Resources Board established the mandatory cap-and-trade rule in 2011, establishing the first multi-sector system in the country. California has the largest cap-and-trade program in the United States based on emissions trading volume. ${ }^{35}$ Compliance obligation began in 2013 with electricity generators and large industrial facilities, ${ }^{36}$ extending coverage to distributors of transportation, natural gas, and other fuels in 2015.

The cap-and-trade program is designed to be complementary to the RPS in decarbonizing the state economy. The Air Resources Board coordinated closely with REC tracking systems and RPS programs to ensure the greenhouse gas reductions are verifiable and not subject to double-

\footnotetext{
${ }^{35}$ The Regional Greenhouse Gas Initiative (RGGI) applied caps to the power generation sector only

${ }^{36}$ Applicable to entities emitting $25,000 \mathrm{MTCO}_{2} \mathrm{e}$ or more per year.
} 
counting (Hamrin 2014). The Voluntary Renewable Electricity Program under California Capand-Trade supports renewable electricity purchases by setting aside a specific percentage of allowances each year outside of the RPS mandate. ${ }^{37}$

\subsubsection{Summary}

As a leader in renewable deployment and policy, San Francisco has taken California's progressive climate and energy policies and implemented comparatively more advanced sustainability initiatives.

However, due to the climate conditions, existing land use, and city boundaries, San Francisco will continue to have serious difficulty meeting the goal of $100 \%$ renewable energy generation within its geographical borders. High attainment will likely have to come from remote clean energy purchased for direct use by the city. This regional approach could be considered an appropriate model for land-constrained cities.

\section{Conclusion}

As indicated throughout this paper, several distinct mechanisms exist through which a government - whether federal, state, or local — can work to incentivize and encourage renewable energy development. Policies can range from tax credits to payments based on production or on installed capacity. Policy design must be carefully undertaken to understand how one policy may stack on another. On one hand, the design should ensure that the incentive is not so great that the financial liability of the government agency grows larger than intended through flooding the market; on the other hand, the design should ensure that sufficient incentive exists to encourage investors to enter the market at all.

\subsection{Importance of Policy Stacking}

The overall impact on the renewable and new-energy market by policies and incentives implemented by the government will depend on the total number and type of policies implemented. As demonstrated by the case studies, it is important that cities first prepare the market for success, then support the early adopters, and finally lead market expansion through financial benefit.

As demonstrated in the detailed case-study descriptions and summarized in figure 34, some of the most successful states in deploying distributed renewable energy have first established "market preparation" policies, then accomplished "market creation" tasks, and are now pursuing many "market expansion" mechanism. For the clean-energy marketplace to be successful, regulators and policy makers should first provide transparency and certainty for renewable projects. As these underlying policies create enabling environments for encouraging renewable energy, policies can be put in place to help create demand through requirements, financing mechanisms, demonstration, and other programs. After the market exists, the government should focus on providing financial support or incentives to expand and grow investment in new energy. Inefficiencies can occur if financial incentives are set in place before enabling environments exist.

\footnotetext{
${ }^{37}$ More information on the Voluntary Renewable Electricity Program is available at http://www.arb.ca.gov/cc/capandtrade/guidance/chapter7.pdf
} 


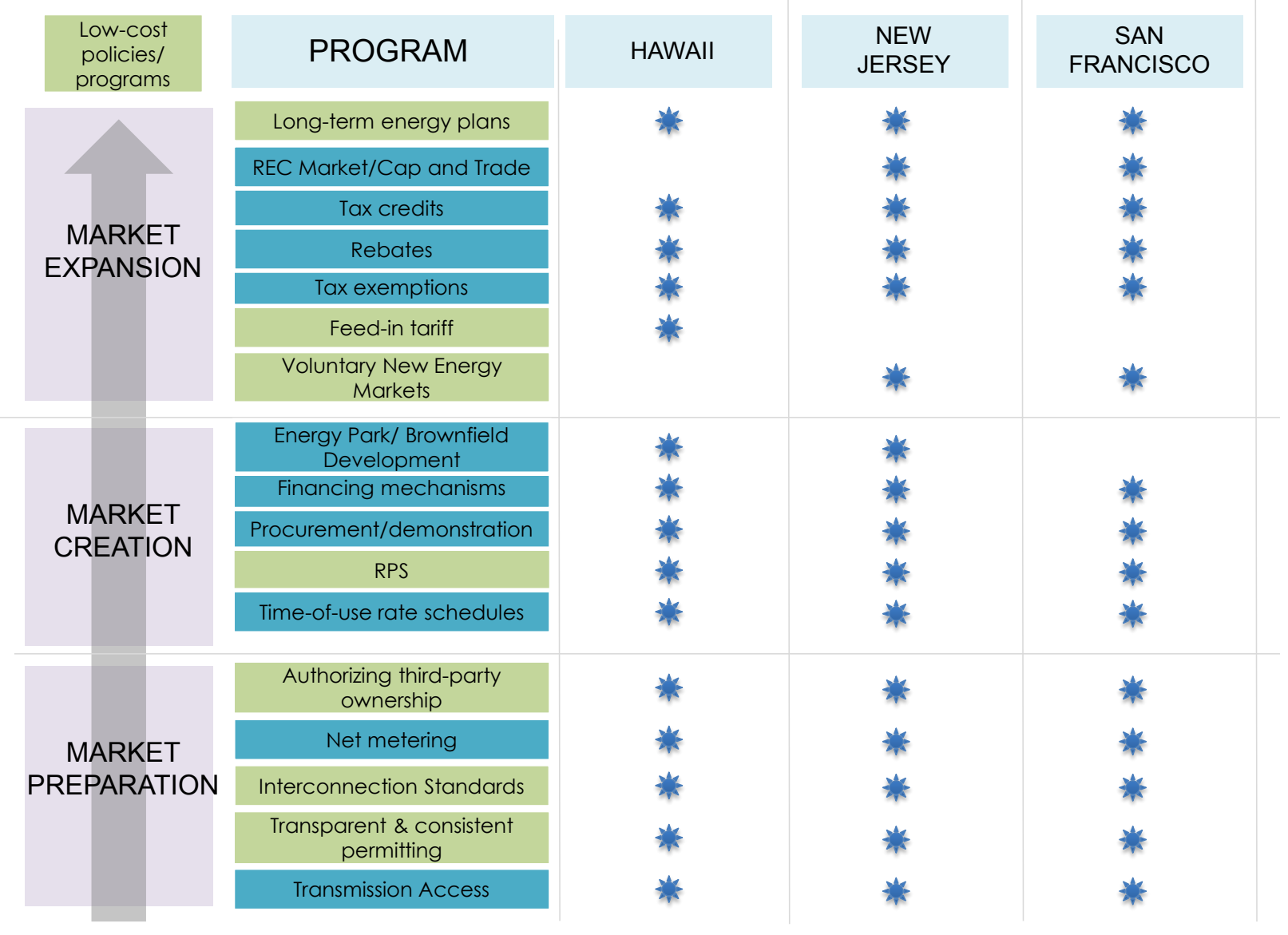

Figure 34. Case studies policy summary

When considering the policies appropriate for a New Energy City, it is important to understand not only if a particular policy would induce the intended outcome but also how one policy may impact another. As discussed above, some policies encourage distributed generation on rooftops, while others encourage utility-scale investments in renewable energy. Similarly, some policies focus more on initial deployment and system size, while others focus on longer-term energy production. Understanding the current market, the need for subsidies, and the appropriate size of each incentive will help ensure that government investment in the support of renewable energy technologies and New Energy Cities is used as effectively as possible. 


\section{References}

American Council for an Energy-Efficient Economy (ACEEE). (2012). On-Bill Financing for Energy Efficiency Improvements.Assessed October 15, 2014: http://aceee.org/files/pdf/toolkit/OBF toolkit.pdf.

Ardani, K; Davidson, C; Margolis, R; Nobler, E. (2015) A State-Level Comparison of Processes and Timelines for Distributed Photovoltaic Interconnection in the United States. NREL/TP-7A40-63556. Golden, CO: National Renewable Energy Laboratory. http://www.nrel.gov/docs/fy15osti/63556.pdf

AWS Truewind,. (2004). "Wind Energy Resource Maps of Hawaii." Accessed January 5, 2015: http://files.hawaii.gov/dbedt/op/gis/data/hawaii_wind_mapping_report.pdf.

Baldick, R. (2012). "Wind and Energy Markets: A Case Study of Texas." IEEE Systems Journal, VOL. 6, NO. 1, pp. 27-34. Accessed November 12, 2014:

http://ieeexplore.ieee.org/stamp/stamp.jsp?arnumber $=6007040$.

Barradale, M. J. (2010). "Impact of public policy uncertainty on renewable energy investment: Wind power and the production tax credit." Energy Policy, 2010: 7698-7709. Accessed October 23, 2014: http://www.sciencedirect.com/science/article/pii/S0301421510006361.

Bureau of Economic Analysis (BEA). (2013). "The U.S. Bureau of Economic Analysis bearfacts : New Jersey." Accessed December 04, 2014: http://bea.gov/regional/bearfacts/action.cfm.

Bifera, L. (2013). "Regional Greenhouse Gas Initiative." Center for Climate and Energy Solutions. Accessed December 3, 2014: http://www.c2es.org/docUploads/rggi-brief-12-18-13-updated.pdf.

Bird, L.; Reger, A.; Heeter, J. (2012). Distributed Solar Incentive Programs:Recent Experience and Best Practice for Design and Implementation. NREL/TP-6A20-56308. Golden, CO: National Renewable Energy Laboratory. Accessed December 11,2014: http://www.nrel.gov/docs/fy13osti/56308.pdf.

Bureau of Labor Statistics (BLS). (2014). "Average Energy Prices, San Francisco-Oakland-San Jose, November 2014." Accessed December 8, 2014: http:/www.bls.gov/regions/west/newsrelease/averageenergyprices sanfrancisco.htm.

Board of Public Utilities State of New Jersey. (2014). Accessed December 20, 2014:

http://www.bpu.state.nj.us/bpu/pdf/boardorders/2014/20141022/10-22-14-8D.pdf.

Busche, S.; Donnelly, C.; Atkins, D.; Fields, R.; Black, C. (2013). Renewable Energy Permitting Barriers in Hawaii: Experience from the Field. NREL/TP-7A20-55630. Golden, CO: National Renewable Energy Laboratory. Accessed December 18, 2014: http://www.nrel.gov/docs/fy13osti/55630.pdf.

Ciarduli, Ralph. (2013). "Renewable Energy Parks: A Blueprint for Locally-Produced Clean Energy." Energy Manager Today. Accessed December 19, 2014: http://www.energymanagertoday.com/renewableenergy-parks-a-blueprint-for-locally-produced-clean-energy-091286/.

California Public Utilities Commission (CPUC). (2012). "Assigned Commissioner's Scoping Memo and Ruling in Application 11-10-002." Accessed December 28, 2014:

http://docs.cpuc.ca.gov/EFILE/RULC/157634.PDF.

California Public Utilities Commission (CPUC). (2014). “About the California Solar Initiative”. Accessed December 29, 2014: http://www.cpuc.ca.gov/puc/energy/solar/aboutsolar.htm. 
Department of Business, Economic Development and Toursim (DBEDT), State of Hawaii. (2014). "Hawaii Energy Facts \& Figures." Accessed December 15, 2014: http://energy.hawaii.gov/wpcontent/uploads/2011/08/HI-Energy-FactsFigures_May2014_2r.pdf.

Department of Treasury. (2015). "Overview and Status Update of the 1603 Program." Accessed Feburary 13, 2015: http://www.treasury.gov/initiatives/recovery/Documents/Status\%20overview.pdf.

Database of State Incentives for Renewables \& Efficiency (DSIRE). (2014). Residential Solar Rights. Accessed March 5, 2015: http://programs.dsireusa.org/system/program/detail/2722.

Energy Information Administration (EIA). (2014a). "Hawaii State Profile and Energy Estimates." Accessed January 25, 2015: http://www.eia.gov/state/?sid=HI.

EIA. (2014b). "Electric Power Monthly." Accessed January 25, 2015:

http://www.eia.gov/electricity/monthly/epm table_grapher.cfm?t=epmt 5 _6 a.

EIA. (2013a). "Feed-in tariff: A policy tool encouraging deployment of renewable electricity technologies." Today In Energy. Accessed January 22, 2015:

http://www.eia.gov/todayinenergy/detail.cfm?id=11471.

EIA. (2013b). "New Jersey State Profile and Energy Estimates." Accessed December 24, 2014 : http://www.eia.gov/state/analysis.cfm?sid=NJ.

Forsyth, T.L.; Pedden, M.; Gagliano, T. (2002). The Effects of Net Metering on the Use of Small-Scale Wind System in the United States. NREL/TP-500-32471 Technical Report, Golden, CO: National Renewable Energy Laboratory. Accessed December 18, 2014: http://www.nrel.gov/docs/fy03osti/32471.pdf.

Friedman, B.; Ardani, K.; Feldman, D.; Citron, R.; Margolis, R. (2013). Benchmarking Non-Hardware Balance-of-System(Soft) Costs for U.S. Photovoltaic System, Using a Bottom-Up Approach and Installer Survey - Second Edition. NREL/TP-6A20-60412. Golden, CO: National Renewable Energy Laboratory. Accessed December 22, 2014: http://www.nrel.gov/docs/fy14osti/60412.pdf.

GeothermEx, Inc. (2005). "Assessment of Energy Reserves and Costs of Geothermal Resources in Hawaii." Accessed January 21, 2015: http://energy.hawaii.gov/wp-

content/uploads/2011/10/AssessmentOfEnergyReservesAndCostsOfGeothermalResourcesInHawaii.pdf.

Hamrin, J. (2014). REC Definitions and Tracking Mechanisms Used by State RPS Programs. Clean Enegy States Alliance. Accessed Feburary 10, 2014: http://www.cesa.org/assets/2014-Files/RECsAttribute-Definitions-Hamrin-June-2014.pdf.

Hartcourt Brown \& Carey. (2013). On-Bill Financing in Hawaii. Hawaii PUC. Accessed December 6, 2014: http://dms.puc.hawaii.gov/dms/DocumentViewer?pid=A1001001A13A04B61718B06948.

Hawaii State Energy Office. (2014). "GEMS Overview." Accessed January 20, 2015 :

http://energy.hawaii.gov/testbeds-initiatives/gems/gems-overview.

Hawaii State Energy Office. (2011). "State of Hawaii - Energy Policy Directives." Accessd November 2, 2014: http://energy.hawaii.gov/energypolicy.

Hawaiian Electric Companies (HECO). (2013a). "2013 Renewable Portfolio Standard Status Report." Accessed December 1, 2014: http://puc.hawaii.gov/wp-content/uploads/2013/07/RPS-HECO-2013.pdf. 
HECO. (2013b). "Biomass." Accessed December 1, 2014: http://www.hawaiianelectric.com/meco/CleanEnergy/Renewable-Energy-Basics/Biomass.

HECO. (2013c). "Biofuels." Accessed December 1, 2014: http://www.hawaiianelectric.com/helco/CleanEnergy/Renewable-Energy-Basics/Biofuels.

HECO. (2014a). "Hawaiian Electric Companies submit plans for Energy Future of Hawaii." Accessed January 20, 2015: http://www.hawaiianelectric.com/heco/ hidden_Hidden/CorpComm/HawaiianElectric-Companies-submit-plans-for-Energy-Future-of-Hawaii.

HECO. (2014b). "Reducing Time and Cost of an Interconnection Study." Accessed December 2, 2014: http://www.hawaiianelectric.com/heco/ hidden Hidden/CorpComm/Reducing-Time-and-Cost-of-anInterconnection-Study?cpsextcurrchannel=1.

HECO. (2014c). "All electricity customers will help finance Hawaii's clean energy future." Accessed January 2, 2015: http://www.hawaiianelectric.com/heco/ hidden_Hidden/CorpComm/All-electricitycustomers-will-help-finance-Hawaii $\% 27 \mathrm{~s}$-clean-energy-future.

HECO. (2015a). "Net Energy Metering for Hawaii Island."Accessed Febuary 2, 2015:

http://www.hawaiielectriclight.com/helco/Clean-Energy/Clean-Energy-Generation/Net-Energy-Meteringfor-Hawaii-Island\#bk10.

HECO. (2015b). "Residential EV Pilot Rates." Accessed Febuary 12, 2015:

http://www.hawaiianelectric.com/heco/ hidden_Hidden/Renewable-Energy/Residential-EV-PilotRates?cpsextcurrchannel=1.

Heeter, J.; Barbose, G.; Bird, L.; Weaver, S.; Flores-Espino, F.; Kuskova-Burns, K.; Wiser, R. (2014). $A$ Survey of State-Level Cost and Benefit Estimates of Renewable Portfolio Standards. NREL/TP-6A2061042, National Renewable Energy Laboratory and Lawrence Berkeley National Laboratory. Accessed December 5, 2014: http://www.nrel.gov/docs/fy14osti/61042.pdf.

Heeter, J.; Belyeu, K.; Kuskoca-Burns, K. (2014). Status and Trends in the U.S. Voluntary Green Power Market (2013 Data). NREL/TP-6A20-63052. Golden, CO: National Renewable Energy Laboratory. Accessed December 8, 2014: http://www.nrel.gov/docs/fy15osti/63052.pdf.

Heeter, J.; Gelman, R.; Bird L. (2014). Status of Net Metering: Assessing the Potential to Reach Program Caps. NREL/TP-6A20-61858. Golden, CO: National Renewable Energy Laboratory. Accessed December 9, 2014: http://www.nrel.gov/docs/fy14osti/61858.pdf.

Hotchkiss, E.; Metzger, I.; Salasovich, J.; Schwabe, P. (2013). Alternative Energy Generation Opportunities in Critical Infrastructure New Jersey. NREL/TP-7A40-60631.Golden, CO: National Renewable Energy Laboratory. Accessed December 9, 2014: http://www.sustainablejersey.com/fileadmin/media/Events and Trainings/Add Event/2013/HMGP Wor kshop/FEMA_GORR Proposal from NREL FINAL.pdf.

Jackson, R. (2014). "GoSolarSF Progress Report: Economic \& Environmental Benefits of San Francisco’s Solar Program." Votesolar. Accessed January 5, 2015:

http://votesolar.org/2014/06/23/gosolarsf-progress-report-economic-environmental-benefits-of-sanfranciscos-solar-program/. 
Kollins, K.; Speer, B.; Cory, K. (2010). Solar PV Project Financing:Regulatory and Legislative Challenges for Third System Owners. NREL/TP-6A2-46723. Golden, CO: National Renewable Energy Laboratory. Accessed December 13, 2014: http://www.nrel.gov/docs/fy10osti/46723.pdf.

Krasko, V.; Doris, E. (2013). "State distributed PV policies: Can low cost (to government) policies have a market impact?" Energy Policy; pp.172-181.Accessed December 29, 2014:

http://www.sciencedirect.com/science/article/pii/S0301421513001699.

Kreycik, C. (2011). "Financing Solar PV at Government Sites with PPAs and Public Debt." Golden, CO: National Renewable Energy Laboratory. Accessed December 12, 2014:

https://financere.nrel.gov/finance/content/financing-solar-pv-government-sites-ppas-and-public-debt.

Lantz, E.; Doris, E. (2009). State Clean Energy Practices:Renewable Energy Rebates. NREL/

TP-6A2-45039. Golden, CO: National Renewable Energy Laboratory. Accessed December 12, 2014: http://www.nrel.gov/docs/fy09osti/45039.pdf.

Lopez, A.; Roberts, B.; Heimiller, D.; Blair, N.; Porro, G. (2012). U.S. Renewable Energy Technical Potentials: A GIS-Based Analysis. NREL/TP-6A20-51946 Golden, CO: National Renewable Energy Laboratory. Accessed December 12, 2014: http://www.nrel.gov/docs/fy12osti/51946.pdf.

Meister Consulting Group. (2014). "Solar Development Volatility In New Jersey." Accessed Febuary 15, 2015: http://www.njcleanenergy.com/files/file/public_comments/MCG\%20$\%$ 20SEA $\% 20$ Solar $\% 20$ Market $\% 20$ Development $\% 20$ Volatility $\% 20$ Report $\% 20$ -

$\% 20$ Discussion $\% 20$ Draft.pdf.

Murray, D. (2012). "San Francisco Mayor's Renewable Energy Task Force Recommendations Report San Francisco" San Francisco Department of Environment. Accessed November 14, 2014 :

http://www.sfenvironment.org/sites/default/files/fliers/files/sfe re renewableenergytaskforcerecommenda tionsreport.pdf.

Natual Energy Laboratory of Hawaii Authority (NELHA). (2011). "NELHA Master Plan." 2011.

Accessed December 14, 2014: http://nelha.hawaii.gov/wpcontent/uploads/2013/05/NELHA_Master_Plan_Final_Nov11.pdf.

New Jersey Agricultural Experiment Station. (2014). "Assessment of Biomass Energy Potential in New Jersey." Vers. 2. Rutgers University. Accessed January 6, 2015: http://bioenergy.rutgers.edu/biomassenergy-potential/NJAES\%20Biomass\%20Assessment $\% 202 \% 200$.pdf.

New Jersey Board of Public Utilities. (2007). "In the matter of the Renewable Energy Portfolio Standards -Alternative Compliance Payments and Solar Alternative Compliance Payments ." 2007. Accessed December 4, 2014: http://www.njcleanenergy.com/files/file/9-12-07-8E.pdf.

New Jersey Board of Public Utilities (BPU). (2014a). "Metering Requirements." Accessed January 12, 2015: www.njcleanenergy.com/renewable-energy/programs/metering-requirements.

New Jersey Board of Public Utilities (BPU). (2014b). "Utility Financing Programs." Accessed December 23, 2014: http://www.njcleanenergy.com/renewable-energy/programs/utility-financing-programs/utilityfinancing-programs.

New Jersey Board of Public Utilities (BPU). (2014c). "Previous Programs." Accessed Dec 23, 2014: http://www.njcleanenergy.com/renewable-energy/programs/2008-programs/2008-programs. 
NREL. (2005). Overcoming Net Metering and Interconnection Objections New Jersey MSR Partnership. Golden, CO: National Renewable Energy Laboratory. Accessed Novermber 12, 2014 : http://www.nrel.gov/docs/fy05osti/38666.pdf.

Pacific International Center For High Technology Research (PICHTR). (2013). Hawaii Geothermal Assessment and Roadmap. Hawaii Natural Energy Institute. Accessed Febuary 2, 2015:

http://www.hnei.hawaii.edu/sites/dev.hnei.hawaii.edu/files/Hawaii\%20Geothermal\%20Assessment\%20an d\%20Roadmap_Jan\%202013.pdf.

Ramseur, JL. (2014). The Regional Greenhouse Gas Initiative: Lessons Learned and Issues for Policy Makers. Congressional Research Service. Accessed January 19, 2015:

http://fas.org/sgp/crs/misc/R41836.pdf.

Reiter, E and Ardani, K. (2015) “A New Breed of Interconnection Reporting: Hawaii’s Integrated Interconnection Queue" Accessed April 1, 2015:

http://www.nrel.gov/tech_deployment/dgic_interconnection_insights_2015-03.html

San Francisco Center for Economic Development (SFCED). (2013). "Environmental \& Cleantech." Accessed Dec 25, 2014: http://sfced.org/case-for-business/sectors/environmental-green-business/.

San Francisco Department of the Environment. (2013). "Virtual Net Energy Metering at Multitenant Buildings." Accessed January 17, 2015:

http://sfenvironment.org/sites/default/files/fliers/files/virtual net energy metering at multitenant buildi ngs 0.pdf.

San Francisco Public Utilities Commission. (2013). "Where Your Hetch Hetchy Power Comes From?" Accessed January 20, 2015: http://www.sfwater.org/modules/showdocument.aspx?documentid=6275.

San Francisco Public Utilities Commission. (2015). GoSolarSF Program Handbook

Fiscal Year 2014-2015. Accessed April 2015:

http://www.sfwater.org/modules/showdocument.aspx?documentid=5698.

Sherwood, L. (2014). "The What \& Why of Solar Trends." Interstate Renewable Energy Council.

Accessed January 20, 2015: http://www.irecusa.org/2014/08/the-what-why-of-solar-trends/.

Solar Energy Industry Association (SEIA). (2013). "California Solar." Accessed December 23, 2014 : http://www.seia.org/state-solar-policy/california.

Solar Energy Industries Association (SEIA). (2014). "Third-Party Solar Financing." Accessed January 27, 2015: http://www.seia.org/policy/finance-tax/third-party-financing.

State of New Jersey. (2011). New Jersey Energy Master Plan. Office of the Governor. Accessed January 5, 2015: http://nj.gov/emp/docs/pdf/2011_Final_Energy_Master_Plan.pdf.

Steinberg, D.; Porro,G.; Goldberg, M. (2012). Preliminary Analysis of the Jobs and Economic Impacts of Renewable Energy Projects Supported by the \$1603 Treasury Grant Program. NREL/TP-6A20-52739. Golden, CO: National Renewable Energy Laboratory. Accessed Novermber 12, 2014 : http://www.nrel.gov/docs/fy120sti/52739.pdf.

U.S. Census Bureau. (2012). "Statistical Abstract of the United States.: 2012." Accessed December 10, 2014: https://www.census.gov/compendia/statab/2012/tables/12s0364.pdf. 
U.S. Census Bureau. (2013). "The U.S. Census Bureau State \& County QuickFacts: New Jersey." Accessed December 15, 2014: http://quickfacts.census.gov/qfd/states/34000.html.

Weissman, S.; Nathaniel, J. (2012)."The Statewide Benefits Of Net-Metering In California." Accessed January 14, 2015: https://www.law.berkeley.edu/files/The_Statewide_Benefits_of_Net-

Metering_in_CA_Weissman_and_Johnson.pdf.

White House. (2014). "FACT SHEET: 16 U.S. Communities Recognized as Climate Action Champions for Leadership on Climate Change." Accessed December 26, 2014: http://www.whitehouse.gov/the-pressoffice/2014/12/03/fact-sheet-16-us-communities-recognized-climate-action-champions-leaders.

Wiser, R.; Barbose, G. (2010). Supporting Solar Power in Renewables Portfolio Standards: Experince from the United States. LBNL-3984E. Berkeley,CA: Lawrence Berkeley National Laboratory. Accessed December 18, 2014: http://eetd.lbl.gov/sites/all/files/publications/report-lbnl-3984e.pdf. 